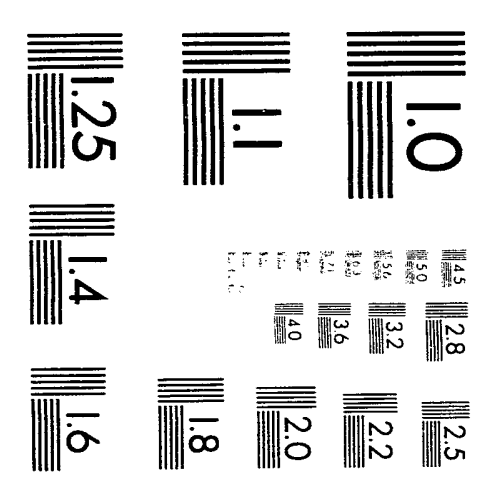



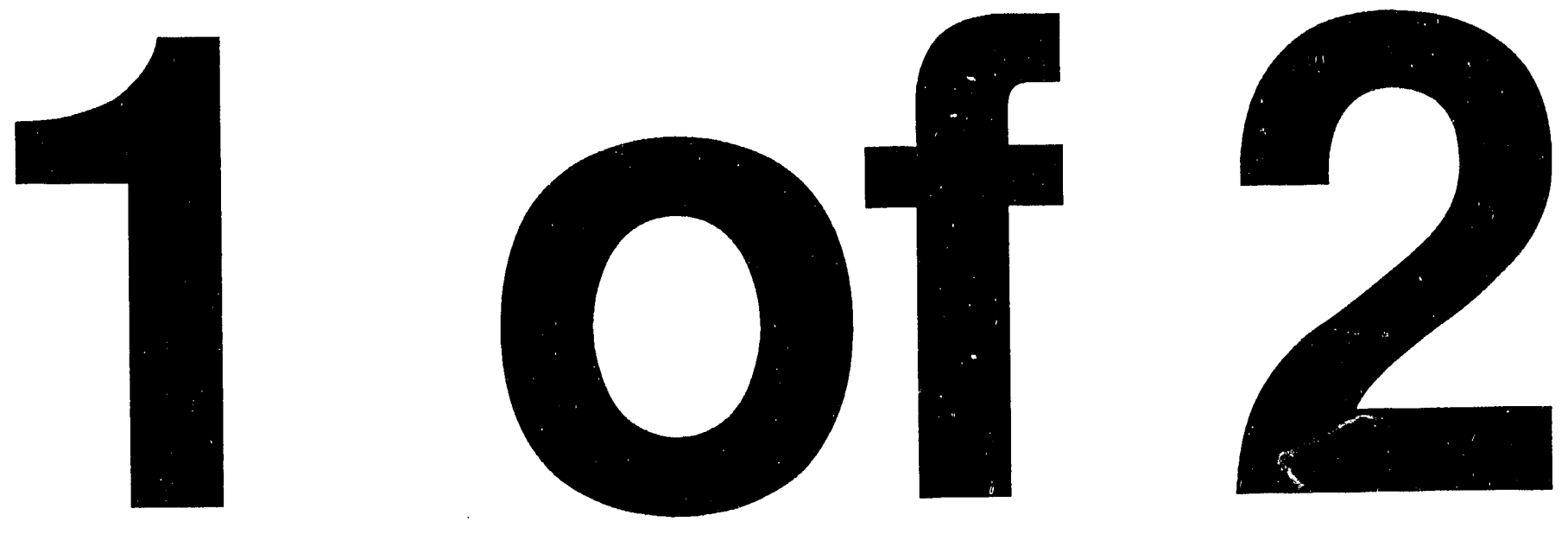


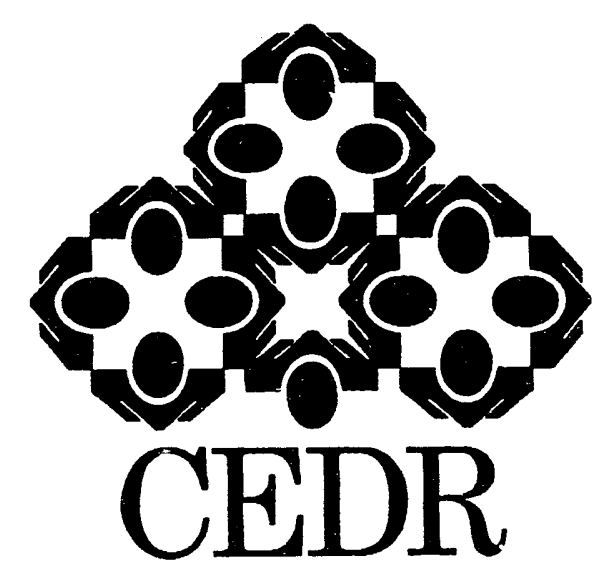

U.S. Department of Energy

Assistant Secretary for Environment, Safety and Health

Washington, D.C. 20585

\section{COMPREHENSIVE EPIDEMIOLOGIC DATA RESOURCE}

Office of Epidemiology and Health Surveillance

August 1993 
This catalog was prepared under the direction of the Department of Energy (DOE) Office

of Health. While funding for much of the research was provided by DOE, the analysis reported in the citations referenced in this catalog and the collection of data available

through CEDR were not necessarily performed under DOE direction or control. The views and opinions of tine authors expressed in the citations do not necessarily reflect those of the United States Government or any agency thereof. No assurance is expressed or implied as to the accuracy, completeness, or usefulness of the data presented. 


\section{Table of Contents}

1 Introduction to the DOE CEDR Program ........ 1

Purpose of This Catalog

References for Obtaining Additional Information .......3

2 Overview of CEDR Data .5

Data Definitions and Relationships

How CEDR Data are Collected .8

Caveats of CEDR Data ….................... 9

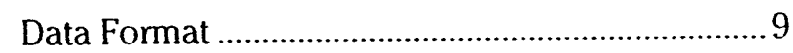

Confidentiality Protection ....................................... 10

3 Becoming an Authorized CEDR Data User .. 11

4 Methods of Accessing CEDR Data ................. 13

Traditional Methods (Phone or Mail) ......................... 13

Electronic Methods ....................................................... 13

CEDR OnLine Bulletin Board ................................. 14

CEDRtext Data and Metadata Viewer ................... 16

Other Electronic Access .......................................... 17

5 CEDR Analytic Data Sets ...............................19

Fernald Facility ............................................................. 23

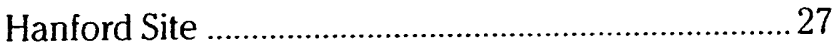

Los Alamos National Laboratory Facility .....................39

Linde Plant .................................................................. 47

Mound Plant …………………………………….... 51

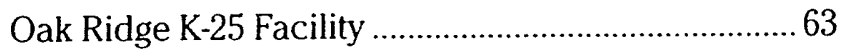

Oak Ridge X-10 Facility .................................................. 79 


\section{Table of Contents (cont.)}

Oak Ridge Y-12 Facility

Pantex Plant

Rocky Flats Plant

111

Savannah River Site

6 CEDR Working Data Sets ............................... 119

Hanford Site …............................................................. 121

Los Alamos National Laboratory Facility ................. 123

Mound Plant ......................................................... 127

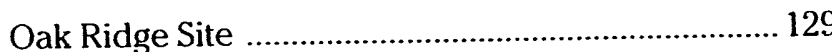

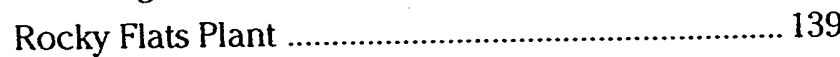

Zia Company ................................................................. 141

Appendix A-Glossary

Appendix B-CEDR Access Request Form

Appendix C - CEDR Data Request Form

Appendix D-Site and Facility Descriptions 


\section{Foreword}

CEDR, the Comprehensive Epidemiologic Data Resource, is a paradigm for the cultural change in the Department of Energy Indeed, its initiation heralded the change, and its development demonstrated the appropriateness of a new way of thinking in the Department. CEDR has incorporated stakeholder involvement, teamwork, and openness as it has evolved to meet changing priorities with limited resources. CEDR is a dynamic system, and the bounds for its usefulness have hardly been explored. This catalog is one way by which we hope to facilitate that exploration and foster new discovery and understanding.

\section{Reart Poldeint}

Robert Goldsmith, PH. D.

DIRECTOR

Office of Epidemiology and Health Surveniance.

\section{Acknowledgements}

The Department of Energy (DOE) wishes to acknowledge the efforts of the organizations and staff who have provided data to CEDR.

They have worked closely with DOE to provide the data, to provide accurate and complete structured documentation, and to verify that the resulting entry into CEDR reflects their submissions. The staff at Lawrence Berkeley Laboratory developed and operate the CEDR computer information system and have been instrumental in designing the system and ensuring the accuracy and availability of data.

DOE also wishes to thank all the states for making their data available to CEDR and, therefore, helping the CEDR Program accomplish its mission. 


\section{Introduction to the DOE CEDR Program}

\section{Mission of the DOE CEDR Program:}

\author{
To enhance DOE's \\ epidemiologic research by \\ facilitating independent \\ research to validate and supple. \\ ment DOE research on heaith \\ effects associated with working \\ at or living near facilities \\ involved with DOE or other \\ energy production activities.
}

The Department of Energy (DOE) and its predecessor agencies have a long history of epidemiologic research programs. The main focus of these programs has been rhe Health and Mortality Study of the DOE work force. This epidemiologic study began in 1964 with a feasibility study of workers at the Hanford facility. Subsequently, epidemiologic studies were undertaken at many DOE facilities to determine the health consequences of working in these facilities. Studies of other populations exposed to radiation have also been supported, including the classic epidemiologic study of radium dial painters and studies of atomic bomb survivors. From a scientific perspective, these epidemiologic research programs have been productive, highly credible, and formed the bases for many radiological protection standards.

Recently, there has been concern that, although research results were available, the data on which these results were based were not easily obtained by interested investigators outside DOE. Therefore, as part of an effort to integrate and broaden access to its epidemiologic information, the DOE has developed the Comprehensive Epidemiologic Data Resource (CEDR) Program. Included in this effort is the development of a computer information system for accessing the collection of CEDR data and its related descriptive information.

The epidemiologic data currently available through the CEDR Program consist of analytic data sets, working data sets, and their associated documentation files. Detailed definitions of these data sets and files are provided in Section 2. In general, data sets are the result of epidemiologic studies that have been conducted on various groups of workers at different DOE facilities during the past 30 years. 


\section{CEDR Program Goals:}

\& To provide data from the DOE epidemiologic studies program to all interested parties

* To provide opportunities for new scientific understandings

* To identify and incorporate other data potentially useful for health studies

To create a central repositony of data related to epidemiologic and health concerns
As these studies are updated and new studies are performed, additional data sets will become available.

As the CEDR Program matures, other types of data useful for epidemiologic and health surveillance activities will be added. Data on the atomic bomb survivors, provided by the Radiation Effects Research Foundation in Japan, will be added shortly. Data from Lawrence Berkeley Laboratory's (LBL's) Socio-Economic Environmental Demographic Information System (SEEDIS), such as census data, geographic base map files, mortality and cancer incidence data, and ecologic summary data will also be added. These are examples of possible future data and are not intended to be an exhaustive list.

Not only is the volume of data expected to increase but also the methods of disseminating and providing access to CEDR data will continue to grow and evolve. Therefore, comments and suggestions for helping the CEDR Program achieve its goals are always welcome and should be directed to the CEDR Program Manager (address and phone number are provided on the next page).

\section{Purpose of This Catalog}

This catalog is intended for use by any individual interested in obtaining information about, or access to, CEDR data. It serves as a starting point for current or potential users by providing an introduction to the DOE CEDR Program and to the types of data available through CEDR. This catalog should provide sufficient information for users to identify and request data sets of potential use.

Section 2 of this catalog discusses the specific types of data available Section 3 describes the process for becoming an authorized CEDR 


\section{Additional Reading:}

DOE supports research on human health effects resulting from the operation of DOE facilities and generation and use of energy. Publications resulting from this research are collected in a bibliography, DOE Epidemiologic Research Program - Selected Bibliography, published by the office of Health. It provides a guide to health-effects research supported by DOE. Single copies are available from the Office of Health. data user, and Section 4 outlines the methods for obtaining CEDR data and access to CEDR's computer information system. A description of each analytic data set and working data set available in the CEDR computer :nformation system, as of the date of this catalog, is presented in Sections 5 and 6, respectively. A glossary of CEDRspecific and computer terms is provided as well as appendixes containing facility descriptions and CEDR data access forms

\section{References for Obtaining Additional Information}

To obtain further information concerning the CEDR Program and access to CEDR data, please contact:

\section{Barbara G. Brooks}

CEDR Program Manager

Office of Health, EH-421

U.S. Department of Energy

Washington, DC 20585

Phone: 301-903-4674

FAX: 301-903-4677

To obtain further information concerning access to the CEDR computer information system, please contact:

\author{
CEDR Project \\ Lawrence Berkeley Laboratory \\ 1 Cyclotron Road, MS 50B-3238 \\ Berkeley, CA 94720 \\ Phone: 510-486-4136 \\ FAX: $510-486-6363$ or $510-486-4004$ \\ Internet: CEDR@lbl.gov
}




\section{Overview of CEDR Data}

The CEDR Program provides a repository of DOE data that have been used to support epidemiologic studies. Most of these epidemiologic studies have been published in peer-reviewed journals; however, there are also data that have been used in student dissertations, presentations, and DOE technical reports.

The sources of the data contained in CEDR are various records and files that were generated by each facility to meet specific needs that usually were not related to epidemiologic studies. The data cover different time spans. The number, type, and format of variables included in studies vary considerably. The studies may represent entirely different groups of people or cohorts. For example, some data files will be limited to specific locations, some to specific exposures, some to certain groups of people, and some will contain only morbidity or mortality information

Data in the CEDR files pertain to approximately 420,000 individuals employed at one or more of $50 \mathrm{DOE}$ sites or facilities. The data support the analyses that have appeared in numerous articles and publications during the last 30 years. The data, approximately 100 megabytes in size, appear at the individual record level and are not aggregated. In order to protect individual privacy, some information has been replaced or is not available. Otherwise, any information, including demographic, socioeconomic, and exposure data, that was collected and placed into an electronic file by the researcher is provided in its entirety.

\section{Data Definitions and Relationships}

To help clarify the different types and groups of data in CEDR, a set of CEDR terminology has been defined. However, due to the diverse 
Data Source
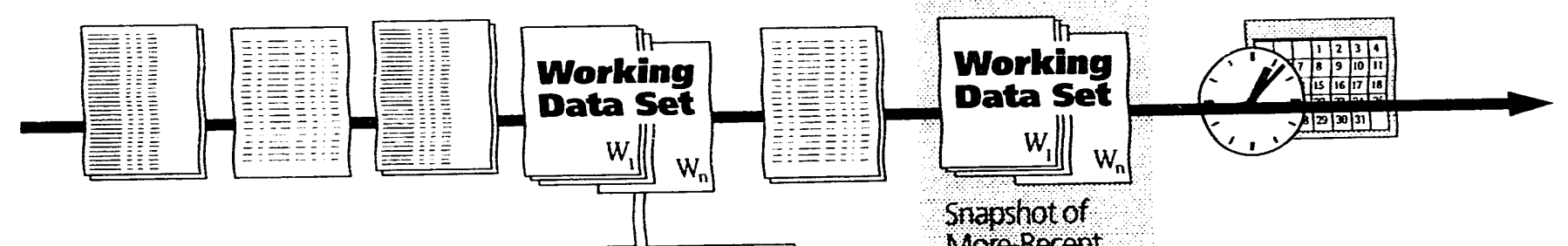

Snapshot of

More-Recent

Researchers manipulate

working data to:

- verify and validate data

- merge data files

- migrate data

- subset data files

- define cohort

Working

nature of the data in CEDR, the

Data Set

definitions are fairly broad.

Some of the most commonly

used CEDR terms are defined

below. Other definitions can be

found in Appendix A.

A data set is a collection of

logicaliy related files. There are

two types of data sets defined for

CEDR: working data sets and

analytic data sets.

A working data set contains files of data—called working fileswith which an investigator worked during the course of the study.

An analytic data set contains files-called analytic files-on which the analyses or results of a study are based. Figure 2-1 shows the relationship between working and analytic data sets in CEDR.

Figure 2-1. CEDR Data Set Figure 2-2 shows the relationship of working and analytic data sets Relationships to their respective files. 


\section{Working}

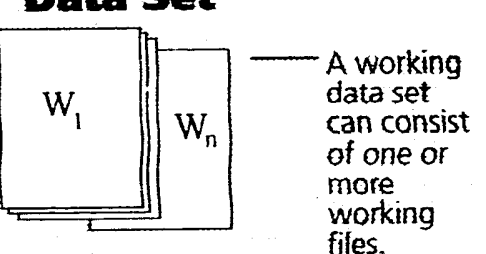

\section{Analytic \\ Data set}

$A_{1} \quad A_{n} \quad \begin{aligned} & \text { An analytic } \\ & \text { data set can } \\ & \text { consist of } \\ & \text { one or more } \\ & \text { analytic } \\ & \text { files. }\end{aligned}$

Figure 2-2. Data Set/ Data File Relationships
Working files may be gathered from a variety of data sources, such as payroll, personnel, or dosimetry systems. Working files may contain an assortment of data, including demographic, work history, industrial hygiene, vital status, internal dosimetry, and/or external dosimetry data. Working files are typically dynamic, with new, updated, and corrected information continually being added to the files. Researchers select data from a number of potentially diverse working files to form their initial analytic data set. Because working files contain the least refined form of data in CEDR, the level of verification and

validation applied to working data wil! vary For continuing studies, working files are periodically replaced in CEDR with the most current version of the file; older versions are archived by CEDR

Analytic files contain data upon which a researcher directly bases a study's reported findings. However, the files may also contain additional data that the researcher collected but did not use in the final analysis of the study. Analytic files are typically composites of data (derived from working files) formulated to meet specific cohort descriptions and study needs that represent the best data available at that time. To create analytic files, researchers may subset data to form a cohort, merge data from multiple working files, validate and edit the working data, and convert the data as necessary to conduct the analysis. Analytic files generally represent data that have been extensively reviewed, validated, and verificd by a researcher. However, if the cohort for a study is a subset of an analytic file, not all variables or records in the file may have the same level of validatior. Analytic files are static and are retained pemanentiy in CDDR. If similar files with updated ciara are used for additional analyses, a new data set will be defined and stored in addition to the original analytic data set 
Structured documentation is information that describes CEDR data CEDR maintains a large volume of documentation in structured data base files that provide an overview of the data sets, list citations, describe files, list variables, and contain much of the information normally found in a researcher's code book. The detailed descriptions of each data set presented in Sections 5 and 6 are taken from CEDR structured documentation supplied by the data providers.

\section{How CEDR Data are Collected}

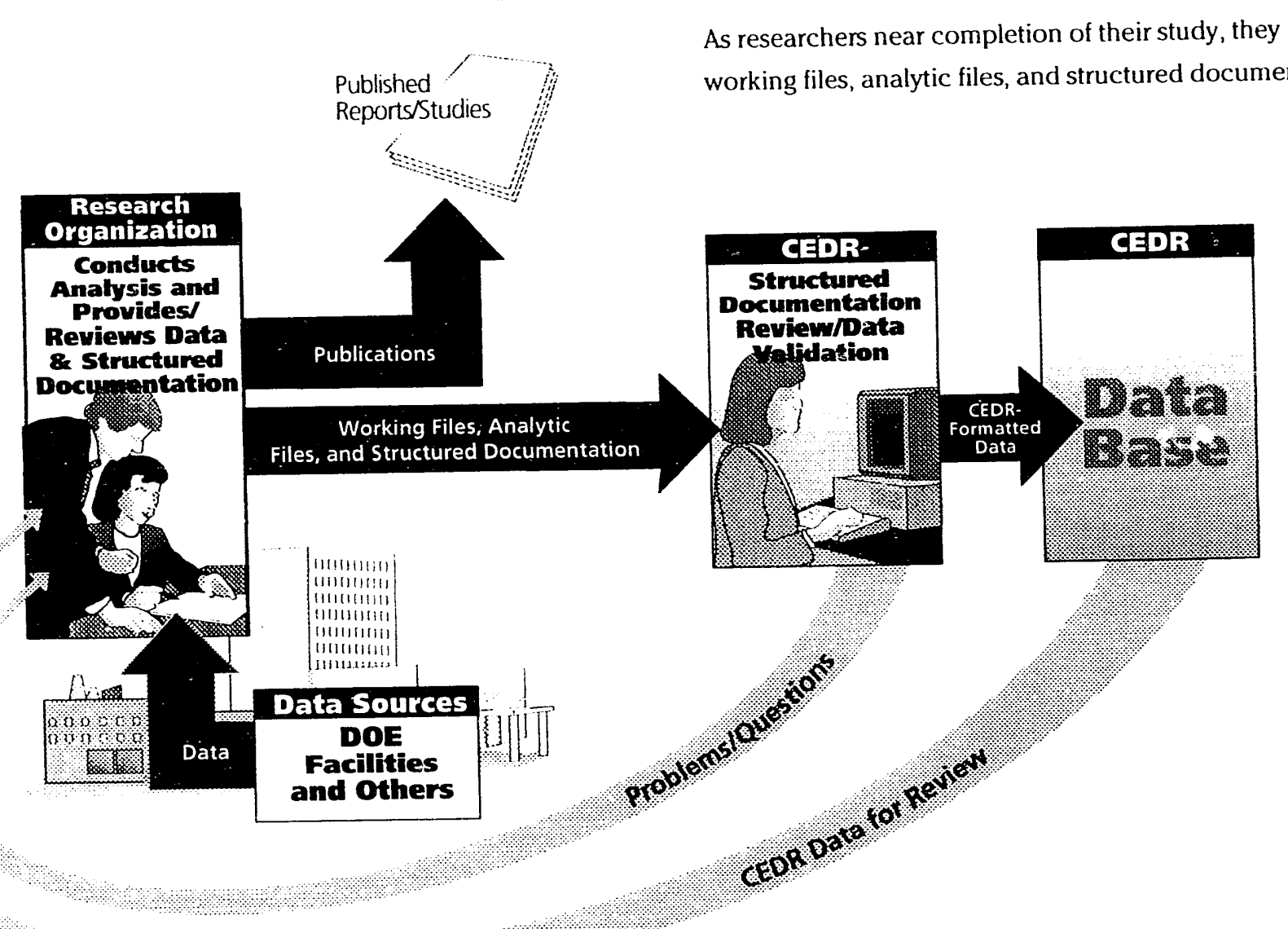

Figure 2-3. CEDR Data Flow Diagram 


\section{Major Contributors:}

\section{DOE studies are coordinated primarily by three organizations:}

Los Alamos National

Laboratory (LANL)

Oak Ridge Institute for Science and Education (ORISE)

Pacific Northwest Laboratory (PNL) sets that are submitted to the CEDR Program Manager. Although the working and analytic files may differ considerably in content and format, the accompanying structured documentation must be submitted in a standard format. This standard format ensures that the structured documentation explains the data as consistently and completely as possible.

Quality assurance procedures have been implemented throughout CEDR processing to ensure proper validation and verification as the data are incorporated and made accessible. CEDR data are processed as shown in the data flow diagram provided in Figure 2-3. When CEDR data are received, the data files are examined and the structured documentation is reviewed for completeness. Data are not accepted until structured documentation requirements are satisfied After acceptance, the working and analytic files are processed and the structured documentation is loaded into the CEDR system.

One step in validating CEDR data is the comparison of the information provided in the structured documentation files with the actual data in the working and analytic files. The results of data and structured documentation validation efforts are reviewed by the researcher providing the data for final verification and approval.

\section{Caveats of CEDR Data}

\section{Data Format}

Because the information collected and examined by various researchers was originally generated by DOE facilities, or other sources, for different purposes and needs, there is considerable variation in the format and content of data files. Terminology used to identify vari- 
ables also varies considerably. There has been no attempt to standardize individual variables (field names) found throughout the CEDR data. Sections 5 and 6 list the variables, as received from the researchers, that are found in each of the named analytic and working data sets. Because no standardization exists among these variables, all of the following situations are possible:

- Different files may have variables that share the same name but have different meanings.

- Different files 1.7ay have variables that share the same name and have the same $n$. eaning but use a different range of values.

- Different files may have variables that have different names but represent exactly the same information.

\section{Confidentiality Protection}

The CEDR Program receives data containing information directly related to specific individuals. To protect the privacy of these individuals, data truncation is performed according to the following guidelines:

- Identifying information, such as individual names, social security numbers, addresses, badge numbers, and similar information, have been replaced with a unique, impersonal number (a pseudo-identifier).

- The specification of race has been limited to white, black, and other.

- The dates of birth and death have been truncated to the year.

- Other personal dates, such as date of employment, are truncated to month and year. 


\section{Becoming an Authorized CEDR Data User}

Information about the CEDR Program and access to files of CEDR structured documentation are available to all interested parties. However, due to the nature of CEDR data, precautions must be taken to ensure that the privacy of the individuals in the studies is not violated. CEDR data are to be used only for research. No attempt is to be made to identify individuals.

All users who wish to receive CEDR data files (working or analytic) must complete the access request and confidentiality forms in Appendix B of this catalog. Approved users will receive a CEDR account and start-up information. These users may share CEDR data with approved secondary users helping with the research. As explained on the access request form, CEDR data may not be shared with unauthorized users and must be used according to the restrictions specified.

The authorization process usually takes a few weeks to complete because some states require special individual authorization or notification. 


\section{Methods of Accessing CEDR Data}

One of the goals of the CEDR Program is to provide easy access to DOE epidemiological data and to stimulate the use of these data by interested researchers. To facilitate the dissemination of CEDR information and to accommodate disparate user working environments, DOE provides a number of different methods--both traditional and electronic - for obtaining CEDR data and related news and information.

All requestors of CEDR data will be contacted by CEDR staff, and their requests will be filled as promptly as possible. The requestor will be provided with specified data files and the structured documentation associated with those files. The structured documentation includes names of individuals who may be contacted for additional information about the data set.

\section{Traditionai Methods (Phone or Mail)}

Authorized users may request data sets or files of interest by completing the Data Request Form in Appendix $\mathrm{C}$ and then mailing or faxing the form to the CEDR Program Manager (see Section 1 for address and phone number). However, the CEDR catalog-this publication-may be viewed and used without prior authorization. Additional catalogs may be requested by phone, fax, or mail from the CEDR Program Manager.

\section{Electronic Methods}

Several electronic access mechanisms have been developed that allow users to establish contact with the CEDR information system 
and to use software developed specifically for working with CEDR information and data. These access methods vary in complexity, ease of use, and required computer skill. They accommodate a wide range of user skills and equipment and allow the novice, as well as the sophisticated user, to satisfy their CFDR data inquiries. For example, users having a personal computer : nd nodem may use commercially available communications softwa: : to dial in to the system for textbased interaction. Or, if they wish to $1 \mathrm{in}$. ract in a graphical mode with the CEDR bulletin board system, they can use free software provided by the CEDR Program. Individuals having access to larger computers may use other communications capabilities, including Internet, to establish contact with the CEDR information system.

Figure 4-1 summarizes the three types of electronic access to CEDR that will be supported. Each method is described in more detail in the subsequent sections. Also, more information concerning any of the electronic methods may be obtained by contacting the CEDR Project at LBL (see Section 1 for the address and phone number).

\section{CEDR OnLine Bulletin Board}

Electronic bulletin boards are used to post information and exchange news much like traditional bulletin boards. CEDR OnLine is a customized electronic bulletin board system for CEDR users. It provides a mechanism for individuals to browse through current information provided by DOE as well as to pose questions or respond to comments posted by other CEDR users. Users may also post their own information or requests. CEDR OnLine will also:

- present the history and scope of the CEDR Program

- provide an explanation of how CEDR data are organized 


\begin{tabular}{|c|c|c|c|}
\hline & \multicolumn{3}{|c|}{ ELECTRONIC ACCESS METHODS } \\
\hline & \multicolumn{2}{|c|}{ CEDR-Specific Methods } & \multirow{2}{*}{$\begin{array}{c}\text { Direct } \\
\text { Software } \\
\text { Access }\end{array}$} \\
\hline & CEDR Online & CEDRtext & \\
\hline Description & $\begin{array}{l}\text { Customized } \\
\text { electronic bulletin } \\
\text { board; provides } \\
\text { news and notes } \\
\text { capabilities }\end{array}$ & $\begin{array}{l}\text { CEDR custom } \\
\text { software; allows } \\
\text { viewing of data } \\
\text { and structured } \\
\text { documentation }\end{array}$ & \begin{tabular}{|l|} 
Direct access to \\
UNIX, Informix, and \\
SAS commands; \\
allows viewing of \\
data and structured \\
documentation
\end{tabular} \\
\hline $\begin{array}{l}\text { Authorization } \\
\text { Required }\end{array}$ & No & Yes & Yes \\
\hline Contact* & $\begin{array}{l}\text { CEDR Program } \\
\text { Manager (DOE) or } \\
\text { CEDR Project (LBL) }\end{array}$ & $\begin{array}{l}\text { CEDR Program } \\
\text { Manager (DOE) or } \\
\text { CEDR Project (LBL) }\end{array}$ & CEDR Project (LBL) \\
\hline $\begin{array}{l}\text { Equipment } \\
\text { Needed }\end{array}$ & $\begin{array}{l}\text { Any } \\
\text { modem-equipped } \\
\text { IBM compatible PC } \\
\text { or Apple } \\
\text { Macintosh, or } \\
\text { Internet access }\end{array}$ & $\begin{array}{l}\text { Any } \\
\text { modem-equipped } \\
\text { IBM compatible } \\
\text { PC or Apple } \\
\text { Macintosh, or } \\
\text { Internet access }\end{array}$ & $\begin{array}{l}\text { Any } \\
\text { modem-equipped } \\
\text { IBM compatible PC } \\
\text { or Apple } \\
\text { Macintosh, or } \\
\text { Internet access }\end{array}$ \\
\hline Commenits & $\begin{array}{l}\text { - May allow future } \\
\text { access to } \\
\text { CEDRtext } \\
\text { - Free graphical- } \\
\text { mode software } \\
\text { available for PC } \\
\text { and Macintosh. } \\
\text { X-windows } \\
\text { graphical } \\
\text { software being } \\
\text { developed for } \\
\text { Internet users. }\end{array}$ & $\begin{array}{l}\text { User Manual } \\
\text { is under } \\
\text { development } \\
\text { Requires 2-3 } \\
\text { weeks for } \\
\text { authorization }\end{array}$ & $\begin{array}{l}\text { - For experienced } \\
\text { users } \\
\text { - Work from } \\
\text { UNIX prompt } \\
\text { - Requires 2-3 } \\
\text { weeks for } \\
\text { authorization }\end{array}$ \\
\hline
\end{tabular}

* See Section 1 for names and addresses.

Figure 4-i. Electronic Access to CEDR
- provide an electronic forum (including an electronic mail capability) where CEDR users could interact about any aspect of CEDR or common data sets of interest

- critique the current system (these critiques will assist DOE in the evaluation and refinement of the CEDR Program and the CEDR computer information system)

— immediately list findings and comments about specific data sets

- list upcoming plans or activities

- record requests for data and structured documentation

CEDR OnI ine bulletin board can be accessed in a number of ways depending on whether individuals have dial-in capability or Internet access. Users also have the choice of text or graphics modes of interaction. The following situations are possible:

- To access CEDR OnLine bulletin board in a text mode, users with terminals or terminal emulation software (for IBM PC, Macintosh, or other computers) can dial in with a modem.

- To create a simple, graphical, point-and-click interface for navigating the bulletin board, users can obtain a free access program. It is available for IBM PC/compatible and Apple Macintosh computers and can be obtained from the CEDR Program or downloaded directly from the bulletin board when in a text mode session.

- Users with Internet access can use UNIX telnet, rlogin, or xterm commands to interact with CEDR OnLine in text mode.

- In the future, users with Intemet access and X-Windows servers can use CEDR OnLine in graphical mode. 


\section{CEDRtext Fact:}

The CEDRtext application runs much faster when accessed through a TELNET session on the internet because the speed of the network connections available to Internet users far exceeds those of telephone connections using the fastest modems.

\section{CEDRtext Data and Structured Documentation Viewer}

CEDRtext is a software tool that provides simple, direct access to CEDR data and structured documentation. It is menu-driven software having a variety of commands for exploration of selected data sets to determine their essential characteristics. Because CEDRtext provides direct access to CEDR data, all CEDRtext users must complete the appropriate confidentiality forms (see Section 3). Upon authorization, users will be provided with a CEDR account (no cost) and startup information. The options available in CEDRtext include:

- listing all currently available data sets

- surveying overviews of each data set, including information on cohort size and properties, exposure types, and citations

- listing information about the files associated with each data set

- generating a list of the variables (fields) in each file, including variable formats and descriptions

- viewing codes used for each variable

- browsing through the actual data contained in each analytic or working file

— viewing help information screens

CEDRtext was designed to be accessible to as many users as possible. Using a modem, authorized users can access CEDRtext by dialing in to the UNIX host computer at LBL from any terminal or from any personal computer with terminal emulation software. Internet users can access CEDRtext via TELNET 


\section{Other Electronic Access}

CEDR data reside on a UNIX computer at $\mathrm{LBL}$. The CEDR data are stored in a data base using the Informix relational data base management system. Authorized users familiar with Informix and the query tool ISQL will have direct, read-only access to CEDR data. Widely used statistical packages, $S$ and SAS, are also available for purposes of data exploration. Users will also have access to basic UNIX commands and utilities that may also be useful in examining data, downloading information, or other functions.

The CEDR host computer at LBL is accessible through the Internet, which provides connections that are much faster than those available through dial-up connections. Internet utilities, such as the file transfer protocol (FTP), are also available to facilitate access to the data. Other Internet access techniques, such as Gopher and Wide Area Information System (WAIS), are under consideration. 


\section{CEDR Analytic Data Sets}

Descriptions of the analytic data sets currently available are presented in this section. These descriptions identify the site or facility from which the data were collected. describe the files and data comprising the data set, and list pertinent citations. In addition, a table that

\begin{tabular}{|l|c|}
\hline \multicolumn{1}{|c|}{ Cause of Death } & $\begin{array}{c}\text { CD Codes } \\
\text { included }\end{array}$ \\
\hline Infectious \& Parasitic Drseases & $1-136$ \\
All Malignant Neoplasms & $140-209$ \\
- Lip. Oral Cavity \& Pharynx & $140-149$ \\
- Digestive Organs \& Peritoneum & $150-159$ \\
- Respiratory System & $160-163$ \\
- Bone \& Connective Tissue & $170-171$ \\
- Skin $\quad$ Breast & $172-173$ \\
- Genitourinary System & $174-174$ \\
- Brain/CNS & $180-189$ \\
- Other \& Unspecified Sites, Except BrainCNS & $191-192$ \\
All Benign Neoplasms & $190.193-199$ \\
All Neoplasms, Unspecified & $200-209$ \\
Endocrine, Nutritional, Metabolic Diseases \& immunity Disorders & $210-228$ \\
Diseases of Blood \& Blood-Forming Organs & $230-239$ \\
Mental Disorders & $280-279$ \\
Diseases of Nervous System \& Sense Organs & $290-315$ \\
Diseases of Circulatory System & $320-389$ \\
Diseases of Respiratory System & $390-458$ \\
Diseases of Digestive System & $460-519$ \\
Diseases of Genitourinary System & $520-577$ \\
Complications of Pregnancy \& Childbirth & $580-629$ \\
Diseases of Skin \& Subcutaneous Tissue & $630-678$ \\
Diseases of Musculoskeletal System \& Connective Tissue & $680-709$ \\
Congenital Anomalles & $710-738$ \\
Symptoms \& Ill-Defined Conditions & $740-759$ \\
Accidents, Pnisoning \& Violence (External Causes) & $780-796$ \\
& $800-999$ \\
\hline
\end{tabular}

summarizes the causes of death in the data set is presented. This table uses categories of death denved from groupings of International Classification of Diseases (ICD) Codes as shuwn in

Figure 5-1. Subsequent pages list the variables found in each file of the data set. For additional information on each of the sites or facilities from which researchers collected data that are available in the CEDR analytic data sets. please see Appendix D.

Figure 5-2 presents a summary table that alphabetically lists the short name for each analytic data set and provides the name of the assoriated study ar. 1 a brief descripton. This table also indicates the order in which the analytic data sets appear in this catalog.

Figure 5-1. Groupings of ICD

Codes Used in the Death

Summary Tab! 
Figure 5-2. CEDR Analytic Data Sets Currently Available

\begin{tabular}{|c|c|c|c|}
\hline Data Set & Study Name & Brief Description* & Page \\
\hline FRW83A01 & Fernald (NLO) Cohort Study, 1983 & $\begin{array}{l}\text { Nonmalignant respiratory morbidity study of } 4,101 \text { Fernald } \\
\text { uranium workers }\end{array}$ & 23 \\
\hline HFC78A01 & Hanford Cohort Study, 1989 & $\begin{array}{l}\text { Mortality study of } 35,869 \text { Hanford operations workers. } \\
\text { 1945-1981 }\end{array}$ & 27 \\
\hline HF89A01 & Hanford Cohort Study, 1993 & $\begin{array}{l}\text { Mortality study of } 37,012 \text { Hanford operations workers, } \\
\text { 1945-1986 }\end{array}$ & 31 \\
\hline HFS93A03 & Hanford Cohort Study, 1993 & $\begin{array}{l}\text { Mortality study of 44,101 Hanford operations workers. } \\
\text { 1944-1986 }\end{array}$ & 35 \\
\hline LAFEMA01 & $\begin{array}{l}\text { Los Alamos National Lab (LANL) Female } \\
\text { Cohort Stedy, } 1987\end{array}$ & $\begin{array}{l}\text { Mortality sturdy of } 5,234 \text { white female workers at LANL research } \\
\text { facility }\end{array}$ & 39 \\
\hline LASUIA02 & $\begin{array}{l}\text { Los Alamos National Lab (LANL) Female } \\
\text { Suicide Case Control Study, } 1988\end{array}$ & $\begin{array}{l}\text { Case-control study of suicide among } 136 \text { female workers at } \\
\text { LANL research facility }\end{array}$ & 43 \\
\hline LND87A01 & Linde Uranium Worker Cohort Study, 1987 & Mortality study of 995 white male uranium workers & 47 \\
\hline MDEXTA02 & $\begin{array}{l}\text { Mound Facility External Radiation Cohort } \\
\text { Study, } 1991\end{array}$ & $\begin{array}{l}\text { Mortality study of } 4,182 \text { workers at a research and production } \\
\text { facility }\end{array}$ & 51 \\
\hline MDPOLA03 & $\begin{array}{l}\text { Mound Facility Polonium Exposure Cohort } \\
\text { Study, } 1991\end{array}$ & $\begin{array}{l}\text { Mortality study of } 4,402 \text { white male workers at a research and } \\
\text { production facility }\end{array}$ & 55 \\
\hline MDSMRA01 & $\begin{array}{l}\text { Mound Facility Cohort Study-Preliminary } \\
\text { SMRs, } 1991\end{array}$ & Mortality study of 4,697 white male workers at Mound & 59 \\
\hline ORK25A01 & $\begin{array}{l}\text { Oak Ridge K-25 (ORGDP) Nickel Exposure } \\
\text { Cohort Study. } 1984\end{array}$ & $\begin{array}{l}\text { Mortality study of 8,366 white male workers at a uranium } \\
\text { facility }\end{array}$ & 63 \\
\hline ORMULA01 & Oak Ridge Facilities Welders Study, 1981 & $\begin{array}{l}\text { Mortality study of } 1,059 \text { white male welders at uranium and } \\
\text { research facilities }\end{array}$ & 67 \\
\hline
\end{tabular}

- The numbers of workers in the brief description represent the number of workers in the study cohort Data in the fites may pertain to a langer number of workers. 
Figure 5-2. CEDR Analytic Data Sets Currently Available (cont.)

\begin{tabular}{|c|c|c|c|}
\hline Data Set & Study Name & Brief Description* & Page \\
\hline ORMULAO2 & $\begin{array}{l}\text { Oak Ridge Facilities World War II Cohort } \\
\text { Study, } 1990\end{array}$ & $\begin{array}{l}\text { Mortality study of } 28,008 \text { white male workers at uranium and } \\
\text { research fadities during } \mathrm{WW} \text { il }\end{array}$ & 71 \\
\hline ORMULA03 & $\begin{array}{l}\text { Oak Ridge Facilities Cohort } \\
\text { Study-lil-defined Cause of Death, } 1992\end{array}$ & $\begin{array}{l}\text { Mortality study of } 1,216 \text { uranium and research workers with } \\
\text { ill-defined causes of death }\end{array}$ & 75 \\
\hline ORX10A01 & $\begin{array}{l}\text { Oak Ridge National Laboratory (ORNL) } \\
\text { Cohort Study, } 1985\end{array}$ & Mortality study of 8,375 white males at ORNL & 79 \\
\hline ORX10A02 & $\begin{array}{l}\text { Oak Ridge National Laboratory (ORNL) } \\
\text { Cohort-Follow-up Study, } 1991 \& 1993\end{array}$ & $\begin{array}{l}\text { Mortality update study on } 8,318 \text { white males at ORNL research } \\
\text { facility }\end{array}$ & 83 \\
\hline ORX10A03 & $\begin{array}{l}\text { Oak Ridge National Laboratory Cancer } \\
\text { Case Control Study, } 1983\end{array}$ & $\begin{array}{l}\text { Cancer mortality study of } 1,785 \text { male workers at ORNL research } \\
\text { facility }\end{array}$ & 87 \\
\hline ORY12A01 & Oak Ridge Y-12 Plant Cohort Study, 1988 & $\begin{array}{l}\text { Mortality study of } 6,781 \text { white males workers at a research and } \\
\text { development facility }\end{array}$ & 91 \\
\hline ORY12A02 & $\begin{array}{l}\text { Oak Ridge Y-12 Plant Mercury Exposure } \\
\text { Cohort Study, } 1984\end{array}$ & $\begin{array}{l}\text { Mortality study of } 5,663 \text { white males at a research and } \\
\text { develop:nent facility }\end{array}$ & 95 \\
\hline ORY12A03 & Oak Ridge TEC Cohort Study, 1981 & $\begin{array}{l}\text { Mortality study of } 18,869 \text { white male TEC workers at a uranium } \\
\text { plant }\end{array}$ & 99 \\
\hline ORY12A04 & $\begin{array}{l}\text { Oak Ridge TEC Phosgene Exposure Cohort } \\
\text { Study, } 1980 \& 1985\end{array}$ & $\begin{array}{l}\text { Mortality study of } 106 \text { male TEC workers highly exposed to } \\
\text { phosgene at a uranium plant }\end{array}$ & 103 \\
\hline †PXSMRAO1 & $\begin{array}{l}\text { Pantex Weapons Facility Cohort Study. } \\
1985\end{array}$ & $\begin{array}{l}\text { Mortality study of } 3,564 \text { white male workers at the Pantex } \\
\text { weapons facility }\end{array}$ & 107 \\
\hline RFPLUA01 & Rocky Flats Cohort Study، 1987 & $\begin{array}{l}\text { Mortality study of } 5,413 \text { white male workers at the Rocky Flats } \\
\text { weapons facility }\end{array}$ & 111 \\
\hline SRC88A01 & Savannah River Plant Cohort Study, 1988 & $\begin{array}{l}\text { Mortality study of } 9,860 \text { white male workers at the Savannah } \\
\text { River Site }\end{array}$ & 115 \\
\hline
\end{tabular}

+ All analytic files pertaining to this data set may not be available until October 1993. 


\section{FERTALD}

FRW83A01 Data Set

\section{Description}

This analytic data set consists of one file generated for a 1983 dissertation that involved a study of nonmalignant respiratory disease among white males at the Fernald Facility.

This cohort morbidity study investigated the relationship between exposure to uranium and the develepment of nonmalignant respiratory disease. Diagnosis was based upon physician diagnoses as recorded on medical insurance claims. An examination of these data, along with exposure associated with job title, suggested tha exposure to uranium dust was the principal exposure at Fernald that contributed to the development of nonmalignant respiratory disease. No statistically significant association was demonstrated for non-radioactive chemical exposures.

The single analytic file (PRELIM09) in this data set contains 13,196 records, with one or more records for each person. Data in the file include demographic, work history, radiation exposure (intemal and external), and smoking history (on a $17.4 \%$ sample) data. A list of all chemicals used in the plant and indicators of exposure risk level also are provided. The study cohort was defined as 4,101 white males who were first hired at Fermald between January 1. 1452, and December 31 1972. and who had at least 3 months of continued employment. Internal and external exposures were obtained through urine bioassay, film badges, and air sampling data. Smoking data were potentially available for workers employed on or after January 1. 1968

The chemicals used in the processes at the facility, along with job title and plant area, were analyzed by plant experts to determine exposure risk classes. Four exposure risk classes ranging from none to heavy were developed. A similar scale that ranged from no exposure above background to regular exposure at low levels was developed for radiation exposures. 


\section{FERNALD}

FRW83A01 Data Set

\section{Citations}

Wilson, J. 1983. "An epidemiologic investigation of nonmalignant respiratory disease among workers at a uranium mill." Ph.D. dissertation. University of North Carolina, Chapel Hill.

\begin{tabular}{|ccc|}
\hline No. of Files: & 1 & \\
File Name & $\begin{array}{c}\text { No. of } \\
\text { Variables }\end{array}$ & Type of Data \\
PRELIM09 & 44 & $\begin{array}{l}\text { demographic; } \\
\text { work history: } \\
\text { radiation } \\
\text { exposure index; } \\
\text { smoking history }\end{array}$ \\
\hline
\end{tabular}

Summary Deatin Tables

\begin{tabular}{|c|c|c|}
\hline \multirow{2}{*}{ Cause of Death } & \multicolumn{2}{|c|}{ No. of Deaths } \\
\hline & Male & Female $^{\dagger}$ \\
\hline Infectious \& Parasitic Diseases & 2 & \\
\hline All Malignant Neoplasms & 116 & \\
\hline - Lip, Oral Cavity \& Pharynx & 1 & \\
\hline - Digestive Organs \& Peritoneum & 38 & \\
\hline - Respiratory System & 40 & \\
\hline - Bone \& Connective Tissue & 1 & \\
\hline - Skin & 1 & \\
\hline - Breast & $\mathbf{0}$ & \\
\hline - Genitourinary System & 7 & \\
\hline - Brain/CNS & 6 & \\
\hline - Other \& Unspecified Sites, Except Brain/CNS & 7 & \\
\hline - Lymphatic/Hematopoietic & 15 & \\
\hline All Benign Neoplasms & o & \\
\hline All Neoplasms, Unspecified & $\mathbf{0}$ & \\
\hline Endocrine, Nutritional, Metabolic Diseases \& Immunity Disorders & 3 & \\
\hline Diseases of Blood \& Blood-forming Organs & 2 & \\
\hline Mental Disorders & 2 & \\
\hline Diseases of Nervous System \& Sense Organs & 0 & \\
\hline Diseases of Circulatory System & 174 & \\
\hline Diseases of Respiratory System & 13 & \\
\hline Diseases of Digestive System & 16 & \\
\hline Diseases of Genitourinary System & 2 & \\
\hline Complications of Pregnancy \& Childbirth & $\mathbf{0}$ & \\
\hline Diseases of Skin \& Subcutaneous Tissue & 0 & \\
\hline Diseases of Musculoskeletal System \& Connective Tissue & $\mathbf{0}$ & \\
\hline Congenital Anomalies & 2 & \\
\hline Symptoms \& III-Defined Conditions & 1 & \\
\hline Accidents, Poisoning \& Violence (External Causes) & 74 & \\
\hline Deaths, With ICD Code & 407 & \\
\hline Deaths, No ICD Code & 15 & \\
\hline Total Deaths, All Causes & 422 & \\
\hline
\end{tabular}

$t$ No females were included in this study 


\section{Analytic File Wame}

\section{PRELIMOS}

1 CER-assigned ID number

2 observation number in Oak Ridge tape

3 date of first hire into this job

4 job title

5 number of days in this particular job

6 numerical job grouping code

7 radiation exposure code

8 trichloroethylene exposure code

9 tributyl phosphate exposure code

10 cutting fluid exposure code in this job

11 kerosene exposure code in this job

12 lime exposure code in this job

13 ammonia exposure code for this job

14 carbon exposure code in this job

15 nitric acid exposure code in this job

16 sodium hydroxide exposure code for job

17 total job days worked

18 date of first hire date at NLO

19 birth date of individual

20 age at first hire at Fernald

21 wage/salary code

22 department code and building number

23 physical location of workplace

24 date of final termination at Femald

FRW83A01
25 total number of respiratory events

26 total number of acute respira tory events

27 total number of chronic respiratory events

28 indicates if person was case or control

29 cumulative exposure index

30 age at first termination

31 year of first acute respiratory diagnosis

32 year of first diagnosis of chronic event

33 year of first respiratory event

34 age at first respiratory event

35 age at first acute respiratory event

36 age at first chronic respiratory event

37 vital status

38 4-character ICD cause of death

39 3-digit ICD code for cause of death

40 ICD code for cancer

41 last known date per vital status

42 code indicating error in vital status

43 smoking history code

44 sequence number 


\section{HANFORD}

HFC78A01 Data Set

\section{Description}

This analytic data set consists of three files generated for the cohort mortality study, published in Health Physics in 1989, of operations workers at the Hanford Site.

The study evaluated the relationship of occupational radiation exposure and mortality from several specific causes. The study showed that Hanford workers exhibited a strong healthy worker effect, having death rates substantially below those of the general : U.S. population. Comparisons by level of exposure within the Hanford worker population provided no evidence of a positive correlation between exposure and mortality from all cancers combined or between exposure and mortality from leukemia.

The three analytic files in the HFC78A01 data set pertain to 44,101 Hanford workers initially employed at Hanford between 1944 and 1978. The first file (CEDR78_1) contains demographic, work history, and vital status data and indicators of internal depositions Mortality data are provided for deaths occurring outside the state of Washington between 1944 and 1981, as well as for deaths occurring in Washington between 1944 and 1985. Intemal deposition data include the radionuclide symbol and the year of first plutonium deposition. There is one record per individual. The second file (CEDR78_2) contains annual external wholebody doses that were compiled from external monitoring data for operations workers. These data include doses received while the worker was employed at other sites but, unlike another Hanford data set (HFI89A01), they do not include doses received while performing construction work at Hanford. There is one record for each year of exposure data for each of the 35,869 workers who were monitored. The third file (CEDR78_3) contains additional data related to onsite exposure and cause of death. There is one record for each worker.
The discussions in the published paper focus on monitored workers of both sexes. Dose response analyses (internal comparison) included 35,869 workers who were monitored for external radiation. Vital status was ascertained through December 31,1981 , the study end date. There were 4,846 deaths identified, and death certificates were obtained for $4,797(99.0 \%)$ of these deaths. Comparisons with the U.S. general population included 42,291 white workers. There were 7,249 deaths identified, and death certificates were obtained for $7,155(98.7 \%)$ of these deaths. Internal exposures were also examined.

Workers at the Hanford Site were involved in a variety of activities that resulted in their exposure to radiation, including reactor operations, chemical separation of reactor fuel to obtain plutonium, treatment and storage of hazardous waste, and biological and engineering research

- Personal dosimeters (film or thermoluminescent) have been used since 1944. Also, bioassay programs to detect exposures to internally deposited radionuclides, primarily transuranics, were initiated in 1944. Dose estimates resulting from these monitoring programs appear in this analytic data set. Annual whole-body doses to penetrating extemal radiation are presented in units of millisieverts. Quality factors of 10 for fast neutrons, 3 for slow neutrons, and 1 for photons and electrons were used in the conversion of exposure to dose. Internal exposure data were collected and evaluated for all individuals who worked in locations where there was a potential for exposure to radioactive material (transuranics) 


\section{HANFORD}

HFC78A01 Data Set

\section{Citations}

Gilbert, E. S., G. R. Petarson and J. A. Buchanan 1989. "Mortality of workers at the Hanford Site: 1945-1981." Health Physics 56:11-25.

\section{Additional References}

Gilbert, E. S., J. A. Buchanan, and N. A. Holter. 1992. Description of the process used to create 1992 Hanford Mortality Study data base. PNL-8449.

\begin{tabular}{|ccc|}
\hline No. of Files: & 3 & \\
File Name & $\begin{array}{c}\text { No. of } \\
\text { Variables }\end{array}$ & Type of Data \\
CEDR78 1 & 19 & $\begin{array}{l}\text { demographic; } \\
\text { work history; } \\
\text { vital status; } \\
\text { internal } \\
\text { deposition }\end{array}$ \\
CEDR78 2 & 7 & $\begin{array}{l}\text { annual external } \\
\text { whole-body } \\
\text { doses }\end{array}$ \\
CEDR78 3 & 15 & $\begin{array}{l}\text { onsite exposure; } \\
\text { cause of death }\end{array}$ \\
\hline & & \\
\hline
\end{tabular}

\section{Summary Death Tables}

\begin{tabular}{|c|c|c|}
\hline \multirow{2}{*}{ Cause of Death } & \multicolumn{2}{|c|}{ No. of Deaths } \\
\hline & Male & Female \\
\hline Infectious \& Parasitic Diseases & 32 & 5 \\
\hline All Malignant Neoplasms & 1437 & 318 \\
\hline - Lip, Oral Cavity \& Pharynx & 41 & 1 \\
\hline - Digestive Organs \& Peritoneum & 405 & 73 \\
\hline - Respiratory System & 466 & 50 \\
\hline - Bone \& Connective Tissue & 8 & 5 \\
\hline - Skin & 21 & 6 \\
\hline - Breast & 3 & 79 \\
\hline - Genitourinary System & 192 & 49 \\
\hline - Brain/CNS & 42 & 9 \\
\hline - Other \& Unspecified Sites, Except Brain/CNS & 129 & 19 \\
\hline - Lymphatic/Hematopoietic & 139 & 27 \\
\hline All Benign Neoplasms & 5 & 2 \\
\hline All Neoplasms, Unspecified & 7 & 1 \\
\hline Endocrine, Nutritional, Metabolic Diseases \& Immunity Disorders & 124 & 27 \\
\hline Diseases of Blood \& Blood-Forming Organs & 10 & 5 \\
\hline Mental Disorders & 44 & 7 \\
\hline Diseases of Nervous System \& Sense Organs & 59 & 16 \\
\hline Diseases of Circulatory System & 3497 & 367 \\
\hline Diseases of Respiratory System & 440 & 52 \\
\hline Diseases of Digestive System & 277 & 65 \\
\hline Diseases of Genitourinary System & 74 & 7 \\
\hline Complications of Pregnancy \& Childbirth & $\mathbf{0}$ & 1 \\
\hline Diseases of Skin \& Subcutaneous Tissue & 1 & 1 \\
\hline Diseases of Musculoskeletal System \& Connective Tissue & 19 & 10 \\
\hline Congenital Anomalies & 11 & 5 \\
\hline Symptoms \& Ill-Defined Conditions & 49 & 5 \\
\hline Accidents, Poisoning \& Violence (External Causes) & 685 & 115 \\
\hline Deaths, With ICD Code & 6771 & 1009 \\
\hline Deaths, No ICD Code & 335 & 68 \\
\hline Total Deaths, All Causes & 7106 & 1077 \\
\hline
\end{tabular}




\section{Analytic File Hame}

\section{Dine1}

1 CER-assigned ID number

2 sex of worker

3 date of birth (century, year. month, day)

4 ending date of study

5 date of last vital status

6 date of initial employment (year, month, day)

7 date of follow-up start

8 date of final employment (year month, day)

9 year of first Pu deposition

10 year of first Pu monitoring

11 year of first $U$ deposition

12 year of first $U$ monitoring

13 other type of internal deposition

14 year of firsi other type of deposition

15 socioeconomic category

16 underlying cause of death

17 ICD revision number

18 number of external dosimetry readings

19 duplicate indicator

\section{Analytic File riame}

\section{CEDRT: 2}

1 CER-assigned ID number

2 sex of worker

3 date of birth (century, year, month, day)

4 year of extemal dosimetry

5 facility

6 total w! ’ole-body penetrating radiation dose, $\mathrm{mSv}$

7 duplicate indicator

\section{Analytic Flle name}

\section{CEDR78 3}

1 CER-assigned ID number

2 sex of worker

3 date of birth (century, year, month, day)

4 race of worker

5 amount of plutonium deposition

6 state of death code

7 study overlap flag

8 first associated cancer cause of death

9 second associated cancer cause of death

10 third associated cancer cause of death

11 fourth associated cancer cause of death

12 fifth associated cancer cause of death

13 number of onsite externa dosimetry readings

14 year of first onsite external dnsimetry reading

15 duplicate indicator 


\title{
HANFORD
}

\author{
HFI89A01 Data Set
}

\section{Description}

This analytical data set consists of three files for the updated study, published in Health Physics in 1993, of operations workers at the Hanford Site.

This study continues to examine the relationship between occupational radiation exposure among Hanford workers and mortality from specific causes. The files used for this paper have been updated and refined since the 1989 publication. The study showed that both male and female workers continue to exhibit a strong healthy worker effect, with death rates from most causes substantially below those of the general U.S. population. Comparisons by level of radiation exposure within the Hanford worker population provided litise evidence of a positive correlation between cumulative radiation exposure and mortality from leukemia or from all other cancers combined.

The three analytic files in the HFI89A01 data set pertain to 44,156 Hanford operations workers initially employed at Hanford between 1944 and 1978. The first file (IARC89_1), with one record per individual, contains demographic, work history, vital status, and internal deposition data. Mortality data are provided for deaths occurring outside Washington State between 1944 and 1986, and deaths occurring in Washington between 1944 and 1989, inclusive. Internal deposition data include the radionuclide symbol and the year of first plutonium deposition. The second file (IARC89_2), contains external exposure data for the years 1944 through 1989. The dosimetry data include doses received while performing construction work at Hanford as well as occupational doses received offsite at other facilities. There is one record for each year of exposure data for each of the 37,012 monitored workers. The third file (IARC89_3) contains additional

data related to internal exposures, offsite exposures, and cause of death. There is one record for each worker

Comparisons with the U.S. general population included a cohort of 42,070 white workers. There were 9.452 deaths identified, and death certificates were obtained for 9,285 $(98.2 \%)$ of these deaths. Dose response analyses included 32,643 workers $(24,672$ males and 7,971 females) who were monitored for external radiation and employed for at least 6 months between 1.944 and 1985 . Vital status was ascertained through 1986 , the study end date. There were 6,286 deaths identified, and death certificates were obtained for 6,200 $(98.6 \%)$ of these deaths. Both types of analyses included deaths through December 31, 1986.

Workers at the Hanford Site were involved in a variety of activities that resulted in their exposure to radiation. including reactor operations, chemical separation of reactor fuel to obtain plutonium, treatment and storage of hazardous waste and biological and engineering research. Personal dosimeters (film or thermoluminescent) have been used since 1944. Bioassay programs to detect exposures to intemally deposited radionuclides, primarily transuranics, also were initiated in 1944. Dose estimates resulting from these monitoring programs appear in this data set. Annual whole-body doses to penetrating external radiation are presented in units of millisieverts. Quality factors of 10 for fast neutrons, 3 for slow neutrons, and 1 for photons and electrons were used in the conversion of exposure to dose. Internal exposure data were collected and evaluated for all individuals who worked in locations where there was a potential for intake of radioactive material (transuranics). 


\section{HANFORD}

HFI89A01 Data Set

\section{Citations}

Gilbert, E. S., E. Omohundro, J. A. Buchanan, and N.A. Holter 1993 "Mortality of workers at the Hanford Site: 1945-1986." Health Physics 64:6

\section{Additional References}

Gilbert, E. S., J. A. Buchanan, and N. A. Holter. 1992. Description of the process used to create 1992 Hanford Mortality Study data base. PNL8449

\begin{tabular}{|c|c|c|}
\hline No. of Files: & 3 & \\
\hline File Name & $\begin{array}{l}\text { No. of } \\
\text { Variables }\end{array}$ & Type of Data \\
\hline IARC89_1 & 18 & $\begin{array}{l}\text { demographic; } \\
\text { work history; } \\
\text { vital status; } \\
\text { internal } \\
\text { deposition date }\end{array}$ \\
\hline IARC89_2 & 11 & $\begin{array}{l}\text { external } \\
\text { exposure }\end{array}$ \\
\hline IARC89_3 & 30 & $\begin{array}{l}\text { internal } \\
\text { exposure; offsite } \\
\text { exposure; } \\
\text { cause of death }\end{array}$ \\
\hline
\end{tabular}

\section{Summary Death Tables}

\begin{tabular}{|c|c|c|}
\hline \multirow{2}{*}{ Cause of Death } & \multicolumn{2}{|c|}{ No. of Deaths } \\
\hline & Male & Female \\
\hline Infectious \& Parasitic Diseases & 42 & 8 \\
\hline All Malignant Neoplasms & 1927 & 451 \\
\hline - Lip. Oral Cavity \& Pharynx & 48 & 4 \\
\hline - Digestive Organs \& Peritoneum & 515 & 92 \\
\hline - Respiratory System & 637 & 80 \\
\hline - Bone \& Connective Tissue & 13 & 7 \\
\hline - Skin & 33 & 6 \\
\hline - Breast & 4 & 113 \\
\hline - Genitourinary System & 264 & 67 \\
\hline - Brain/CNS & 55 & 13 \\
\hline - Other \& Unspecified Sites, Except Brain/CNS & 156 & 26 \\
\hline - Lymphatic/Hematopoietic & 202 & 43 \\
\hline Ail Benign Neoplasms & 6 & 4 \\
\hline All Neoplasms, Unspecified & 9 & 2 \\
\hline Endocrine, Nutritional, Metabolic Diseases \& Immunity Disorders & 165 & 32 \\
\hline Diseases of Blood \& Blood-forming Organs & 13 & 5 \\
\hline Mental Disorders & 53 & 10 \\
\hline Diseases of Nervous System \& Sense Organs & 88 & 21 \\
\hline Diseases of Circulatory System & 4330 & 510 \\
\hline Diseases of Respiratory System & 609 & 98 \\
\hline Diseases of Digestive System & 331 & 82 \\
\hline Diseases of Genitourinary System & 92 & 11 \\
\hline Complications of Pregnancy \& Childbirth & 0 & 1 \\
\hline Diseases of Skin \& Subcutaneous Tissue & 3 & 3 \\
\hline Diseases of Muscuioskeletal System \& Connective Tissue & 22 & 12 \\
\hline Congenital Anomalies & 11 & 5 \\
\hline Symptoms \& III-Defined Conditions & 62 & 10 \\
\hline Accidents, Poisoning \& Violence (External Causes) & 778 & 133 \\
\hline Deaths, with ICD Code & 8541 & 1398 \\
\hline Deaths, No ICD Code & 224 & 101 \\
\hline Total Deaths, All Causes & 8765 & 1499 \\
\hline
\end{tabular}




\section{Analytic File Wame}

\section{ARCe9.}

1 CER-assigned ID number

2 sex of worker

3 date of birth (century, year month, day)

4 ending date of study

5 date of last vital status

6 date of initial employment (year month, day)

7 date of follow-up start

8 date of final employment (year, month, day)

9 year of first Pu deposition

10 year of first Pu monitoring

11 year of first $U$ deposition

12 year of first $U$ monitoring

13 type of internal deposition

14 year of first other type of deposition

15 longest general social class

16 underlying cause of death

17 ICD revision number

18 number of external dosimetry readings

HFI89A01

\section{Analytic File Mame}

\section{Ares9 2}

1 CER-assigned ID number

2 sex of worker

3 date of birth (century, year month, day)

4 year of external dosimetry

5 facility

6 penetrating radiation dose $\mathrm{mSv}$

7 neutron radiation dose $\mathrm{mSv}$

8 tritium radiation dose, $\mathrm{mSv}$

9 total wholebody penetrating radiation dose, $\mathrm{mSv}$

10 x-ray dose $\mathrm{mSv}$

11 extremity dose, $\mathrm{mSv}$

\section{Amalytic File Rane}

\section{IARC893}

1 CER-assigned ID number

2 sex of worker

3 date of birth (century, year. month, day)

4 race of worker

5 amount of plutonium deposi-

6 amount of deposition other than $\mathrm{Pu}$

7 strontium flag

8 state of death code

9 study overlap flag

10 first associated cancer cause of death

11 second associated cancer cause of death

12 third associated cancer cause death

13 fourth associated cancer cause of death

4 fifth associated cancer cause of death

15 last social class

16 longest general social class

17 longest social class

18 length of employment

19 year of first offsite dose

20 amount of first offsite dose

21 year of second offsite dose

22 amount of second offsite dose

23 year of third oftsite dose

24 amount of third offsite dose

25 year of fourth offsite dose

26 amount of fourth oflsite dose
27 year of fifth offsite dose 28 amount of fifth offsite dose

29 year of sixth offsite dose

30 amount of sixth offsite dose 


\section{HANFORD}

HFS93A03 Data Set

\section{Description}

This analytic data set consists of one file constructed for another analysis, published in the American Joumal of Industrial Medicine in 1993, of operations workers at the Hanford Site. This study examines the relationship between low level occupational radiation doses among Hanford workers and mortality from specific causes. The approach taken in this study makes new use of standard epidemiologic procedures and reveals evidence of increased cancer risk at low dose levels.

The reanalysis does not indicate that radiation is more likely to cause leukemia than solid tumors or that there is a rerluced cancer effectiveness of radiation at low dose levels However, the estimated proportion of radiogenic cancers was much higher for the 175 nonfatal cancers than for the 1,732 fatal cases.

The analytic file consists of seven records per worker for a cohort of 44,101 workers. The cohort was restricted to individuals who worked at Hanford between 1944 and 1978. The follow-up period for this reanalysis nuns from January 1944 through December 1986. The file contains demographic data, offsite doses, internal exposure data, annual external doses, work history, and vital status data. Due to the many job titles at Hanford. six job categories were established professional, managerial, clerical, crafts people, blue collar, other. and not specified. Data include the date on which a worker was first monitored (by urinalysis) for interial depesition as well as the dates on which the result was first greater than zero ( $i e$. measurable), the result was greater than the standard error. and the result was greater than twice the standard error. Results of in vive counting include the years at which depositions of one. two. or three nuclides were detected There were 9.443 deaths identified through the follow-up period of Decenber 31. 1986.

Workers at Hanford were involved in a variety of activities resulting in exposure to radiation, including reactor operations, chemical separation processes, treatment and storage of hazardous waste. and biological and engineering research. Personal dosimeters were first used in 1944. The doses contained in the file are

expressed in centirad. Intemal exposure data were collected and evaluated for all individuals who worked in locations where there was a potential for intake of radioactive matterials 


\section{HANFORD}

HFS93A03 Data Set

\section{Citations}

Kneale, G. W., and A. Stewart. 1993. "Reanalysis of Hanford Data: 1944-1986 Deaths." Americun Joumal of Industrial Medicine 23:371-389.

$\begin{array}{lcl}\text { No. of files: } & 1 & \\ \text { File Name } & \begin{array}{c}\text { No. of } \\ \text { Variables }\end{array} & \text { Type of Data } \\ \text { HAN_A2 } & 106 & \begin{array}{l}\text { demographic; } \\ \text { work history; } \\ \text { vital status; } \\ \text { external } \\ \text { exposure }\end{array}\end{array}$

\section{Summany Death Tables}

\begin{tabular}{|c|c|c|}
\hline \multirow{2}{*}{ Cause of Death } & \multicolumn{2}{|c|}{ No. of Deaths } \\
\hline & Male & Female \\
\hline Infectious \& Parasitic Diseases & 42 & 8 \\
\hline All Malignant Neoplasms & 1927 & 451 \\
\hline - Lip, Oral Cavity \& Pharynx & 48 & 4 \\
\hline - Digestive Organs \& Peritoneum & 515 & 92 \\
\hline - Respiratory System & 637 & 80 \\
\hline - Bone \& Connective Tissue & 13 & 7 \\
\hline - Skin & 33 & 6 \\
\hline - Breast & 4 & 113 \\
\hline - Genitourinary System & 264 & 67 \\
\hline - Brain/CNS & 55 & 13 \\
\hline - Other \& Unspecified Sites, Except Brain/CNS & 156 & 26 \\
\hline - Lymphatic/Hematopoietic & 202 & 43 \\
\hline All Benign Neoplasms & 6 & 4 \\
\hline All Neoplasms. Unspecified & 9 & 2 \\
\hline Endocrine, Nutritional, Metabolic Diseases \& Immunity Disorders & 165 & 32 \\
\hline Diseases of Blood \& Blood-forming Organs & 13 & 5 \\
\hline Mental Disorders & 53 & 10 \\
\hline Diseases of Nervous System \& Sense Organs & 88 & 21 \\
\hline Diseases of Circulatory System & 4330 & $\mathbf{5 1 0}$ \\
\hline Diseases of Respiratory System & 609 & 98 \\
\hline Diseases of Digestive System & 331 & 82 \\
\hline Diseases of Genitourinary System & 92 & 11 \\
\hline Complications of Pregnancy \& Childbirth & 0 & 1 \\
\hline Diseases of Skin \& Subcutaneous Tissue & 3 & 3 \\
\hline Diseases of Musculoskeletal System \& Connective Tissue & 22 & 12 \\
\hline Congenital Anomalies & 11 & 5 \\
\hline Symptoms \& II-Defined Conditions & 62 & 10 \\
\hline Accidents, Poisoning \& Violence (External Causes) & 778 & 133 \\
\hline Deaths, With ICD Code & 8541 & 1398 \\
\hline Deaths, No ICD Code & 224 & 101 \\
\hline Total Deaths, All Causes & 8765 & 1499 \\
\hline
\end{tabular}




\section{Andyic Fle wame}

\section{$\operatorname{mat} 12$}

1 CER-assigned ID number

2 sex

3 race

4 birth year

5 hire year

6 year of first offsite dose

7 lirst oflsite dose

8 number of years of offsite doses

9 year of first plutonium deposition

10 plutoniuin deposition

11 death year

12 state of death

13 cause of death (underlying)

14 cause of death (contributory)

15 cause of death (second contributory)

16-50 external dose by year. $1944-1978$

51-85 job code by year, 1944 - 1978

86 definite termination

87 bioassay !evel one

88 bioassay level two

89 bioassay level three

90 bioassay level four

91 bioassay level five

92 in vivo level one

93 in vivo level two

94 in vivo level three

95 in vivo level four

96 in vivo level five
97 in vivo level six

98 in vivo level seven

99 in vivo level eight

100 in vivo level nine

101 in vivo level ten

102 in vivo level eleven

103 in vivo level twelve

104 in vivo level thirteen

105 in vivo level fourteen

106 in vivo level fifteen 


\title{
LANL
}

\author{
LAFEMA01 Data Set
}

\section{Description}

The LAFFMA01 data set contains one analytic file used in a mortality study of white female workers at Los Alamos National Laboratory (1.ANL), published as a doctoral dissertation in 1987

The analysis sought to determine whether mortality among these workers differed significantly from the general population of females in the United States and whether the subgroup of this cohort that was exposed to radiation was at an increased risk if dying from cancer when compared to the unexpersed group The analysis focused on 6.573 white (tho se with race unkiu own wert assumed to be white) females who were employed at LANI. between 1943 and 1978 inclusive Minst analyses were further limited to the 5.234 white workers employed at least 6 months The study found a standardized mortality ration (SMR) for suicide that was significantly elevated Rate ratios for cancers of the ovar and pancreas were also signific antly elevated for radiationmonitored inembers of the cohon but to the elevated risk of suicide an elesated rate ratio for deatio due tu all causes was also observed for the radiation workers in thus cohor

The single analytic file (LAFEFIIF, contains data for 6,700 femahes of all races emplused at I ANI. and represents a complete ruxter of females hired through December $3 i, 1978$ some later hires are included in the file but not in the analysis Fxtermal expensure data in the file consist of jales ( given in decimalized notation I on which the worker was first monitored. first received a positive exposure, first accumulated $1 \mathrm{rem}$ whole-body dose. first accumulated 5 rems whole body dose, and first recened I0 rems whole-body dose Whole body dose was defined as the sum of all tritium. neutron. and penetrating gamma readings. Fxtermal readings were available through 1981 . Data pertaining to internal plutonium exprsure include isotope. dattes (in derimalized notation) of first and last samples and estimated body burdens ( in units of both nci and ne i-vears of plutonium. Dates of first and last sample were through January 1. 1985. Fstimated body burdens were taken through [ fecember 31 . 1284: date of death, or date of the last binassiy sample The computer coxte fli gPlA was used to estimate olutumim bety burckens incurred by workers through 1984 Demographic data were extracted from a number of sources, including LANI. persunnel ant? medical records and was computerized in 1982 and $11+8$ ? by the LANI. Fpictemioling Section

Vital satus was ase entained for 87 of the $6, T(M)$ fernales through Dereminer 31 . 1981, the study and diate There were 430 deaths identified in this cohort

The LANL has been a center for research in nuclear phisics and weapons development since the 1940s Sources of ix cupational exposures include external radiation. primarily gamma and potential internal depesition of plutonium-238 and plutenium-239. Pocket chambers in film dusineters were used for persunnel monitoring until 1984) when they were replaced with thermoluminescent dosimeters. Fomal bioassay prograres to monitor for internal exposures were begun in 19.5. Results of beth types of monitoring programs reffect technological improvenents and changes in concets and moxtets. 


\section{LANL}

LAFEMA01 Data Set

\section{Citations}

Wiggs, L. D 1987. Mortality among fernales employed by the Los Alamos National Latoratory An epidemiologic investigation." Ph 1) the sis. University of Oklahoma

\section{Additional References}

Lawrence. J N P 1962. PUOFIA An IBM 704 code for computing plutonium body burdens " Health Physics 861tit;

\begin{tabular}{|lcl|}
\hline No. of Files: & 1 & \\
File 1 & $\begin{array}{l}\text { No. of } \\
\text { Variables }\end{array}$ & Type of Data \\
& 38 & $\begin{array}{l}\text { vital status; } \\
\text { external whole- } \\
\text { body doses; } \\
\text { demographic; } \\
\text { plutonium body } \\
\text { burden }\end{array}$ \\
\hline
\end{tabular}

Semangy Deafl Tables

\begin{tabular}{|c|c|c|}
\hline \multirow{2}{*}{ Cause of Death } & \multicolumn{2}{|c|}{ No. of Deaths } \\
\hline & Male & Female \\
\hline Infectious \& Parasitic Diseases & & 7 \\
\hline All Malignant Neoplasms & & 182 \\
\hline - Lip, Oral Cavity \& Pharyox & & 3 \\
\hline - Digestive Organs \& Peritoneum & & 30 \\
\hline - Respiratory Syseem & & 29 \\
\hline - Bone \& Connective Tissue & & 3 \\
\hline - Slin & & 5 \\
\hline - Breast & & 51 \\
\hline - Genitourinary System & & 32 \\
\hline - Brain/Cus & & 7 \\
\hline - Other \& Uaxpecified Sites, Except Brainucus & & 10 \\
\hline - Lymphatic/Hematopoietic & & 12 \\
\hline All Benign Meoplasms & & 3 \\
\hline All Neoplasms, Unspecified & & 1 \\
\hline Endocrine, Mutritional, Metabolic Diseases \& Immunity Disorders & & 5 \\
\hline Diseases of 8lood \& Blood-forming Organs & & $\mathbf{0}$ \\
\hline Mental Disorders & & 6 \\
\hline Diseases of Mervous System \& Sense Organs & & 4 \\
\hline Diseases of Cinculatory System & & 155 \\
\hline Diseases of Respiratory System & & 36 \\
\hline Diseases of Digestive System & & 32 \\
\hline Diseases of Genitourinary System & & 5 \\
\hline Complications of Pregnancy \& Childibirth & & 4 \\
\hline Diseases of Skin \& Subcutaneous Tissue & & 1 \\
\hline Diseases of Musculoskeletal System \& Connective Tissue & & 3 \\
\hline Congenital Anomalies & & 1 \\
\hline Symptoms \& It-Defined Conditions & & 6 \\
\hline Accidents. Poisoning \& Violence (External Causes) & & 60 \\
\hline
\end{tabular}

\begin{tabular}{|l|r|}
\hline Deaths, With KCD Code & 511 \\
Deaths, No ICD Code & 25 \\
Total Deaths, All Causes & 536 \\
\hline
\end{tabular}

$t$ No males were included in this study. 


\section{Analyfic Fille nane}

\section{LAFEFIL}

1 CER-assigned ID number

2 identifies worker as radiation worker

3 sex of the worker

4 race

5 highest level of education

6 vital status from SSA as of $12 \pi 3179$

7 vital status as of $12 / 31 / 8$

8 ethnicity of the worker

9 first job title at LANL.

10 last job title at LANL

11 date worker was bom

12 date of first hire at LANL

13 latest known termination date from LANL

14 date worker was last known to be alive

15 date last worked

16 duration of employment at LANL

17 date of death

18 caise of death - ICDA 8th revision

19 plutonium monitored flag

20 isotope of plutonium measured

21 number of bioassay sample for worker

22 number of valid bioassay readings

23 date of first bioassay reading

24 date of first positive plutonium uplake

LAFEMA01
25 date of last bicassay reading

26 boxly burden $(12 / 31 / 81)$ nCiyears

27 body busden ( $\mathrm{nCi}$ ) at last sample date

28 bxdy burden (nCi-years) last sample date

29 body burden ( $\mathrm{nCi}$ ) as of $12 / 31 / 83$

30 boxdy burden ( $\mathrm{nCi}$ ) as of $12 / 31 / 8$

31 external monitoring flag

32 date first monitored for external radiation

33 date external radiation dose greater than 0

34 date external adiation dose reached I rem

35 date external radiation dise reached 5 rems

36 date external radiation dose reached 10 rems

37 cumulative whole-bixty dose external

38 latest date employed during study 


\section{LANL}

LASUIA02 Data Set

\section{Description}

This data set contains one analytic file that was used in a study of deaths from suicide anong female workers at Los Alamos National Laboratory (LANL) in 1988

A nested case-control study was undertaken to identify characteristics distinguishing white females dying from suicide from white females dying from all other types of injuries and those dying from noninjury causes. Two separate analyses were presented: one contrasting the 19 suicide deaths and the 41 other injury deaths, the other contrasting the 19 suicide deaths and 76 noninjury deaths. Extemal radiation monitoring status and job classification both showed an association with risk of suicide when suicide deaths were compared with noninjury deaths. An association was also found between suicide and external radiation monitoring status when comparing suicide to deaths from all other injuries. No significant associations were found between risk of suicide and duration if employment, plutonium inonitoring status, or mantal status. Education was controlled in all comparisons.

The single analytic file (LAJUFILE) pertains to 136 white females employed at LANL. This number includes all suicide, all other injury deaths, and a 4:1 random sample of all other deaths. External monitoring data consist of dates (in decimalized notation) on which the worker was first monitored, first received a positive exposure, first received 1 rem sumulative whole-body dose, first received 5 rems cumulative whole-body dose, and inst received 10 rems cumulative whole-body dose. Whole-body dose was defined as the sum of all tritium, netutron. and penetrating gammat readings Extemal readings were available through [lecember 31 , 198

Only eight of the females in this file were monitored for plutonium Intemal exporsure data consist of plutonium-239 body burdens that were calculated by the PUQFUA computer code, the official code used at LANL to estimate body burdens from binassay data. The date of first positive uptake of plutonium was hand-abstracted from data valid through 1986 . Plutonium monitoring data inciude isotope type; first sample date (in decimalized notation): last sample date (decimalized); and estimated whole-body burdens (both nCi and nCi-years) as of December 31. 1983, as of December 31,1984 , and as of the last sample date.

LANL has been a center for research in nuclear physic's and weapons development since the 1940s. Sources of occupational exposures include extemal radiation, primarily gamma, and potential internal deposition of plutonium-2:38 and plutonium-2:39.

Pocket chambers or film dosimeters were used for personnel monitoring until 1980. when they were replaced with

themoluminescent dosimeters. Formal bioassiy programs to monitor for intemal exposures were begun in 19.15. Results of both types of monitoring programs reflect technological improvernents and changes in concepts and models. 


\section{LANL}

LASUIA02 Data Set

\section{Citations}

Wiggs, L. D., C. A. 'M Ler, and E. T. Lee. 1988 "Suicide mortality among female nuclear industry workers." Proceedings of the 116th Annual Meeting of the American Public Health Association, Boston, MA, p. 46.

\section{Additional References}

Lawrence, J. N. P. 1962. "PUQFUA, an IBM 704 code for computing plutonium body burdens." Health Physics 8:61-66.

Wiggs, L. D. 1987. "Mortality among females employed by the Los Alamos National Laboratory: An epidemiologic investigation, Ph.D. thesis, University of Oklahoma

\begin{tabular}{|ccc|}
\hline No. of Files: & 1 & \\
File Name & $\begin{array}{l}\text { No. of } \\
\text { Lasuriables }\end{array}$ & Type of Data \\
& 45 & $\begin{array}{l}\text { external whole- } \\
\text { body dose; } \\
\text { plutonium whole- } \\
\text { body burden: } \\
\text { demographic: } \\
\text { vital status }\end{array}$ \\
\hline
\end{tabular}

\section{Summary Death Tables}

\begin{tabular}{|c|c|c|}
\hline \multirow{2}{*}{ Cause of Death } & \multicolumn{2}{|c|}{ No. of Deaths } \\
\hline & Male $†$ & Female \\
\hline Infectious \& Parasitic Diseases & & 1 \\
\hline All Malignant Neoplasms & & 26 \\
\hline - Lip, Oral Cavity \& Pharyn: & & 1 \\
\hline - Digestive Organs \& Peritoneum & & 7 \\
\hline - Respiratory System & & 6 \\
\hline - Bone \& Connective Tissue & & 0 \\
\hline - Skin & & 2 \\
\hline - Breast & & 6 \\
\hline - Genitourinary System & & 2 \\
\hline - Brain/CNS & & 0 \\
\hline - Other \& Unspecified Sites, Except Brain/CNS & & 1 \\
\hline - Lymphatic/Hematopoietic & & 1 \\
\hline All Benign Nesplasms & & 1 \\
\hline All Neoplasms, Unspecified & & 0 \\
\hline Endocrine, Nutritional, Metabolic Diseases \& Immunity Disorders & & 1 \\
\hline Diseases of Blood \& Blood-Forming Organs & & 0 \\
\hline Mental Disorders & & 1 \\
\hline Diseases of Nervous System \& Sense Organs & & $\mathbf{0}$ \\
\hline Diseases of Circulatory System & & 28 \\
\hline Diseases of Respiratory System & & 4 \\
\hline Diseases of Digestive System & & 12 \\
\hline Diseases of Genitourinary System & & 0 \\
\hline Complications of Pregnancy \& Childbirth & & 1 \\
\hline Diseases of Skin \& Subcutaneous Tissue & & 0 \\
\hline Diseases of Musculoskeletal System \& Connective Tissue & & 0 \\
\hline Congenital Anomalies & & 0 \\
\hline Symptoms \& Ill-Defined Conditions & & 1 \\
\hline Áccidents, Poisoning \& Violence (External Causes) & & 60 \\
\hline Deaths, With KCD Code & & 136 \\
\hline Deaths, No ICD Code & & 0 \\
\hline Total Deaths, All Causes & & 136 \\
\hline
\end{tabular}

† No males were included in this study. 


\section{Analytic Flle Mome}

LASUFILE

1 CER-assigned ID number 2 type of death

3 identifies worker as radiation monitored

4 sex of the worker

5 race

6 highest level of education

7 vital status from SSA as of

$$
12 / 31 / 79
$$

8 vital status as of $12 / 31 / 81$

9 ethnicity of the worker

10 first job title at LANL

11 last job title at LANL

12 date worker was born

13 date of first hire at LANL

14 latest known termination date from LANL microfiche

15 date worker was last known to be alive

16 date last worked

17 duration of employment at LANL

18 date of death

19 cause of death - ICDA 8th revision

20 plutonium monitored flag

21 isotope of plutonium measured

22 number of bioassay samples for employee

23 number of valid bioassay readings

24 date of first bioassay reading

25 date of first positive plutonium uptake
-. s date of last bioassay reading 27 body burden (12/31/84) in nCi-years

28 body burden $(\mathrm{nCi})$ at last sample date

29 body burden ( $\mathrm{nCi}$-years) last sample date

30 body burden ( $\mathrm{nCi}$ ) as of 12/31/83

31 body burden ( $\mathrm{nCi}$ ) as of 12/31/84

32 external monitored flag

33 date first monitored for external radiation

34 date external radiation dose was greater than 0

35 date external radiation dose reached $1 \mathrm{rem}$

36 date external radiation dose reached 5 rems

37 date external radiation dose reached 10 rems

38 cumulative whole-body dose external

39 latest known date employed in study

40 state of death

41 marital status at time of death

42 occupation listed on death certificate

43 autopsy

44 grouped recode of last job title

45 grouped occupation on death cert

LASUIA02 


\title{
LINDE
}

\author{
LND87A01 Data Set
}

\section{Description}

This analytic data set consists of one file generated for a cohort mortality study, published in the Scandinavian Joumal Work Environment Health in 1987, of white males employed at the Linde Plant.

This retrospective cohort mortality study investigated the relationship between exposure to low-level ionizing radiation and subsequent health outcomes among workers at the linde Plant. Two comparison groups were used in this analysis. The first group consisted of all U.S. white males; the second was the white male population of Erie and Niagara counties in New York State. Significantly increased standardized mortality ratios (SMRs) were observed for all causes of death, laryngeal cancer. all circulatory diseases, arteriosclerotic heart disease, all respiratory diseases, and pneumonia. No association was found with length of employment or with work in the most hazardous areas of the plant. The comparison with regional rates gave similar resuits.

The single analytic file (MOSTEXP) in this data set consists of one record per person in the study cohort and contains demographic, work history, and vital status data as well as information conceming exposures to chemicals and uranium. Examples of these are exposures to uranium hexafluoride, nitric acid, and hydrofluoric acid.

The cohort was selected from a roster of all persons $(1,551)$ employed at the Linde Plant, which was in operation from 1943 to 1949. All females, non-white males, males of unknown race, and people employed less than 30 days were excluded, leaving 995 white males in the study cohort. Vital status was ascertained for $94.3 \%$ of the cohort through December 31, 1979, the study end date. There were 429 deaths identified, and death certificates were obtained for $406(94.6 \%)$ of these deaths

At the linde Plant, Congo pitchblende and uranium from domestic mines were converted to uranium tetrafluoride This process yielded intermediate products, including uranium oxide, uranium trioxide, and uranium dioxide Compared to uranium tetrafluoride, these products are relatively insoluble. Workers were also potentially exposed to low levels of extemal radiation and to a wide variety of chemicals. The more hazardous chemicals included chlorine, hydrofluoric acid, lead sulfate, nickel, nitric acid and nitrogen oxides, silicon dioxide, sulfuric acid, uranium dust, and uranium hexafluoride. Generally, four types of measurements contained information useful in assessing radiation hazards. They were (1) air monitoring results for radon-222 and airborne uranium, (2) measurements of surface contamination, (3) urinalysis results, and (4) personnel film badge results. The first three types of measurements were used to assess the potential for internal radiation exposure for each job that existed at the plant. Three separate analyses were carricd out using each type of data, and the results were combined to assign a given job to one of three exposure groups. These data also were used to estimate individual lung doses. The limited film badge data were used to evaluate the potential for exposure to external radiation. Each job at the plant was assigned to one of two categories, namely, jobs with mean weekly film badge results below the minimum detectable level and jobs with mean weekly film badge results above the minimum detectable level 


\section{LINDE}

LND87A01 Data Set

\section{Citations}

Dupree, E. A., D. L. Cragle, R. W. McLain, D. J Crawford-Brown, and M. J. Teta. 1987. "Mortality among workers at a uranium processing facility. the Linde Air Products Company Ceramics Plant, 1943-1949." Scundinavian Journal Work Environmental Health 13:100-107.

\begin{tabular}{ccc} 
No. of Files: & 1 & \\
File Name & $\begin{array}{l}\text { No. of } \\
\text { Variables }\end{array}$ & Type of Data \\
MOSTEXP & 38 & $\begin{array}{l}\text { demographic; } \\
\text { work history; } \\
\text { vital status; } \\
\text { chemical, } \\
\text { external, and } \\
\text { internal } \\
\text { exposure levels }\end{array}$ \\
\hline
\end{tabular}

\section{Summary Death Tables}

\begin{tabular}{|c|c|c|}
\hline \multirow{2}{*}{ Cause of Death } & \multicolumn{2}{|c|}{ No. of Deaths } \\
\hline & Male & Female ${ }^{\dagger}$ \\
\hline Infectious \& Parasitic Diseases & 5 & \\
\hline All Malignant Neoplasms & 73 & \\
\hline - Lip, Oral Cavity \& Pharynx & 2 & \\
\hline - Digestive Organs \& Peritoneum & 26 & \\
\hline - Respiratory System & 26 & \\
\hline - Bone \& Connective Tissue & 0 & \\
\hline - Skin & o & \\
\hline - Breast & 0 & \\
\hline - Genitourinary System & 7 & \\
\hline - Brain/CNS & 2 & \\
\hline - Other \& Unspecified Sites, Except Brain/CNS & 4 & \\
\hline - Lymphatic/Hematopoietic & 6 & \\
\hline All Benign Neoplasms & 1 & \\
\hline All Neoplasms, Unspecified & 1 & \\
\hline Endocrine, Nutritional, Metabolic Diseases \& Immunity Disorders & 7 & \\
\hline Diseases of Blood \& Blood-Forming Organs & 0 & \\
\hline Mental Disorders & 5 & \\
\hline Diseases of Nervous System \& Sense Organs & 1 & \\
\hline Diseases of Cinculatory System & 216 & \\
\hline Diseases of Respiratory System & 29 & \\
\hline Diseases of Digestive System & 18 & \\
\hline Diseases of Genitourinary System & 3 & \\
\hline Complications of Pregnancy \& Childbirth & 0 & \\
\hline Diseases of Skin \& Subcutaneous Tissue & 0 & \\
\hline Diseases of Musculoskeletal System \& Connective Tissue & 2 & \\
\hline Congenital Anomalies & 0 & \\
\hline Symptoms \& Ill-Defined Conditions & 3 & \\
\hline Accidents, Poisoning \& Violence (External Causes) & 25 & \\
\hline Deaths, With ICD Code & 389 & \\
\hline Deaths, No ICD Code & 24 & \\
\hline Total Deaths, All Causes & 413 & \\
\hline
\end{tabular}

$\dagger$ No females were included in this study. 


\section{Anplytic Fle Mame}

\section{MOSTEXP}

1 CER-assigned ID number

2 first hire into ceramics plant

3 last termination date

4 multiple hire/term at ceramics plant

5 vital status code

6 last known date alive

7 ICD code for underlying cause of death

8 underlying cancer cause of death

9 birth date of individual

10 ICD code for underlying cause of death

11 total days employed at ceramics

12 job days with exposure not assignable

13 external radiation (er) level most days at

14 job days at er level

15 date first at er level

16 internal radiation (ir) level most days spent at

17 job days spent at ir level

18 first date at ir level

19 uranium deposition (ud) leve! most days spent at

20 job days spent at ud level

21 first date at ud level

22 nitric acid ( $h n$ ) level most days spent at

23 job days spent at hn level

24 first date at hn level
25 hydrofluoric acid ( $h f$ ) level

most days spent at

26 job days spent at hf level

27 first date at hi level

28 uranium hexafluoride (hf6)

level most days spent at

29 job days spent at hf6 level

30 first date at hf6 level

31 sulfuric acid (h2s) level most days spent at

32 job days spent at h2s level

33 first date at h2s level

34 silicone dioxide ( $($ io) leve mosi days spent at

35 job days spent at sio level

36 the first date at sio level

37 ICD code for underlying cause of death

38 sequence number of row

LND87A01 


\title{
MOUND
}

\author{
MDEXTA02 Data Set
}

\section{Description}

This data set contains one analytic file generated for a cohort mortality study, published in the Joumal of Occupational Medicine in 1991, of men and women employed at the Mound Plant in Ohio.

This cohort mortality study of Mound workers was conducted to test the association between mortality and exposure to radiation. The published analyses focused on 3,229 white males monitored for exposure to external radiation, who were already employed as of January 1, 19.47, or who were subsequently hired before 1979 A strong healthy worker effect was noted among white males who were monitored for extemal radiation lall causes of death standardized montality ratio $(\mathrm{SMR})=79,95 \%(\mathrm{l}=70.88) \mathrm{No}$ ) cause of death was significantly elevated. When mortality for workers who received external, cumulative whole-body doses that were at least $10 \mathrm{mSv}$ was compared with mortality among nonexposed workers, the rate ratios were not significantly elevated for any cause of death. However, a dose-response analysis was conducted considering three categories: nonexposed, or less than $10 \mathrm{mSv}$ cumulative whole-body dose; exposed, $10-49.9 \mathrm{mSv}$; and exposed, greater than or equal to 50 $\mathrm{mSv}$. This analysis reported a statistically significant relationship between external dose and mortality from all leukemias. This result was based on the identification of two deaths in the highest exposure category, one of which was a chronic lymphatic leukemia (CLL), a type of leukemia which has not been considered a radiogenic cancer
The analytic file (ANFILE) contains 6,904 records representing each worker first hired from the beginuing of the Dayton Project (about 1943) through part of 1979. During the course of the analyses, 20 of these records were found to be duplicates of other records in the file. The analyses in the published paper did not include these 20 duplicate records $(N=6,884)$. After the paper was published, two additional records were found to be either duplicative or belonging to a person who never worked at Mound. These 22 records are identified in this file by blank ORAUID numbers. Monitoring data in the file include estimated first date of monitoring, cumulative whole-body dose through the end of 1979 , and dates on which the cumulative whole-body dose reached 10,50 . or $100 \mathrm{mSv}$.

Vital status ascertainment was $98.1 \%$ complete for the 4.182 white males through January I, 1980. Death certificates were obtained for $98.8 \%$ (586) of the 593 deaths that occurred between 1947 and 1979 , inclusive.

Major operations conducted at Mound included the separation, chemistry. and metallurgy of polonium-210 and processing of plutonium-238 for heat sources. Later, small research projects involved other isotopes, including radium and thorium. Mound began its external dosimetry monitoring program in 1947 . first using film badges and later switching to thermoluminescent dosimeters (TLDs). 


\section{MOUND}

MDEXTA02 Data Set

\section{Citation}

Wiggs, L. D., C. A Cox-DeVore, G. S. Wilkinson, and M. Reyes. 1991. "Mortality among workers exposed to external ionizing radiation at a nuclear facility in Ohio." Joumal of Occupational Medicine 33:632637.

\begin{tabular}{|lcl|}
\hline No. of Files: & 1 & \\
File Name & $\begin{array}{l}\text { No. of } \\
\text { Variables }\end{array}$ & Type of Data \\
& 21 & $\begin{array}{l}\text { annual, external } \\
\text { whole-body } \\
\text { doses; work } \\
\text { history; vital } \\
\text { status; } \\
\text { demographic }\end{array}$ \\
\hline
\end{tabular}

\section{Summary Death Tables}

\begin{tabular}{|l|r|r|}
\hline \multicolumn{1}{|c|}{ Cause of Death } & No. of Deaths \\
\hline Infectious \& Parasitic Diseases & Male & Female \\
\hline All Malignant Neoplasms & 178 & 0 \\
- Lip, Oral Cavity \& Pharynx & 8 & 1 \\
- Digestive Organs \& Peritoneum & 40 & 4 \\
- Respiratory System & 72 & 4 \\
Bone \& Connective Tissue & 2 & 0 \\
Skin $\quad$ Breast & 5 & 0 \\
- Cenitourinary System & 0 & 11 \\
Brain/CNS & 19 & 7 \\
Other \& Unspecified Sites, Except Brain/CNS & 3 & 1 \\
All Benign Neoplasms & 13 & 1 \\
All Neoplasms, Unspecified & 16 & 2 \\
Endocrine, Nutritional, Metabolic Diseases \& immunity Disorders & 2 & 0 \\
Diseases of Blood \& Blood-Forming Organs & 1 & 0 \\
Mental Disorders & 19 & 2 \\
Diseases of Nervous System \& Sense Organs & 1 & 0 \\
Diseases of Circulatory System & 5 & 0 \\
Diseases of Respiratory System & 7 & 1 \\
Diseases of Digestive System & 454 & 19 \\
Diseases of Genitourinary System & 53 & 1 \\
Complications of Pregnancy \& Childbirth & 50 & 2 \\
Diseases of Skin \& Subcutaneous Tissue & 19 & 2 \\
Diseases of Musculoskeletal System \& Connective Tissue & 0 & 1 \\
Congenital Anomalies & 0 & 0 \\
Symptoms \& lli-Defined Conditions & 0 & 0 \\
Accidents, Poisoning \& Violence (External Causes) & 1 & 0 \\
\hline & 4 & 1 \\
\hline & & 11 \\
\hline
\end{tabular}

\begin{tabular}{|l|r|r|}
\hline Deaths, With ICD Code & 900 & 71 \\
Deaths, No ICD Code & 227 & 49 \\
Total Deaths, All Causes & 1127 & 120 \\
\hline
\end{tabular}




\section{Analytic File Dame}

\section{ANIFILE}

1 date of birth

2 date of first hire at the Mound Plant

3 date of final termination prior to 1980

4 duration of employment at Mound

\section{5 sex}

6 race

7 education level

8 date of death

9 cause of death - ICDA 8th rev.

10 sex as shown on the death certificate

11 race as shown on the death certificate

12 current vital status as of 12/31/79

13 results of 1982 SSA search

14 vital status as of 1983 from SSA

15 cum. ext. rad. dose as of 1979

16 date cum. ext. rad dose reached I rem

17 date cum. ext. rad. dose reached 5 rems

18 date cum ext rad dose reached 10 rems

19 est. date first measure ext. rad. dose

20 state of death

21 CER-assigned ID number 


\section{MOUND}

\author{
MDPOLA03 Data Set
}

\section{Description}

This data set consists of one analytic file generated for a cot:ont montality study, published in Health Physics in 1941. of men who were employed at the Mound Plant.

This cohort mortality study of Mound workers was conducted to test the association between mortality and exposure to polonium-210. The published analyses focused on 4.402 white males employed during 1944-1972, the period during which Mound conducted operations using polonum-210. Of the 4.402 white males, there were 2.181 who were monitored for exposure to polonium. A healthy worker effect was noted among the cohort of 4,402 white males lall causes of death standardized montality ratio $($ SMR $)=93,90 \% \mathrm{Cl}=89-99$; all cancer $S M R=100.90 \% \mathrm{Cl}=89-113 \mathrm{j}$. The $\mathrm{SMR}$ for lung cancer was elevated to a level of statistical significance only for workers employed between 1944 and 1945. The SMR for deaths due to all causes for workers exposed to polonium was less than $100(\mathrm{SMR}=92,90 \% \mathrm{Cl}=85-98)$. Although the SMR for lung cancer was elevated $(S M R=113)$. the $90 \%$ confidence limits included $100(87-117)$. Dose response analyses using the MOX program were performed using kidney dose as the exposure metric. No statistically significant trends in mortality were obsened

The single anaiytic file (ANFILE) in this data set contains data for 6884 workers who were initially hired between 1943 through 1979. inclusive Exposure data in the file include the estimated first date of monitoring. cumulative whole-body dose through the end of 1979 , and dates on which the wholebedy dose reached 10.50 . or $100 \mathrm{mSs}$. Polonium exposure data include the date and volume of the sample. the results of the radiochemical analysis. and any comments sperific to the sample or the radiochemical analysis of the sample An electronic file containing these data was used by Mound staff to calculate kidney and spleen doses due to polonium-210 in millirems). These organ duses appear in this analytic file.

Vital status was ascertained for $95.6 \%$ of the 4,402 white males through Janua y 1. 1984 There were 987 deaths identified in this group, and death certificates were obtained for $97.4 \%$ (961) of these deaths. Vital status was ascertained for $96.6 \%$ $(2,106)$ of the 2,181 polonium workers. and death certificates were obtained for $98.6 \%$ (558) of them.

Major eperations conducted at Mound include the separation chemistry. and metallurgy of polonium-210 and processing of plutonium-238 for heat sources. Later. small research projects involved other isotopes. including radium and thorium. Records pertaining to Mound's external dosimetry monitoring program, first using film badges and later switching to thermoluminescent dosimeters (TLDs), began in 1947. Mound began urine bioassays for polonium in 1944. The last time a worker entered the polonium bioassay program was in 1972 


\section{MOUND}

MDPOLA0:3 Data Set

\section{Citations}

Wiggs, L D. C A Cox-DeVore, and C L Voetz 1991. "Mortality among a cohort of

workers monitored for Por2lo Exprsure

1944-1972 " Health Hhwsics til 71.76.

\section{Senumary Death Tables}

\begin{tabular}{|c|c|c|}
\hline \multirow{2}{*}{ Cause of Death } & \multicolumn{2}{|c|}{ No. of Deaths } \\
\hline & Mate & Female \\
\hline Infectious \& Parasitic Diseases & 8 & 1 \\
\hline All Malignant Neoplasms & 243 & 49 \\
\hline - Lip. Oral Cavity \& Pharynx & 10 & 1 \\
\hline - Digestive Organs Peritoneum & 60 & 8 \\
\hline - Respiratory System & 96 & 6 \\
\hline - Bone \& Connective Tissue & 2 & $\mathbf{0}$ \\
\hline - Skin & 5 & $\mathbf{0}$ \\
\hline - Breast & $\mathbf{0}$ & 18 \\
\hline - Genitourinary System & 25 & 10 \\
\hline - Brain/CNS & 5 & 1 \\
\hline - Other \& Unspecified Sites, Except Braindaus & 18 & 1 \\
\hline - Lymphatic/Hematopoietic & 22 & 4 \\
\hline All Benign Neoplasms & 2 & $\mathbf{0}$ \\
\hline All Neoplasms, Unspecified & $\mathbf{1}$ & $\mathbf{0}$ \\
\hline Endocrine, Mutritional, Metabolic Diseases \& immunity Disorders & 20 & 5 \\
\hline Diseases of Blood \& Blood-forming Organs & 2 & $\mathbf{0}$ \\
\hline Mental Disorders & 7 & $\mathbf{0}$ \\
\hline Diseases of Nervous System \& Sense Organs & 12 & 1 \\
\hline Diseases of Circulatory System & 545 & 33 \\
\hline Diseases of Respiratory System & 64 & 5 \\
\hline Diseases of Digestive System & 56 & 4 \\
\hline Diseases of Genitourinary System & 21 & 2 \\
\hline Complications of Pregnancy \& Childbirth & $\mathbf{0}$ & 1 \\
\hline Diseases of Skin \& Subcutaneous Tissue & $\mathbf{0}$ & 0 \\
\hline Diseases of Musculoskeletal System \& Connective Tissue & $\mathbf{0}$ & $\mathbf{0}$ \\
\hline Congenital Anomalies & 1 & $\mathbf{0}$ \\
\hline Symptoms \& m-Defined Conditions & 6 & 1 \\
\hline Accidents, Poisoning \& Violence (External Causes) & 107 & 13 \\
\hline
\end{tabular}

doses; work

history, vital

status:

demographic polonium data

\begin{tabular}{|l|r|r|}
\hline Deaths, With KO Code & 1095 & 115 \\
Deaths, No KCO Code & 172 & 23 \\
Total Deaths, All Causes & 1267 & 138 \\
\hline
\end{tabular}




\section{Andric fore nane}

ADF

1 date of birth

2 date of first hire at the Mound Plant

3 date of final termination prior to 1980

4 duration of empluyment at

Mound

5 sex

6 race

7 education leve

8 date of death

9 cause of death - ICDA

8th revision

10 sex as shown on the death certificate

11 race as shown on the dealh centificate

12 current vital status as of

$$
12 / 31 / 79
$$

13 results of 1982 SSA search

14 results of 1983 SSA search

15 cum. ext rad dose as of 1970

16 date cum ext rad dose reached I rem

17 date cum ext rad dose reached 5 rems

18 date cum ext rad dise reached 10 rems

19 est date furst measure ext rad dose

20 kidney dose of Por-210. mrem

21 spleen dose o! Por-2in. mrem

22 firs sample date for Po-210

23 last sample date for Por-210

24 date last known alive

MDPOLA03
25 vital status. 1983

26 state of death

27 (FR-assigned II) number 


\section{MOUND}

\author{
MDSMRA01 Data Set
}

\section{Description}

This analytic data set consists of one file generated for a cohum mortality sudy, published as a LANL. Report, of white malts employed at the Mound Plant

A cohor montality study of workers was conducted to tect for an association between mortality and employment at the Mound

Plant. The study examined differences in montality for workers at the plant during its polonium-210 e ra $(1942-1959)$ and for its plutonium-238 era 1960 (1980) by computing period-spectific standardized monality ratios (SMRs) based on (IS rates. The analysis focused on 4.697 white and presumed white males who were emploved betwern April 1. 1942 and December 31 1979 at the Mound Plant SMRs of 96 were oisened for both all causes and for all cancers for the study period ( 194:-1979) NoSMR was significantly greater than I $100 \mathrm{for}$ these workers A significantly elevated SMR for lung cancer $(S M R=204 \text {. } 0)^{\prime} \cdot(\mathrm{C}=1.40 .2(\mathrm{H}))$ was observed for workers employed during World War II 1 1943-1945) Similar results were noted for all cause's of death, all cancers. cancers of the rectum. nonmalignant respiratory diseases and all injuries furing this time period SMRs for these: causes of death during the pollonium era but after Worlit War II. were not elevated No elevated SMRs were observed during the plutonium era A ven strong healtw woker effect was ofkered for workers in the plutonium ora although the length of followetp for these workers was relativety shu

The single analvtic file ( ANFIIF) in this (hatis sof contans demographic and vital stans tata for 1697 white males and

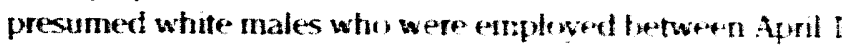

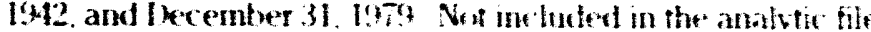
are workers emplesed less than ?h days turing the perif ext workers with unkmewn hirth dates. and workets with both unknown hire and termination dates Nerexpande dath ant included in the file

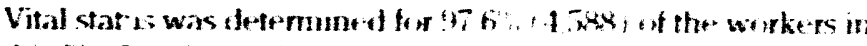

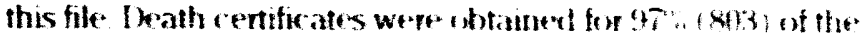
known deaths

The Menund Plant has been a center fo the separatum chemstry and metallury of polemmin-2ll and processing of

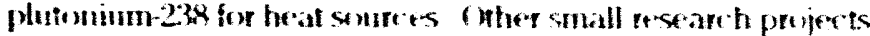
involsed radium and thomum Workfers conld have heen expesed to extemal and internal sume of of ndiation. however.

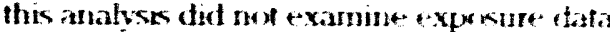




\section{MOUnd}

MDSMRA01 Data Set

\section{Citations}

Reyes, M., G. S. Wilkinson, G. L. Tietjen, L. D Wiggs, and W. A Galke 1991. "Montality among workers at the Mound Facility. "Los Alamos Report LA-11997-MS.

\begin{tabular}{|lcl|} 
No. of Files: & 1 & \\
File Name & $\begin{array}{c}\text { No. of } \\
\text { Variables }\end{array}$ & Type of Data \\
ANFILE & 11 & $\begin{array}{l}\text { demographic; } \\
\text { work history: } \\
\text { vital status: } \\
\text { internal } \\
\text { deposition }\end{array}$ \\
\hline
\end{tabular}

\section{Summary Death Talbles}

\begin{tabular}{|c|c|c|}
\hline \multirow{2}{*}{ Cause of Death } & \multicolumn{2}{|c|}{ No. of Deaths } \\
\hline & Male & Femalet \\
\hline Infectious \& Parasitic Diseases & 7 & \\
\hline All Mabignant Neoplasms & 208 & \\
\hline - Lip. Oral Cavity \& Phanymx & 9 & \\
\hline - Digestive Organs \& Peritoneum & 48 & \\
\hline - Respiratory System & 83 & \\
\hline - Bone \& Connective Tissue & 2 & \\
\hline - Skin & 4 & \\
\hline - Breast & 1 & \\
\hline - Genitourinary System & 23 & \\
\hline - Brain/Cus & 3 & \\
\hline - Other \& Unspecified Sites, Except Brain/CuS & 16 & \\
\hline - Lymphatic/ttematopoietic & 19 & \\
\hline All Benign Meoplasms & 2 & \\
\hline All Neoplasms, Unspecified & 1 & \\
\hline Endocrine, Mutritional Metabolic Diseases \& kmmunity Disonders & 17 & \\
\hline Diseases of Blood \& Blood-forming Organs & 2 & \\
\hline Mental Disonders & 6 & \\
\hline Diseases of Nervous System \& Sense Organs & 9 & \\
\hline Diseases of Circulatory System & 458 & \\
\hline Diseases of Respiratory System & 51 & \\
\hline Diseases of Digestive System & 49 & \\
\hline Diseases of Genitourinary System & 18 & \\
\hline Complications of Pregnancy $\&$ Childbirth & o & \\
\hline Diseases of Skin \& Subcutaneous Tissue & $\mathbf{0}$ & \\
\hline Diseases of Musculoskeletal System \& Connective Tissue & $\mathbf{0}$ & \\
\hline Congenital Anomalies & $\mathbf{0}$ & \\
\hline Symptoms \& m-Defined Conditions & 5 & \\
\hline Accidents, Poisoning \& Violence (External Causes) & 93 & \\
\hline
\end{tabular}

\begin{tabular}{|l|r|r|}
\hline Deaths, With ICD Code & 926 & \\
Deaths, No ICD Code & 26 & 952 \\
Total Deaths, All Causes & 952 \\
\hline
\end{tabular}

$t$ No females were included in this study. 


\section{Amalytic File Name}

\section{AMFILE}

1 date of birth

2 date of first hire at Mound

3 date of last termination from

Mound

4 date of death

5 cause of death - ICD 8th rev.

$6 \operatorname{sex}$

7 race

8 education level

9 current vital status as of $12 / 31 / 79$

10 the state of death

11 CER-assigned ID number 


\section{OR/K-25}

ORK25A01 Data Set

\section{Description}

This analytic data set consists of one file generated for a study, published in IARC Scientific Publications, of nickel workers at the Oak Ridge K-25 Facility.

This study examined mortality patterns in a group of 814 workers potentially exposeci to nickel powder because previous studies of workers at nickel refineries had shown excesses of lung and nasal sinus cancers. Between January 1, 1948, and December 31, 1953, the Oak Ridge Gaseous Diffusion Plant (ORGDP, now known as the K-25 Facility) employed over 800 white males in the manufacture of "barrier" material for nuclear weapons. This process required the use of metallic nickel powder. For the study, a comparison group of 7,552 white males employed for at least 1 day at K-25 between Januarv !, 1948, and December 31, 1953, and who had no indications of occupational involvement in the production of barrier material was selected. Mortality rates in the nickel workers and non-nickel workers were compared with each other and with those of U.S. white males. There was no evidence of increased mortality due to lung cancers or nasal sinus cancers in the nickel workers. Increases, not statistically significant, in mortality due to cancers of the buccal cavity, pharynx, and digestive system were observed in the nickel worker group when compared to the non-nickel worker group.
The single analytic file (K25EVER1) contains one record for each of the 8,378 individuals in the cohort that includes the nickel workers and the comparison group of non-nickel workers. Vital status was ascertained for 100\% of the cohort through December 31,1977 , which allowed at least 24 years of follow-up for each individual. There were 137 deaths identified in the nickel worker group and 1,920 deaths in the comparison group. Death certificates were ubtained for $97 \%$ of the total number $(2.057)$ of deaths.

Radiation monitoring data were not used in this study; however smoking histories for some workers were available through the plant medical records. All of the nickel workers' medical records and a random sample of $20 \%$ of the comparison group's medical records were abstracted for smoking data. Information was obtained for $54 \%$ of the nickel workers and for $48 \%$ of the other workers whose records were in the sample. The nickel workers had a slightly lower frequency of smoking than the other workers based on the sample. Air monitoring data indicated that nickel workers worked in an enviroment where nickel levels were above NIOSH standards. 


\section{OR/K-25}

ORK25:01 Data Set

\section{Citations}

Cragle, D. L., D. R. Hollis, and T. H. Newport 1984. "A retrospective cohort mortality study among workers occupationally exposed to metallic nickel powder at the Oak Ridge Gaseous Diffusion Plant." IARC Scientific No. 53:57-63.

\begin{tabular}{|c|c|c|}
\hline No. of Files: & 1 & \\
\hline File Name & $\begin{array}{l}\text { No of } \\
\text { Variables }\end{array}$ & Type of Data \\
\hline K25EVER1 & 14 & $\begin{array}{l}\text { vital status; } \\
\text { smoking history? } \\
\text { work history }\end{array}$ \\
\hline
\end{tabular}

\section{Summary Death Tables}

\begin{tabular}{|c|c|c|}
\hline \multirow{2}{*}{ Cause of Death } & \multicolumn{2}{|c|}{ No. of Deaths } \\
\hline & Male & Femalet \\
\hline Infectious \& Parasitic Diseases & 19 & \\
\hline All Malignant Neoplasms & 427 & \\
\hline - Lip, Oral Cavity \& Pharynx & 7 & \\
\hline - Digestive Organs \& Peritoneum & 96 & \\
\hline - Respiratory System & 177 & \\
\hline - Bone \& Connective Tissue & 1 & \\
\hline - Skin & 7 & \\
\hline - Breast & $\mathbf{0}$ & \\
\hline - Genitourinary System & 50 & \\
\hline - Brain/CNS & 14 & \\
\hline - Other \& Unspecified Sites, Except Brain/CNS & 25 & \\
\hline - Lymphatic/Hematopoietic & 50 & \\
\hline All Benign Neoplasms & 2 & \\
\hline All Neoplasms, Unspecified & 4 & \\
\hline Endocrine, Nutritional, Metabolic Diseases \& Immunity Disorders & 28 & \\
\hline Diseases of Blood \& Blood-Forming Organs & 4 & \\
\hline Mental Disorders & 12 & \\
\hline Diseases of Nervous System \& Sense Organs & 13 & \\
\hline Diseases of Circulatory System & 1135 & \\
\hline Diseases of Respiratory System & 122 & \\
\hline Diseases of Digestive System & 81 & \\
\hline Diseases of Genitourinary System & 17 & \\
\hline Complications of Pregnancy \& Childbirth & 0 & \\
\hline Diseases of Skin \& Subcutaneous Tissue & 1 & \\
\hline Diseases of Musculoskeletal System \& Connective Tissue & 5 & \\
\hline Congenital Anomalies & 7 & \\
\hline Symptoms \& III-Defined Conditions & 99 & \\
\hline Accidents, Poisoning \& Violence (External Causes) & 220 & \\
\hline Deaths, with ICD Code & 2196 & \\
\hline Deaths, No ICD Code & 64 & \\
\hline Total Deaths, All Causes & 2260 & \\
\hline
\end{tabular}

$t$ No females were included in this study. 
Analytlc File Name

K25EMERT

1 birth date

2 worked at $\mathrm{K}-25(\mathrm{Y} / \mathrm{N})$

3 first hire date at any Oak Ridge

facility

4 last termination date

5 last known status date

6 vital status

7 CER-assigned ID number

8 3-digit ICD code for cause of

death

9 first hire at $\mathrm{K} 25$ facility

10 last term from K25 facility

11 smoking history code

12 barrier worker $(\mathrm{Y} / \mathrm{N})$

13 first date in a nickel department

14 sequence number 


\section{OR/MULTI}

ORMULA01 Data Set

\section{Description}

This analytic data set consists of one file generated for a study, published in Archives of Environmental Health in 1981. of welders employed at one or more of the three Oak Ridge facilities.

This study examined mortality from various diseases, including cancer of the respiratory system, in a cohort of 1,059 white male welders exposed to nickel compounds. The study also examined the long-term health effects of exposure to several other compounds (dust, fumes, and gases) among welders. A subgroup of these welders was exposed to nickel oxides at the Oak Ridge K-25 Facility, formerly known as the Oak Ridge Gaseous Diffusion Plant (ORGDP). These workers were subjected to air concentrations of nickel higher than proposed standards. However, standardized mortality ratios (SMRs) for lung cancer and diseases of the respiratory system were not higher among $\mathrm{K}-25$ welders than among other welders.
The single analytic file (ANALYSIS) in this data set contains demographic and vital status data for 1,062 indiviruals. There is one record per person; three individuals were not included in the final analyses. Radiation monitoring data were not used in the analysis.

The study cohort of 1,059 white male welders was determined by examining work histories (payroll records) that specified job

titles and job codes indicative of welding. Industrial hygienists at the plant were consulted to avoid possible exclusion of job titles and job codes associated with welding on a full-time basis. Vital status was ascertained for approximately $92 \%$ of the study cohort through December 31, 1974, the study end date. There were 173 deaths identified. and death certificates were obtained for 166 $(95.9 \%)$ of these deaths. Personal radiation monitoring data were not used; however, some air monitoring data and smoking history data were analyzed. Smoking data were obtained for $356(33.6 \%)$ of the 1059 welders. 


\section{OR/MULTI}

ORMULA01 Data Set

\section{Citation}

Polednak, A. 1981. "Mortality among welders, including a group exposed to nickel oxides." Archives of Environmental Heulth 36(5)

\begin{tabular}{ccc|} 
No. of Files: & 1 & \\
File Name & $\begin{array}{c}\text { No. of } \\
\text { Variables }\end{array}$ & Type of Data \\
ANALYSIS & 12 & $\begin{array}{l}\text { demographic; } \\
\text { vital status }\end{array}$ \\
\hline
\end{tabular}

\section{Summary Death Tables}

\begin{tabular}{|c|c|c|}
\hline \multirow{2}{*}{ Cause of Death } & \multicolumn{2}{|c|}{ No. of Deaths } \\
\hline & Male & Female $\dagger$ \\
\hline Infectious \& Parasitic Diseases & 1 & \\
\hline All Malignant Neoplasms & 69 & \\
\hline - Lip. Oral Cavity \& Pharynx & $\mathbf{0}$ & \\
\hline - Digestive Organs \& Peritoneum & 15 & \\
\hline - Respiratory System & 33 & \\
\hline - Bone \& Connective Tissue & 0 & \\
\hline - Skin & 0 & \\
\hline - Breast & 1 & \\
\hline - Genitourinary System & 5 & \\
\hline - Brain/CNS & 3 & \\
\hline - Other \& Unspecified Sites, Except Brain/CNS & 8 & \\
\hline - Lymphatic/Hematopoietic & 4 & \\
\hline All Benign Neoplasms & D & \\
\hline Ail Neoplasms, Unspecified & 0 & \\
\hline Endocrine, Nutritional, Metabolic Diseases \& Immunity Disorders & 1 & \\
\hline Diseases of Blood \& Blood-Forming Organs & 0 & \\
\hline Mental Disorders & D & \\
\hline Diseases of Nervous System \& Sense Organs & 3 & \\
\hline Diseases of Circulatory System & 149 & \\
\hline Diseases of Respiratory System & 28 & \\
\hline Diseases of Digestive System & 17 & \\
\hline Diseases of Genitourinary System & 2 & \\
\hline Complications of Pregnancy \& Childbirth & 0 & \\
\hline Diseases of Skin \& Subcutaneous Tissue & 0 & \\
\hline Diseases of Musculoskeletal System \& Connective Tissue & 1 & \\
\hline Congenital Anomalies & 0 & \\
\hline Symptoms \& III-Defined Conditions & 11 & \\
\hline Accidents, Poisoning \& Violence (External Causes) & 43 & \\
\hline Deaths, with ICD Code & 325 & \\
\hline Deaths, No ICD Code & 9 & \\
\hline Total Deaths, All Causes & 334 & \\
\hline
\end{tabular}

$t$ No females were included in this study. 
Anabytic File Wame

\section{AnALYsIs}

1 CER-assigned ID number

2 birth date of individual

3 first hire as a welder

4 vital status

5 last date status date

6 the underlying cause of death

7 number of days worked at $\mathrm{K} 25$

8 days as a welder not at $K 25$

9 the year of birth

10 first hire year as a welder

11 latency time

12 sequence number of row 


\section{OR/MULTI}

ORMULA02 Data Set

\section{Description}

This analytic data set consists of one file generated for a study, published in Radiation Research in 1990, of white males who worked at the Oak Ridge facilities during World War II (WWII).

This study demonstrated that Poisson regression methods can effectively describe the effect of multiple risk factors on causespecific mortality. The cohort was defined as 28,008 white males who were employed for at least 1 month at any one of the three Oak Ridge facilities. During WWII (1943-1947), two of the facilities (Y-12 and K-25) were plants that produced enriched uranium, and Oak Ridge National Laboratory was a research and development facility. During WWII, radiation monitoring programs were in developmental stages; only persons considered likely to be exposed, or those who were thought to be representative samples of workers likely to be exposed, were monitored. The paper discusses how a modified version of the traditional standardized mortality ratio (SMR) analysis was used to compare the cause-specific mortality experience of these workers with the U.S. population. The SMR for all causes was

1.11 , and there was a significant upward trend of $0.74 \%$ per year. The excess mortality was primarily due to lung cancer and diseases of the respiratory system.

The single analytic file (PHASEIB) in this data set contains 28,008 records, one for each person in the cohort. Each record consists of demographic, vital status, and work history data and extemal exposure indicators. The indicators were used as surrogates for external exposure data and were determined by analyzing job title and department combinations, categorizing each combination by risk of exposure.

The cohort included only those workers who were hired at one of the facilities between the start of operations at that respective facility and December 31, 1947. Fach person was considered to have entered the cohort on January $1,1950$.

Vital status was ascertained for $98.1 \%$ of the cohort through December 31. 1979, the study end date. There were 11671 deaths identified, and death certificates were obtained for $96.8 \%$ of these deaths

Because radiation monitoring programs were still in developmental stages, complete personal monitoring data for this cohort were not available during the time period. Therefore, exposure indices based on job title and department combinations were developed as surrogates for monitoring data 


\section{OR/MULTI}

ORMULA02 Data Set

\section{Citation}

Frome. E. L. D. L. Cragle, and R W McLain. 1990. "Poisson regression of the mortality among a cohort of World War Il nuclear industry workers." Radiation Research 123:138-152

\begin{tabular}{lcl} 
No. of Files: & 1 & \\
File Name & $\begin{array}{l}\text { No. of } \\
\text { Variables }\end{array}$ & Type of Data \\
PHASE1B & 22 & $\begin{array}{l}\text { demographic; } \\
\text { vital status; } \\
\text { work history; } \\
\text { time at exposure } \\
\text { level }\end{array}$ \\
\hline
\end{tabular}

\section{Summary Death Tables}

\begin{tabular}{|c|c|c|}
\hline \multirow{2}{*}{ Cause of Death } & \multicolumn{2}{|c|}{ No. of Deaths } \\
\hline & Male & Female \\
\hline Infectious \& Parasitic Diseases & 150 & \\
\hline All Malignant Neoplasms & 2188 & \\
\hline - Lip, Oral Cavity \& Pharynx & 75 & \\
\hline - Digestive Organs \& Peritoneum & 486 & \\
\hline - Respiratory System & 877 & \\
\hline - Bone \& Connective Tissue & 22 & \\
\hline - Skin & 33 & \\
\hline - Breast & 5 & \\
\hline - Genitourinary System & 255 & \\
\hline - Brain/CNS & 67 & \\
\hline - Other \& Unspecified Sites, Except Brain/CNS & 174 & \\
\hline - Lymphatic/Hematopoietic & 194 & \\
\hline All Benign Neoplasms & 7 & \\
\hline All Neoplasms, Unspecified & 25 & \\
\hline Endocrine, Nutritional, Metabolic Diseases \& Immunity Disorders & 151 & \\
\hline Diseases of Blood \& Blood-Forming Organs & 9 & \\
\hline Mental Disorders & 81 & \\
\hline Diseases of Nervous System \& Sense Organs & 76 & \\
\hline Diseases of Circulatory System & 5727 & \\
\hline Diseases of Respiratory System & 790 & \\
\hline Diseases of Digestive System & 470 & \\
\hline Diseases of Genitourinary System & 147 & \\
\hline Complications of Pregnancy \& Childbirth & $\mathbf{0}$ & \\
\hline Diseases of Skin \& Subcutaneous Tissue & 6 & \\
\hline Diseases of Musculoskeletal System \& Connective Tissue & 25 & \\
\hline Congenital Anomalies & 13 & \\
\hline Symptoms \& II-Defined Conditions & 338 & \\
\hline Accidents, Poisoning \& Violence (External Causes) & 1046 & \\
\hline Deaths, With ICD Code & 11249 & \\
\hline Deaths, No ICD Code & 367 & \\
\hline Total Deaths, All Causes & 11616 & \\
\hline
\end{tabular}

$\dagger$ No females were included in this study. 


\section{Analyfic File Hame}

\section{PHASEIB}

1 CER-assigned ID number

2 cancer cause in not underly. ing

3 birth date

4 last date known alive

5 length of employment in days

6 date of lirst hire

7 last termination date before $1 / 1 / 48$

8 hire date if after $1 / 1 / 48$

9 vital status of individual

10 number of days at yes exposure level

11 number of days at no exposure level

12 number of days at Substitute Alloy Material (SAM)

$$
\text { Laboratory }
$$

13 number of days at unknown level

14 underlying cause of death code

15 facility of employment

16 category of duration of employment

17 highest socioeconomic status reached

18 first socioeconomic status

19 exposed on job (yes, no. unknown)

20 age category at 1945

21 this variable was not used in analysis

22 sequence number of row 


\section{OR/MULTI}

ORMULA03 Data Set

\section{Description}

This analytic data set consists of one file generated for a study. published in the American Jumal of Public Health in 1992. examining ill-defined causes of death of white males at the three Oak Ridge facilities

This study determined the association between various factors and a recorded ill-defined cause of death. A matc hed pair case-rontrol study, with one control per case and within an occupational cohort of workers at three facilities (the Oak Ridge Y-12 and K-25 Plants and the Oak Ridge National Laboratory), was conducted. The study found a strong association between the ill-defined classification given as a cause of death and particular centifiers, especially if the certifier was a medical exaniner. Results from other cohon mortality studies of workers at the (lak Ridge facilities have indicated unusual increases in the rate of deaths due to unexplained or unsperified causes In this study the standardized mortality ratio (SMR) for deaths coded to these categories was 3.05 (338 obsenved versus 11092 expected)

The single analytic file in this data set contains 1,2 lit records one for each case and each matched control. The file contains demographic. work history, and fatality data, plus codes for the different certifiers Fach individual in this cohort must have

worked for more than 30 days at any ()ak Ridge facility between 1943 and 1982 and must have died between 1945 and 1982. Death certificates were obtained for 608 cases in which deaths were due to unexplained or unspecified causes. Based on cause of death and matching birth and death dates within? years (plus or minus), a control was selected for each case. The control also had to work at the sane facility as the caste

Death certificates were ohtained for all 1.216 cases and controls. from which considerable data in arddition in cause of death were abstracted

Personal or enviromental ratiation monitoring data were not used in this study 


\section{OR/MULT}

ORMULA03 Data Set

\section{Critations}

Cragle, D L., and A Fetcher 1942. "Risk tactors associated with the classification of

unspecified and/or unexplained causes of death in an occupational cohort." American Joumal of Public Health 82(3):455-457

\begin{tabular}{|ccc|} 
No. of Files: & 1 & \\
File Name & $\begin{array}{l}\text { No. of } \\
\text { Variables }\end{array}$ & Type of Data \\
ANALYSIS & 38 & $\begin{array}{l}\text { demographic: } \\
\text { work history; } \\
\text { death certificate } \\
\text { data }\end{array}$ \\
\hline
\end{tabular}

\section{Semuady Death Tables}

\begin{tabular}{|c|c|c|}
\hline \multirow{2}{*}{ Cause of Death } & \multicolumn{2}{|c|}{ No. of Deaths } \\
\hline & Male & Femalet \\
\hline Infectious \& Parasitic Diseases & 7 & \\
\hline All Malignant Neoplasms & 141 & \\
\hline - Lip. Oral Cavity \& Pharyoux & 6 & \\
\hline - Digestive Organs \& Perito. reum & 41 & \\
\hline - Respiratory System & 53 & \\
\hline - Bone \& Connective Tissue & 1 & \\
\hline - Skin & 1 & \\
\hline - Breast & 0 & \\
\hline - Genitourinary System & 13 & \\
\hline - Brain/Cus & 3 & \\
\hline - Other \& Unspecified Sites, Except Brain/CNS & 8 & \\
\hline - Lymphatic/Hematopoietic & 15 & \\
\hline All Benign Neoplasms & 1 & \\
\hline All Neoplasms, Unspecified & 1 & \\
\hline Endocrine, Mutritional, Metabolic Diseases \& immunity Disorders & 13 & \\
\hline Diseases of Blood \& Blood-forming Organs & $\mathbf{0}$ & \\
\hline Mental Disonders & 2 & \\
\hline Diseases of Nervous System \& Sense Organs & 3 & \\
\hline Diseases of Circulatory System & 300 & \\
\hline Diseases of Respiratory System & 34 & \\
\hline Diseases of Digestive System & 25 & \\
\hline Diseases of Genitourinary System & 8 & \\
\hline Complications of Pregnancy \& Childbirth & o & \\
\hline Diseases of Skin \& Subcutaneous Tissue & $\mathbf{0}$ & \\
\hline Diseases of Musculoskeletal System \& Cormective Tissue & 2 & \\
\hline Congenital Anomalies & $\mathbf{0}$ & \\
\hline Symptoms \& at-Defined Conditions & 607 & \\
\hline Accidents, Poisoning \& Violence (External Causes) & 70 & \\
\hline Deaths, Writh ICD Code & 1214 & \\
\hline Deaths, No ICD Code & 2 & \\
\hline Total Deaths, All Causes & 1216 & \\
\hline
\end{tabular}

t No females were included in this studty 


\section{Aochic Fie Whane}

\section{Amalysts}

1 autopsy code

2 autopsy used to complete death certificate

3 case/control indicator

4 case/control indicator

5 death centificate centifier

6 code indicating name of centifiet

7 continuous employment indicator

8 date of birth

9 date of death

10 East Tennessee county of death

11 East Tennessee county of residence

12 employment duration

13 facility first employed

14 first hire date at any Oak Ridge tacility

15 code for hospital name

16 code for hospital status

17 type of hospital

18 cause of death

19 CER-assigned ID number

20 job classilication per death centificate

21 last job title per CER Data Model

22 number of days employed at Oak Ridge

23 last term date from any Oak Ridge facility

24 marital status

25 mobility indicator
26 worked at more than one fac indicator

27 death cert physician attending $(\mathrm{Y} / \mathrm{N})$

28 place of death

29 place of last residence

30 set number

31 state of birth

32 state of death

33 state of last known residence

34 was sate of last residence Tennessee

35 was state of birth Tennessee

36 was state of death Tennessee

37 code for Tennessee county of death

38 code for Tennesset couniy of residence

ORMULA03 


\section{$0 R / x-10$}

ORX10A01 Data Set

\section{Bescription}

This analytic data set consists of four files generated for the cohort mortality study, published in the Britsh Journal of Industrial Medicine in 1985, of white males employed at oak Ridge National Laboratory (ORNL).

The publication focuses on 8,375 white males employed at ORNL for at least 1 month ( 30 days) between 1943 and 1972 The study presents internal comparisons of mortality (standardized rate ratios) between subgroups of the cohort according to radiation dose level and duration of employment in various job categories. No consistent gradients of cause-specific mortality were assessed with respect to radiation exposure Among monitored workers, deficits in mortality due to arteriosclerotic heart disease and all cancers were found. However, elevated (but not statistically signilicant) standardized mortality ratios (SMRs) were seen for all leukemias, cancer of the prostate. and Hodgkin's disease

There are four analytic files in the ORX10A01 data set. The first file (X1CH0210) provides information for 12 employment groupings, which were based on an examination of each individual's work history and on the calculation of a 10-year latency period for each person. The second file (XICH0810) contains extemal radiation doses as assessed from extemal monitoring data. The third file (XICH1201) contains all demographic data and summary exposure data pertaining to the cohort. This file contains one record per individual in the cohort, whereas the other files may contain several or no records per individual, depending on the availability of monitoring data for those individuals. The fourth file (CUMEXP) contains all internal monitoring data pertinent to the cohort
Vital status was ascentained for $922^{\prime \prime \prime}$ of the cohort of 4.35 white males through December $31,197 \%$, the study end date There were $\$ 66$ deaths identified and death centificates were obtained for $939(972 \%)$ of these deaths External and intemat exposures to radiation were examined

ORNL began monitoring personel for exposure to pentetrating external radiation, primarily gamma ravs in 1943. Pocket chambers were used until June 1944 when film dosimeters iffir badges) became the primary dosimeters. Film dosimeters were used for personnel monitoring until 1975. when they were replaced with themoluminescent dosimeters (TLI): From 1943 until the early 1950s, the usual practice was to provicis personal dosimeters to only those workers entering designated areas where the potential for exposure was presumed to exist. Subsequently, all workers at ORNL were monitored for $\mathrm{e}$ xposure to radiation. In 1951, based primarily on the potential for contamination from their work area. some workers began to be monitored by urine bioassays for internal exposure to, radionuclides. Additional workers were monitored to evaluate exposures incurred during incidents Internal exposures were determined by results of urine and fecal bioassays and wholebody counting. For purposes of the study, internal monitoring results were used to place the worker into one of three exposure categories each year. Quantitative dose estimates due to internally deposited radionuclides are not available because they usually were not required to be calculated in the past, and all of the basic data needed to compute doses for the many radionuclides used at ORNL are not computerized However. knowledgeable plant health phisicists and dosimetrists state that the maiority of internal monitoring results for this colort suggest small intemal doses. especially when compared to external doses. 


\section{OR/X-10}

ORX10A01 Data Set

\section{Citations}

Checkoway, H. R. M. Mathew, C M. Shy, J.E. Watson, W. G. Tankersley, S. H. Wolf, J. C. Smith, and S. A. Fry. 1985. "Radiation, work experience, and cause-specific mortaiity among workers at an energy research laboratory." British Joumal of Industrial Medicine 42:525-533.

No. of Files: 4

\begin{tabular}{|c|c|c|}
\hline File Name & $\begin{array}{l}\text { No. of } \\
\text { Variables }\end{array}$ & Type of Data \\
\hline $\mathrm{X1CH0210}$ & 49 & work history \\
\hline$\times 1 C H 0810$ & 71 & $\begin{array}{l}\text { external radiation } \\
\text { dose }\end{array}$ \\
\hline $\mathrm{X1CH1201}$ & 38 & $\begin{array}{l}\text { demographic; } \\
\text { summary } \\
\text { exposure; vital } \\
\text { status }\end{array}$ \\
\hline CUMEXP & 71 & $\begin{array}{l}\text { internal } \\
\text { monitoring }\end{array}$ \\
\hline
\end{tabular}

\section{Summary Death Tables}

\begin{tabular}{|c|c|c|}
\hline \multirow{2}{*}{ Cause of Death } & \multicolumn{2}{|c|}{ No. of Deaths } \\
\hline & Male & Femalet \\
\hline Infectious \& Parasitic Diseases & 6 & \\
\hline All Malignant Neoplasms & 194 & \\
\hline - Lip. Oral Cavity \& Pharynx & 4 & \\
\hline - Digestive Organs \& Peritoneum & 45 & \\
\hline - Respiratory System & 61 & \\
\hline - Bone \& Connective Tissue & 4 & \\
\hline - Skin & 4 & \\
\hline - Breast & o & \\
\hline - Genitourinary System & 22 & \\
\hline - Brain/CNS & 9 & \\
\hline - Other \& Unspecified Sites, Except Brain/CNS & 15 & \\
\hline - Lymphatic/Hematopoietic & 30 & \\
\hline All Benign Neoplasms & $\mathbf{0}$ & \\
\hline All Neoplasms, Unspecified & 1 & \\
\hline Endocrine, Nutritional, Metabolic Diseases \& Immunity Disorders & 12 & \\
\hline Diseases of Blood \& Blood-forming Organs & 2 & \\
\hline Mental Disorders & 3 & \\
\hline Diseases of Nervous System \& Sense Organs & 6 & \\
\hline Diseases of Girculatory System & 472 & \\
\hline Diseases of Respiratory System & 42 & \\
\hline Diseases of Digestive System & 26 & \\
\hline Diseases of Genitourinary System & 15 & \\
\hline Complications of Pregnancy \& Childbirth & o & \\
\hline Diseases of Skin \& Subcutaneous Tissue & 1 & \\
\hline Diseases of Musculoskeletal System \& Connective Tissue & 1 & \\
\hline Congenital Anomalies & 1 & \\
\hline Symptoms \& III-Defined Conditions & 28 & \\
\hline Accidents, Poisoning \& Violence (Extemal Causes) & 129 & \\
\hline Deaths, With ICD Code & 939 & \\
\hline Deaths, No ICD Code & 27 & \\
\hline Total Deaths, All Causes & 966 & \\
\hline
\end{tabular}

$t$ No females were included in this study. 


\section{Analytic File Hame \\ X1CH0210}

1 CER-assigned ID number

2 total time spent in grp 01

3 total time spent in grp 02

4 total time spent in grp 03

5 total time spent in grp 04

6 total time spent in grp 05

7 total time spent in grp 06

8 total time spent in grp 07

9 total time spent in grp 08

10 total time spent in grp 09

11 total time spent in grp 10

12 total time spent in grp 11

13 total time spent in grp 12

14 date first worked in grp 01

15 date first worked in grp 02

16 date first worked in grp 03

17 date first worked in grp 04

18 date first worked in grp 05

19 date first worked in grp 06

20 date first worked in grp 07

21 date first worked in grp 08

22 date first worked in grp 09

23 date first worked in grp 10

24 date first worked in grp 11

25 date first worked in grp 12

26 1-yr date of eligibility into grp 01

27 1-yr date of eligibility into grp 02

281 -yr date of eligibility into grp 03

29 1-yr date of eligibility into grp 04

30 1-yr date of eligibility into grp 05

31 1-yr date of eligibility into grp 06

32 1-yr date of eligibility into grp 07

33 1-yr date of eligibility into grp 08
34 1-yr date of eligibility into grp 09

35 1-yr date of eligibility into grp 10

36 1-yr date of eligibility into grp 11

37 1-yr date of eligibility into grp 12

38 10-yr date of eligibility into grp 01

39 10-yr date of eligibility into grp 02

40 10-yr date of eligibility into grp 03

41 10-yr date of eligibility into grp 04

42 10-yr date of eligibility into grp 05

4310 -yr date of eligibility into grp 06

4410 -yr date of eligibility into grp 07

45 10-yr date of eligibility into grp 08

46 10-yr date of eligibility into grp 09

47 10-yr date of eligibility into grp 10

4810 -yr date of eligibility into grp 11

49 10-yr date of eligibility into grp 12

\section{Anatytic File Name}

\section{X1CH0810}

1 CER-assigned ID number

2-36 annual film badge dose by year, $1943-1977$

37-71 cumulative film badge dose by year, $1943-197$ ?

ORX10A01

\section{Analytic File Name}

\section{X1CH1201}

1 CER-assigned ID number

2 highest internal exposure code

3 code for highest in vivo value

4 highest bioassay value ever

5 number of times individual was. hired

6 current employee

7 final termination date of individual

8 sex code

9 race code

10 number of facilities

11 first date of hire at ORNL

12 duration of employment at ORNL.

13 exposure to mercury

14 beryllium exposure indicator

15 exposure tu lead

16 birth date

17 date of death

18 vital status

19 DAG code

20 cumulative neutron dose

21 year of earliest neutron record

22 number of neutron records

23 neutron exposure flag

24 date of last observation

25 total film badge dose at ORNL

26 total number of film badge records

27 days from final term to date last observation

28 film badge error flag

29 year of first exposure at ORNL 
30 length of follow-up in years

31 first year in vivo monitoring

- 32 total number of in vivo records

- 33 first monitoring year of bioassay

- 34 total number of bioassay records

35 status of internal monitoring

36 earliest internal monitoring year

. 37 underlying cause of death

38 other cancers

\section{Analytic Fle Wame}

\section{CUMEXP}

1 CER-assigned ID number

.2-36 highest annual intemal

exposure code by year, 1943

1977

37-71 highest cumulative interna exposure code by year, 1943 1977 


\section{OR/X-10}

ORX10A02 Data Set

\section{Description}

This analytic data set consists of three files that were used in updated analyses, presented in two papers, of white males employed at the Oak Ridge National Laboratory (ORNL).

Both papers analyzed data for a cohort of 8,318 white males employed at ORNL for at least 30 days between 1943 and 1972. In the first paper (JAMA 1991), two types of analyses were performed. The first was a cause-specific mortality analysis comparing the study population to the mortality of white males in the U.S. The second was an analysis of the relationship between protracte exposure to low levels of external penetrating ionizing radiation and mortality within the study population. Compared with the mortality experience of all U.S. white males, relatively low mortality was observed for most causes of death. However, mortality from leukemia was elevated in the total cohort and in workers who had at some time been monitored for exposure to internally deposited radionuclides. The second publication

(AJIM 1993) examines the role of possible selection and confounding factors not previousiy studied. Risks associated with length of time in 15 job categories were considered as proxies for the effects of other occupational carcinogens. The findings suggest that selection factors and potential for chemical exposure do not account for the previously noted association of extemal radiation dose with cancer mortality.

There are three analytic files in the ORX10A02 data set. The firs file (X1UPGEN2) contains demographic and some work history data for the entire cohort. The original study (ORX10A01) contained 8,375 males, but further investigation revealed that 57 individuals in the original cohort were not white males. The second file (XIUPFLAT) contains annual and cumulative externa whole-body doses for each individual. The third file (X1UPJTGB) contains a record for each individual, including the unique job title of the individual and the number of days, by year, that the person retained the job title.

Vital status was ascertained for $91.8 \%$ of the cohort $(96.5 \%$ of potential person-years of follow-up), and 1,524 deaths were identified by the end of 1984 , the study end date. Death certificates were obtained for $1,490(97.8 \%)$ of these deaths. External radiation monitoring data were used to compile annual and cumulative whole-body doses. For the $4.9 \%$ of the work-years for which external monitoring data were not availabit, doses were estimated. By using internal monitoring data qualitatively as a "yes/no" indicator of potential exposure to internal radiation, workers who had at sume time been monitored for internal exposure $(\mathrm{N}=3.763)$ generally had higher external doses; $50 \%$ of those ever monitored but only $8 \%$ of those never monitored, for internal exposure had cumulative external doses greater than I rem (10 mSv).

ORNL began monitoring personnel for exposure to external penetrating radiation, primarily gamma rays, in 1943. Pocket chambers were used until June 1944, when film dosimeters (film badges) became the primary dosimeter. Film dosineters were used for personnel monitoring until 1975, when they were replaced with thermoluminescent dosimeters (TLDs). From 1943 until the early 1950s, the usual practice was to provide personal dosimeters to only those workers entering designated areas where there was a potential for exposure. Subsequently, all workers at ORNL were monitored

Based primarily on the potential for contamination from their work area, some workers were monitored for intemal exposure to radionuclides beginning in 1951. Additional workers were 


\section{OR/X-10}

\section{ORX10A02 Data Set}

monitored to evaluate exposures incurred during incidents. Internal exposures were determined by examining results of urine and fecal bioassays and whole-body counting. Quantitative dose estimates due to internally deposited radionuclides are not available because they usually were not required to be calculated in the past. Also, all of the basic data needed to compute doses for the many radionuclides used at ORNL are not computerized. However, knowledgeable plant health physicists and dosimetrists state that the majority of internal monitoring results for this cohort suggest small internal doses, especially when compared to extemal doses. 


\section{OR/X-10}

ORX10A02 Data Set

\section{Citations}

Wing, S., C. M. Shy, J. Wood, S. Wolf, D. Cragle, and E. L. Frome. 1991. "Mortality among workers at Oak Ridge National Laboratory." The Joumal of the American Medical Associa tion 265(11):1397-1402

Wing, S., C. M. Shy, J. Wood, S. Wolf, D. Cragle W. Tankersley, and E. L. Frome. 1993. "Job factors, radiation and cancer mortality at Oak Ridge National Laboratory: Follow-up through 1984." American Journal of Industrial Medicine 23:265-279

\section{No. of Files: 3}

\begin{tabular}{|c|c|c|}
\hline File Name & $\begin{array}{l}\text { No. of } \\
\text { Variables }\end{array}$ & Type of Data \\
\hline X1UPGEN2 & 24 & $\begin{array}{l}\text { demographic; } \\
\text { work history }\end{array}$ \\
\hline XIUPFLAT & 90 & $\begin{array}{l}\text { annual and } \\
\text { cumulative } \\
\text { extemal, whole } \\
\text { body dose }\end{array}$ \\
\hline X1UPITGB & 46 & work history \\
\hline
\end{tabular}

Summary Death Tables

\begin{tabular}{|c|c|c|}
\hline \multirow{2}{*}{ Cause of Death } & \multicolumn{2}{|c|}{ No. of Deaths } \\
\hline & Male & Female \\
\hline Infectious \& Parasitic Diseases & 6 & \\
\hline All Malignant Neoplasms & 345 & \\
\hline - Lip, Oral Cavity \& Pharynx & 6 & \\
\hline - Digestive Organs \& Peritoneum & 94 & \\
\hline - Respiratory System & 101 & \\
\hline - Bone \& Connective Tissue & 5 & \\
\hline - Skin & 8 & \\
\hline - Breast & 0 & \\
\hline - Genitourinary System & 41 & \\
\hline - Brain/CNS & 15 & \\
\hline - Other \& Unspecified Sites, Except Brain/CNS & 26 & \\
\hline - Lymphatic/Hematopoietic & 49 & \\
\hline All Benign Neoplasms & 1 & \\
\hline All Neoplasms, Unspecified & 1 & \\
\hline Endocrine, Nutritional, Metabolic Diseases \& Immunity Disorders & 15 & \\
\hline Diseases of Blcod \& Blood-Forming Organs & 2 & \\
\hline Mental Disorders & 5 & \\
\hline Diseases of Nervous System \& Sense Organs & 9 & \\
\hline Diseases of Circulatory System & 738 & \\
\hline Diseases of Respiratory System & 73 & \\
\hline Diseases of Digestive System & 45 & \\
\hline Diseases of Genitourinary System & 16 & \\
\hline Complications of Pregnancy \& Childbirth & o & \\
\hline Diseases of Skin \& Subcutaneous Tissue & 2 & \\
\hline Diseases of Musculoskeletal System \& Connective Tissue & 2 & \\
\hline Congenital Anomalies & 2 & \\
\hline Symptoms \& III-Defined Conditions & 55 & \\
\hline Accidents, Poisoning \& Violence (External Causes) & 172 & \\
\hline
\end{tabular}

\begin{tabular}{|l|r|r|}
\hline Deaths, With ICD Code & 1489 & \\
Deaths, No ICD Code & 34 & 1523 \\
Total Deaths, All Causes & \\
\hline
\end{tabular}

$t$ No females were included in this study. 


\section{Analytic rte Name}

\section{XXUPGE?}

1 highest internal exposure index 2 status of internal monitoring

3 earliest year for internal monitoring

4 sex codt

5 race code

6 number of facilities worked at

7 first hire date at ORNL

8 birth date

9 flag indicating deleted from study

10 vital status of individual

11 underlying cause of death

12 other cancers

13 date of last observation

14 date of death

15 cutoff date of study (12/31/84)

16 flag indicating current employee

17 last termination date from ORNL

18 number of times hired at ORNL

19 number of days cmployed at ORNL.

20 old ID number

21 length of follow-up

22 date of first intemal monitoring

23 pay code

24 CER-assigned ID number
Anabytic File Name

\section{XIUPFLAT}

1-42 annual wholebody dose by year, $1943-1984$

43-84 cumulative body dose by year, 1943 - 1984

85 CER-assigned ID number 86 missing quarter was estimated

87 missing years est. by nearby yrs

88 missing years est. from dept median

89 missing years est. from plant median

90 no. of years of data for person

\section{Anahtic Flle Name}

\section{XIUPJTGE}

1 variable created by SAS proce dure

2 variable created by SAS proce dure

3 CER-issigned ID number

4 job title grouping code

5-46 duration in job through year. $1943-1984$ 


\section{OR/X-10}

ORX10A03 Data Set

\section{Description}

This analytic data set consists of one file generated for a doctoral dissertation completed in 1983 that examined the cancer mortality of workers at Oak Ridge National Laboratory (ORNL).

The dissertation investigated the relationship between cancer mortality and occupational exposure to radiation among the male employees at ORNL. The study was based on a case control study nested in a cohort study, using two controls per case. Results indicated that certain subgroups encountered excess cancer mortality risk in relation to radiation exposure.

The single analytic file (NAIMA) in this data set contains data relating to demographics, work history, exposure index

rankings, internal hazard codes based on urine bioassay data, vital status, and causes of death. There are 1,785 records in this file, including orie record for each of the 423 cases and one record for each of the 846 matched controls (the case-control group) plus one record for each of the remaining 516 workers in the overall cohort. A case was defined to be any male employee who died between January 19433 and

December 1977, whose death certificate indicated cancer as the cause of death. Controls were selected from the

"population at risk" at ORNL, excluding those who died of cancer. The controls could be either dead or alive

Vital status was ascertained for $91.7 \%$ of the male controls and for $66.5^{\%} \%$ of the female controls through December 31 1977, the study end date

Personal monitoring data were used to place workers into exposure classes; doses were not calculated. Groups based on job title were also formed for the analysis. Smoking histories were obtained for a sample $(25 \%)$ of the cohort. Exposures to lead, beryllium, and mercury were also considered in the analysis. 


\section{OR/X-10}

ORX10A03 Data Set

\section{Citations}

Elghany, Naima Abd. 1983. "An epidemiological study of cancer mortality among workers exposed to occupational low levels of ionizing radiation." Ph.D. dissertation, University of North Carolina, Chapel Hill.

\begin{tabular}{|lll|}
\hline No. of Files: 1 & & \\
FAle Name & $\begin{array}{l}\text { No. of } \\
\text { Variables }\end{array}$ & Type of Data \\
& 111 & $\begin{array}{l}\text { demographic; } \\
\text { work history; } \\
\text { exposure index } \\
\text { ranking; internal } \\
\text { hazard code; vital } \\
\text { status; cause of } \\
\text { death }\end{array}$ \\
\hline
\end{tabular}

\section{Summary Death Tables}

\begin{tabular}{|c|c|c|}
\hline \multirow{2}{*}{ Cause of Death } & \multicolumn{2}{|c|}{ No. of Deaths } \\
\hline & Male & Femalet \\
\hline Infectious \& Parasitic Diseases & 1 & \\
\hline All Malignant Neoplasms & 499 & \\
\hline - Lip, Oral Cavity \& Pharynx & 8 & \\
\hline - Digestive Organs \& Peritoneum & 115 & \\
\hline - Respiratory System & 162 & \\
\hline - Bone \& Connective Tissue & 6 & \\
\hline - Skin & 13 & \\
\hline - Breast & 1 & \\
\hline - Genitourinary System & 76 & \\
\hline - Brain/CNS & 18 & \\
\hline - Other \& Unspecified Sites, Except Brain/CNS & 32 & \\
\hline - Lymphatic/Hematopoietic & 68 & \\
\hline All Benign Neoplasms & o & \\
\hline All Neoplasms, Unspecified & $\mathbf{0}$ & \\
\hline Endocrine, Nutritional, Metabolic Diseases \& Immunity Disorders & 4 & \\
\hline Diseases of Blood \& 8lood-forming Organs & 1 & \\
\hline Mental Disorders & 0 & \\
\hline Diseases of Nervous System \& Sense Organs & 2 & \\
\hline Diseases of Grculatory System & 210 & \\
\hline Diseases of Respiratory System & 24 & \\
\hline Diseases of Digestive System & 5 & \\
\hline Diseases of Genitourinary System & 9 & \\
\hline Complications of Pregnancy \& Childbirth & $\mathbf{0}$ & \\
\hline Diseases of Skin \& Subcutaneous Tissue & 1 & \\
\hline Diseases of Musculoskeleta! System \& Connective Tissue & 0 & \\
\hline Congenital Anomalies & 2 & \\
\hline Symptoms \& III-Defined Conditions & 15 & \\
\hline Accidents, Poisoning \& Violence (External Causes) & 8 & \\
\hline
\end{tabular}

\begin{tabular}{|l|r|r|}
\hline Deaths, With ICD Code & 781 & \\
Deaths, No ICD Code & 0 & 781 \\
Total Deaths, All Causes & \\
\hline
\end{tabular}

$t$ No females were included in this study. 


\section{Anablic File Hane}

\section{MATHa}

1 CER-assigned ID number

2 flag indicating completeness of job title grouping

3 autopsy performed (Y/N)

4 smoking code

5 current vital status

6 cumulative film badge reading

7 total film badge record count

8 film badge readings with no errors

9 total film badge record count no error

10 film badge readings with minor errors

11 total film badge record count. minor

12 film badge readings with serious errors

13 cum. "serious" badge record count yr. exp.

14 unusable film badge readings

15 total film badge record count unusable

16 film badge, minor errors. pending

17 total film badge record count minor pending

18 film badge, serious errors pending

19 total film badge record count serinus pending

20 film badge, unusable, pending

21 total film badge record count unusable pending
22 film badge with unknown code

23 total film badge record coun unknown

24 used to get random order sort

25 number of facilities

26 date of birth

27 entry date into the study

28 exit date from the study

29 ICD code for underlying cause of death

30 cancer code

31 year of death

32 month of death

33 day of death

34 ICD code for underlying cause of death

35 cancer code

36 this variable not used in analysis

37 first use in population

38 last 2 digits of CER-assigned ID number

39 stan year at ORNL

40 stop year at ORNL

41 year of birth

42 date began work at ORNL.

43 date ended work al ORNL

44 date of birth

45 date of death

46 mortality status

47 year of death

48 person is a case $(\mathrm{Y} / \mathrm{N})$

49 cancer death $(\mathrm{Y} / \mathrm{N})$

50 stop date of follow-up

51 start date of follow-up

52 year of first hire

53 match criteria

54 match criteria 3
55 sex code

56 race code

57 type of cancer (if applicable)

58 eligibie for inclusion (Y/N)

59 one of 3 cancers (Y/N)

60 case/control category by race

61 match group code

62 type of control

63 description if case or control

64 date of death

65 age at first hire at ORN!

66 duration of employment at ORNL in years

67 cumulative external exposure thr 1978

68 cumulative external exposure thru 1977

69 intemal hazard code

70 internal hazard code from bioassay

71 internal hazard code

72 person exposed to mercury (Y/N)

73 exposed to beryllium ( $Y / N$ )

74 person exposed to lead ( $Y / N)$

75 age at last termination

76 the date 12/31/7t in SAS format

77 the date 12/31/79 in SAS format

78 age at death or age on 12/31/77

79 age at death or age on 12/31/79

$\mathbf{8 0}$ year of last termination

81 latency based on 197? date

82 latency based on 1979 date

83 job title grouping code

84 duration of job with job title grouping

85 cumulative duration of all jobs at ORNL

86 exposure index (ei)

87 total duration of employment at ORNL.
88 total exprosure score

89 total job days at ei level

90 total job days at ei level:

91 total job davs at ei lovel 3

92 number of employment periods at ORNL

93 number of different jobs at ORNI.

94 date of first hire

95 date of last termination

96 employment status

97 tetal exposure score in ei level 1

98 total exposure score in el level 2

99 total exposure score in ei level 3

100 cumulative dose score in e level 1

101 cumulative dose score in ei level 1.2

102 cumulative dose score in ei level 1,2,3

103 observation number

104 duration of employment at ORNL in months

105 duration of job title group in months

106 duration at ei level 1

107 duration at ei level 2

108 duration at ei level 3

109 first pay code

110 last pay conde

111 sequence number of row

ORX10A03 


\title{
OR/N-12
}

\author{
ORYI2A01 Data Set
}

\section{Description}

This data set consists of three analytic files for the cohor mortality study, published in the American Joumal of Epidemiolegy in 1988, of white males employed at the Y-12 Facility.

This study examines the mortality of a cohort of 6.781 white males who worked at the Y-12 Facility for at least 30 days between May 4, 1947 and December 31. 1974. This cohort included workers who were known to have worked only at Y-12 Individuals who worked at $Y-12$ when Tennessee Eastman Corporation (TFC) operated the facility (which was before May 4,1947 ) or who worked at any other DOE-owned or operater facility were excluded. Workers in this cohort were exposed to low levels of alpha and gamma radiation while working with uranium compounds at an enriched nuclear materials fabrication plant. Relative to US. white males, the cohort experienced mortality deficits from all causes of death combined, from cardiovascular diseases, and from most sitespecific cancers. When compared with national and state rates. excess mortality due to cancer of the lungs, brain, and central nervous system were seen. Dose-response trends, which diminished in magnitude when a 10-year latency assumption was applied, were detected for lung cancer mortality with respect to cumulative alpha and gamma radiation. The most pronounced trend associated with gamma doses was among workers who received doses equal to or greater than 5 rems of alpha radiation. There were 22 workers who received greater than or equal to 10 rems of extenal radiation, including 8 workers involved in a criticality accident at the facility in 1958

There are three analytic files in this data set. The first file (LDBEST01) contains annual and cumulative lung doses for each person for the years 1947 through 1979 Fstimates of doses delivered to the lungs were based on results of urinanalysis measurements and in vive counting of internally deposited uranium. The second file (YIANGEIA) contains demographic, work history, and vital status data for the cohort The third file (YIANFBO)3) contains annual and cumulative penetrating doses that were compiled from external personnel monitoring information. Periods in which a worker was not in the monitoring pregram were assigned doses of zero, under the assumption that only workers with a reasonable likelituod of expesure hat been monitored.

Vital status was ascertained for 6.475 workers $(955 \%$ of the cohort) through December 31, 1979, the stuly end date.

There were 862 deaths identified $(12.7 \%$, and death certificates were ohtained for $846(98.1 \ldots)$ of these deaths Eighty-five percent of the cohort was followed for at least 10 years. The median duration of follow-up was 20.6 years, and the cohort contributed 133,535 person years of ohsenation

Workers at $Y-12$ were exposed to radiation resulting from external sources (primarily gamma radiation from the uranium decay series) and trom internal depusition of uranium (primarily alpha particles). Personal monitoring for extemal exposure began in 1948 with the use of film dosimeters. They were used for persomet monitoring until the late 1970s, when they were replaced with thermoluminescent dosimeters (TLIs) Monitoring for internal exposure to uranium began in 195. hut was not in full effect until 1953. By 1961, the internal monitoring program included in vivo measurements. such as lung counting Metabolic models were used to convert urinatvis and in vivo measurements fo ling doses for each worker 


\section{OR/Y-12}

ORY12A01 Data Set

\section{Citations}

Checkoway, H., N. Pearce, D. J Crawford-Brown, and D. L. Cragle. 1988. "Radiation doses and causespecific riortality among workers at a nuclear materials fabrication plant." American Joumal of Epidemiology 127(2):255-266.

\begin{tabular}{|lll} 
No. of Files: 3 & $\begin{array}{l}\text { No. of } \\
\text { Fariables }\end{array}$ & Type of Data \\
LDBEST01 & 77 & $\begin{array}{l}\text { annual and } \\
\text { cumulative lung } \\
\text { dose }\end{array}$ \\
Y1ANGE14 & 27 & $\begin{array}{l}\text { wemographic } \\
\text { work history: } \\
\text { vital status } \\
\text { annual and } \\
\text { cumulative } \\
\text { penetrating dose }\end{array}$
\end{tabular}

Sannmary Death Tables

\begin{tabular}{|c|c|c|}
\hline \multirow{2}{*}{ Cause ot Death } & \multicolumn{2}{|c|}{ No. of Deaths } \\
\hline & Male & Female ${ }^{\dagger}$ \\
\hline Infectious \& Parasitic Diseases & 3 & \\
\hline All Malignant Neoplasms & 197 & \\
\hline - Lip, Oral Cavity \& Pharynx & 1 & \\
\hline - Digestive Organs \& Peritoneum & 38 & \\
\hline - Respiratory System & 94 & \\
\hline - Bone \& Connective Tissue & $\mathbf{0}$ & \\
\hline - Skin & 3 & \\
\hline - Breast & $\mathbf{0}$ & \\
\hline - Genitourinary System & 16 & \\
\hline - Brain/Cas & 14 & \\
\hline - Other \& Unspecified Sites. Except Brainfcaus & 12 & \\
\hline - Lymphatic/Hematopoietic & 19 & \\
\hline All Benign Neoplasms & $\mathbf{0}$ & \\
\hline All Neoplasms, Unspecified & 3 & \\
\hline Endocrine, Mutritional, Metabolic Diseases \& Immunity Disonders & 7 & \\
\hline Diseases of Blood \& Blood-forming Organs & 3 & \\
\hline Mental Disorders & 5 & \\
\hline Diseases of Nervous System \& Sense Organs & 7 & \\
\hline Diseases of Circulatory System & 382 & \\
\hline Diseases of Respiratory System & 37 & \\
\hline Diseases of Digestive System & 29 & \\
\hline Diseases of Genitourinary System & 8 & \\
\hline Complications of Pregnancy \& Childbirth & $\mathbf{0}$ & \\
\hline Diseases of Skin \& Subcutaneous Tissue & $\mathbf{0}$ & \\
\hline Diseases of Musculoskeletal System \& Connective Tissue & $\mathbf{0}$ & \\
\hline Congenital Anomalies & $\mathbf{0}$ & \\
\hline Symptoms \& Ut-Defined Conditions & 35 & \\
\hline Accidents, Poisoning \& Violence (External Causes) & 129 & \\
\hline
\end{tabular}

\begin{tabular}{|l|r|r|}
\hline Deaths, With ICD Code & 845 & \\
Deaths, No ICD Code & 16 & \\
Total Deaths, All Causes & 861 & \\
\hline
\end{tabular}

$t$ No females were inctuded in this study. 


\section{Amalytic folle Mame \\ IDBESTO1}

1 CFR-assigned ID number

2 2-digit ID number

3 year of birth

4 year of first hire

5 year of last termination

6 year follow-up started

7 year follow-up ended

8 status of individual in study

9 annual lung dose for 1947

10 cumulative lung dose thru 1947

11 annual lung dose for 1948

12 cumulative lung dose thru 1948

13 annual lung dose for 1949

14 cumulative lung dose thns 1949

15 annual iung dose for 1950

16 cumulative lung dose thru 1950

17 annual lung dose for 1951

18 cumulative lung dose thru 1951

19 annual lung dose for 1952

20 cumulative lung dose thru 19.92

21 annual lung dose for 195.3

22 cumulative lung dose thru 195:

23 annual lung dose for 1954

24 cumulative lung duse thru 1954

25 annual lung dose for 1955

26 cumulative lung dose thru 1955

27 annual lung dose for 1956

28 cumulative lung dose thru 1956

29 arnual lung dose for 1957

30 cumulative lung duse thn 1957

31 annual lung dose for 1958

32 cumulative lung dose thru 1958
33 annual lung dose for 1959

34 cumulative lung dose thru 1959

35 annual lung dose for 19F,

36 cumulative lung dose thru [9;

37 annual lung dose for 1961

38 cumulative lung dose thru $19 \%$

39 anmual lung dose for 1962

40 cumulative lung dose thru 1962

41 annual lung dose for 19xi3

42 cumulative lung dose thru 1963

43 annual lung dese for 19\%

44 comulative lung dose thru I:

45 annibal lung dose for 1965

46 cumulative lung dose thru i:65

47 annual lung dose for 1966

48 cumulative fung dose thru 1966

49 annual lung dose for 1967

50 cumulative lung dose thru 1967

51 annual lung dose for 1968

52 cumulative lung dose thru 1968

53 annual lung dese for 1969

54 curnulative lung dose thru 1969

55 annual lung duse for 1970

56 cumulative lung dose thru 1970

57 annual lung dorse for 1971

58 cumulative ling dose thru 197

59 annual lung dose for 1972

60 cumulative lung dose thru 1972

61 annual lung dose for 1973

62 cumulative lung dose thru 1973

63 annual lung dose for 1974

64 cumulative lung duse thru 1974

65 annual lung dose for 1975

66 cumulative lung dose thru 1975

67 annual lung dose for 1976

68 cumulative lung dose thru 1976

69 annual lung dose for 1977
70 cumulative lung dene thru 1977

71 annual lung dose for $1: 78$

72 cumulative lung derse thri 1978

73 annual lung dose for 197 ?

74 cumulative lung dese thru $197^{\circ}$ )

75 total number of years ef internal exposure

76 total cumulative lung dese

77 ICL8 death code

\section{amatic Fe mane \\ YMATE14}

1 (ER-assigned II) number

2 intal penetrating docke

3 2efigit II number

4 year in birth

5 date last observiation

6 year of first hire

7 vital salus of imtiveturs

8 year of last termmation

9 date of firct hur" at $\mathrm{Y}-\mathrm{l} 2$

10 year forihw up stirtect

11 sexconde

12 year follow-up ented

13 race conise

14 satus of indivitual in study

15 birth date of individual

16 last termination date at Y-12

17 number of days emplovert at Y-12

18 current emplowment indicator

19 recoded vital status

20 length of company service

21 length of follow-tip

22 age at first hire at $Y \cdot 12$

23 first pay code at Y-12

24 les pay coxie known for an individual

25 cause of death

26 cancer conde (ICD) if

applicable

27 cause of death - numeric 
Analytic File Wame

YIANFBO3

1 CER-assigned ID number

2 2-digit ID number

3 year of birth

4 date of first hire at $Y-12$

5 year of termination at Y.12

6 year follow-up started for this

7 ending year of follow-up for this person

8 vital status

9-41 annual penetrating dose by year, 1947-1979

42-74 cumvlative penetratung dose by year, 1947 - 1979

75 total number of years with penetrating data

76 3-digit ICD code

77 total cumulative penetrating dose 


\section{OR/Y-12}

ORY12A02 Data Set

\section{Description}

This analytic data set consists of one file generated for a study, published in the Joumal of Occupational Medicine in 1984, of white males exposed to elemental mercury at the Oak Ridge $Y-12$ Facility

This study examined the mortality experience of a group of white male workers who were exposed to elemental mercury and

mercury vapors. The morality experience of the mercury workers was examined with respect to mercury-sensitive systems, including

lung, liver, and kidney organs, and the central nervous system (CNS). Statistically significant excesses of deaths from cancer of the lung, brain, and CNS were observed in the group not involved in the mercury process. Exposure to mercury vapors at $\mathrm{Y}-12$ was not found to be related to any excess of deaths from diseases or cancers of target organs for mercury, but an excess of lung cancer was observed in the mercury worker group. No excesses were

found when level of exposure and length of exposure were considered.

The single analytic file (MERANAI 2) in this data set contains demographic, vital status, and empioyment data and results of urinalysis monitoring (for mercury). There is one record for each of 5,664 workers; one individual was not included in the final analyses.

The overall population was defined as all white males why worked at least 4 months at $Y-12$ between Jamuary 1,1953 and April 30.1958 . These criteria allowed 5,663 individuals to enter the study. The study group was separated into two smaller ones. The first group consisted of 3.530 workers for whom an urinalysis results were recorded and who were presumed as never having been monitored for mercury exposure. The remaining 2,133 were placed into the mercury worker gronp because their records contained results of mercurv urinalyses.

Vital status was ascertained for all $5,6 f i 3$ workers through December 31, 1978. the study end date. There were 1.141 deaths identified and death certificates were obtained for 1.125 $\left(98.7^{\prime \prime \prime}\right)$ of these deaths

Records indicating participation in a mercury urinalysis program were used to classify the individual as a meroury worker. Personal radiation monitoring data were not used in the study 


\section{OR/N-12}

ORY12A '2 Data Set

\section{Citations}

Cragle, D. L., D. R. Hollis, J. Qualters, W. G. Tankersley, and S. A. Fry. 1984. "A mortality study of men exposed to elemental mercury." Joumal of Occupational Medicine 26(11):817821.

\section{No. of Files: 1

\begin{tabular}{|c|c|c|}
\hline File Name & $\begin{array}{l}\text { No. of } \\
\text { Variables }\end{array}$ & Type of Data \\
\hline MERANAL2 & 19 & $\begin{array}{l}\text { demographic; } \\
\text { vital status; } \\
\text { work history, } \\
\text { results of } \\
\text { urinalysis } \\
\text { monitoring }\end{array}$ \\
\hline
\end{tabular}

\section{Summary Death Tables}

\begin{tabular}{|c|c|c|}
\hline \multirow{2}{*}{ Cause of Death } & \multicolumn{2}{|c|}{ No. of Deaths } \\
\hline & Male & Female \\
\hline Infectious \& Parasitic Diseases & 3 & \\
\hline All Malignant Neoplasms & 274 & \\
\hline - Lip Oral Cavity \& Pharynx & 4 & \\
\hline - Digestive Organs \& Peritoneum & 54 & \\
\hline - Respiratory System & 123 & \\
\hline - Bone \& Connective Tissue & 3 & \\
\hline - Skin & 4 & \\
\hline - Breast & 0 & \\
\hline - Genitourinary System & 26 & \\
\hline - Brain/CNS & 18 & \\
\hline - Other \& Unspecified Sites, Except Brain/CNS & 18 & \\
\hline - Lymphatic/Hematopoietic & 24 & \\
\hline All Benign Neoplasms & 0 & \\
\hline All Neoplasms, Unspecified & 3 & \\
\hline Endocrine, Nutritional, Metabolic Diseases \& Immunity Disorders & 10 & \\
\hline Diseases of Blood \& Blood-Forming Organs & 3 & \\
\hline Mental Disorders & 3 & \\
\hline Diseases of Nervous System \& Sense Organs & 7 & \\
\hline Diseases of Circulatory System & 536. & \\
\hline Diseases of Respiratory System & 59 & \\
\hline Diseases of Digestive System & 39 & \\
\hline Diseases of Genitourinary System & 10 & \\
\hline Complications of Pregnancy \& Childbirth & 0 & \\
\hline Diseases of Skin \& Subcutaneous Tissue & 1 & \\
\hline Diseases of Musculoskeletal System \& Connective Tissue & 1 & \\
\hline Congenital Anomalies & 2 & \\
\hline Symptoms \& III-Defined Conditions & 45 & \\
\hline Accidents, Poisoning \& Violence (External Causes) & 128 & \\
\hline
\end{tabular}

Accidents, Poisoning \& Violence (External Causes)

\begin{tabular}{|l|r|r|}
\hline Deaths, With ICD Code & 1124 \\
Deaths, No ICD Code & 15 & 1139 \\
Total Deaths, All Causes & \\
\hline
\end{tabular}

t No females were included in this study. 


\section{MERATIAL?}

1 CER-assigned ID number

2 length of employment at Y-12

3 length of employment between 1953-1957

4 underlying cause of death (3 digits)

5 vital status

6 underlying cause of death

7 cancer cause of death

8 last date known alive

9 birth date

10 first hire date at $Y-12$ facility

11 Oak Ridge first hire

12 last termination date from Y-12

13 Oak Ridge last term

14 date of first mercury monitoring

15 first mercury monitoring date > p.a.l.

16 added mercury worker

17 early mercury worker

18 mercury workers

19 sequence number of row 


\section{OR/Y-12}

ORY12A03 Data Set

\section{Description}

This analytic data set consists of one file generated for a cohort mortality study, published in Joumal of Occupational Medicine in March 1981, of white males at the Oak Ridge Y-12 Facility.

The study examined the mortclity experience of white male workers employed at a uranium enrichment facility (the Y-12 Facility) between June 1943 and May 1947. During this time, the plant was operated for the government by the Tennessee Eastman Corporation (TEC). In May 1947, Union Carbide Corporation Nuclear Division became the operating contractor. With this transition, significant changes were made to plant processes, and most of the Y-12 work force was replaced. These occurrences led epidemiologists to study the Y-12 workers employed by TEC (the TEC cohort) separately from those working at the Y-12 Facility after May 1947 (the Y-12 cohort). The TEC cohort was selected for this mortality study because (1) a long period of follow-up was available, (2) data were available showing that average levels of airborne uranium dust were high in certain departments, (3) the size of the sample was large, and (4) data were limited on the possible long-term health effects of uranium exposure in human populations.

Standardized mortali: atios (SMRs) for various causes of death in the entire cohort wer: enerally less than 1.00; however, after correction for missins Jeath certificates and unascertained deaths, the SMR for lung cancer was 1.22. Other causes of particular interest, including bone cancer, leukemia, and diseases of respiratory and genitourinary systems, did not exhibit high SMRs. The authors suggested that an increased number of lung cancer deaths occurred in chemical workers who were 45 or more years old when first hired.

The single analytic file (FROMFPOL) in this data set contains 38,521 records, i.e., one record for each person who had a payroll record at the plant when TEC was the operating contractor. Application of the cohort selection criteria reduced the cohort under study to 18,869 white males. The records excluded from the analysis pertained to females (about 18,100), non-white males, individuals who worked less than 2 days at $Y-12$, and those lacking essential vital status and demographic data. Records for the study cohort can be determined by examining the published manuscript for all the criteria and checking certain variables in the file. The file contains demographic. work history, vital status, and some urinalysis data.

Vital status was ascertained for $97.6 \%$ of the cohort through December 31,1973 , the study end date. There were 5,394 deaths identified in this cohort, and death certificates were obtained for $5,133(95.2 \%)$ of these deaths. The study had 494,742 person-years of follow-up.

The TEC cohort did not wear personal dosimeters (film badges); however, exposure to penetrating extemal (gamma) radiation was low due to the nature of plant operations. The primary radiological hazard for the TEC cohort was inhalation of uranium compounds. Some urinalysis for uranium was performed for individuals working in areas of airbome material, and these data were used in the analysis. 


\section{OR/Y-12}

ORY12A03 Data Set

\section{Citations}

Polednak, A. P., and E. L. Frome. 1981.

"Mortality among men employed

between 1943 and 1947 at a uraniumprocessing plant." Joumal of Occupa-

tional Medicine 23(3):169-178.

\begin{tabular}{|c|c|c|}
\hline \multicolumn{3}{|c|}{ No. of Files: 1} \\
\hline File Name & $\begin{array}{l}\text { No. of } \\
\text { Variables }\end{array}$ & Type of Data \\
\hline FROMEPOL & 27 & $\begin{array}{l}\text { demographic; } \\
\text { work history; } \\
\text { vital status; } \\
\text { results of some } \\
\text { urinalysis } \\
\text { monitoring }\end{array}$ \\
\hline
\end{tabular}

\section{Summary Death Tables}

\begin{tabular}{|l|r|r|}
\hline \multicolumn{1}{|c|}{ Cause of Death } & No. of Deaths \\
\cline { 2 - 3 } & Male & Female \\
\hline Infectious \& Parasitic Diseases & 115 & 14 \\
All Malignant Neoplasms & 933 & 291 \\
- Lip, Oral Cavity \& Pharynx & 30 & 6 \\
- Digestive Organs \& Peritoneum & 227 & 47 \\
- Respiratory System & 354 & 26 \\
- Bone \& Connective Tissue & 11 & 4 \\
- Skin & 18 & 10 \\
Breast & 1 & 63 \\
- Genitourinary System & 101 & 67 \\
Brain/CNS & 32 & 15 \\
Other \& Unspecified Sites, Except Brain/CNS & 72 & 20 \\
All Benign Neoplasms & 87 & 33 \\
All Neoplasms, Unspecified & 2 & 6 \\
Endocrine, Nutritional, Metabolic Diseases \& Immunity Disorders & 14 & 4 \\
Diseases of Blood \& Blood-Forming Organs & 61 & 24 \\
Mental Disorders & 11 & 4 \\
Diseases of Nervous System \& Sense Organs & 39 & 6 \\
Diseases of Circulatory System & 41 & 8 \\
Diseases of Respiratory System & 2682 & 355 \\
Diseases of Digestive System & 355 & 52 \\
Diseases of Genitourinary System & 236 & 51 \\
Complications of Pregnancy \& Childbirth & 73 & 20 \\
Diseases of Skin \& Subcutaneous Tissue & 0 & 7 \\
Diseases of Musculoskeletal System \& Connective Tissue & 3 & 4 \\
Congenital Anomalies & 11 & 9 \\
Symptoms \& Ill-Defined Conditions & 9 & 6 \\
Accidents, Poisoning \& Violence (External Causes) & 167 & 27 \\
\hline & 683 & 111 \\
\hline Deaths, With ICD Code & 5435 & 999 \\
Deaths, No ICD Code & 306 & 125 \\
Total Deaths, All Causes & 5741 & 1124 \\
\hline
\end{tabular}




\section{Anabtic File Tane \\ FROMEPOL}

1 CER-assigned ID number

2 year of birth

3 birth date

4 sex code

5 race code

6 year of first hire at plant

7 first date of hire at plant

8 multiple hire/term from plant

9 termination year

10 last termination date from plant

11 worked in alpha l $(\mathrm{Y} / \mathrm{N})$

12 worked in alpha $2(\mathrm{Y} / \mathrm{N})$

13 worked in beta $1(\mathrm{Y} / \mathrm{N})$

14 worked in beta $2(\mathrm{Y} / \mathrm{N})$

15 worked in electrical department $(\mathrm{Y} / \mathrm{N})$

16 worked in office $(Y / N)$

17 worked in other departments $(\mathrm{Y} / \mathrm{N})$

18 duration in weeks in alpha 1

19 duration in weeks in beta 1

20 vital status code

21 date of death

22 code for underlying cause of death

23 underlying cancer cause of death

24 urinalysis test number

25 date of urinalysis

26 urinalysis test results

27 sequence number of row 


\title{
OR/ $\mathbf{Y - 1 2}$
}

\author{
ORY12A04 Data Set
}

\section{Description}

This analytic data set consists of one file generated for a study, published in Environmental Research and in Toxicology and Industrial Health, of white males exposed to phosgene at the Oak Ridge Y-12 Facility from 1943 to 1945

Studies of humans and animals indicate that exposure to high levels of phosgene result in short-term health effects that include emphysema, pulmonary edema, pneumonitis, and other possible effects. This study examined the mortality experience of workers exposed to phosgene gas while working at the Oak Ridge Y-12 Facility from 1943 through 1945 . The study population consisted of 18,869 white males employed at Y-12 while Tennessee Eastman Corporation was the operating contractor (1943-1945). There were two groups of interest: the first group included 699 white males that received daily exposure to low levels of phosgene, and the second group consisted of 106 men with definite acute exposures and symptoms that indicated exposure to levels as high as $50 \mathrm{ppm}$ or higher. No evidence of excess overall mortality or mortality from diseases to the respiratory system was found. Pneumonitis - was diagnosed in $23.6 \%$ of the 106 workers in the second group.
The primary author analyzed updated information for this cohort approximately 5 years after the initial study. The major finding in the updated study was the occurrence of 5 deaths in the second group of 106 workers due to respiratory diseases (1.88 cieaths expected), although the standardized mortality ratio did not reach statistical significance. There were no deaths due to lung cancer in the second group despite 33 to 35 years of follow-up.

The single analytic file (ANALYSIS) consists of 106 records, one for each person in the second group. The file contains demographic and work history data.

Vital status was ascertained through December 31,1973 , for the initial study and through December 31,1978 , for the updated study. There were 29 deaths identified in the highly exposed group for the first study, and 41 deaths found for the group in the updated study.

No personal monitoring data were used in either study. 


\section{OR/Y-12}

ORY12A04 Data Set

\section{Citations}

Polednak, A. P. 1980. "Mortality among men occupationally exposed to phosgene in 19431945." Environmental Research 22:357-367.

Polednak, A. P., and D. R. Hollis. 1985. "Mortality and causes of death among workers exposed to phosgene in 1943-1945." Toxicology and Industrial Health 1(2):137-148

No. of Files: 1

$\begin{array}{|ccc|}\text { File Name } & \begin{array}{l}\text { No. of } \\ \text { ANALIables }\end{array} & \text { Type of Data } \\ & 11 & \begin{array}{l}\text { demographic: } \\ \text { work history }\end{array}\end{array}$

\section{Summary Death Tables}

\begin{tabular}{|c|c|c|}
\hline \multirow{2}{*}{ Cause of Death } & \multicolumn{2}{|c|}{ No. of Deaths } \\
\hline & Male & Femalet \\
\hline Infectious \& Parasitic Diseases & 0 & \\
\hline All Malignant Neoplasms & 3 & \\
\hline - Lip. Oral Cavity \& Pharynx & 0 & \\
\hline - Digestive Organs \& Peritoneum & 2 & \\
\hline - Respiratory System & 0 & \\
\hline - Bone \& Connective Tissue & 0 & \\
\hline - Skin & 0 & \\
\hline - Breast & 0 & \\
\hline - Genitourinary System & 1 & \\
\hline - Brain/CNS & $\mathbf{0}$ & \\
\hline - Other \& Unspecified Sites, Except Brain/CNS & $\mathbf{0}$ & \\
\hline - Lymphatic/Hematopoietic & 0 & \\
\hline All Benign Neoplasms & 0 & \\
\hline All Neoplasms, Unspecified & $\mathbf{0}$ & \\
\hline Endocrine, Nutritional, Metabolic Diseases \& Immunity Disorders & 1 & \\
\hline Diseases of Blood \& Blood-Forming Organs & $\mathbf{0}$ & \\
\hline Mental Disonders & 2 & \\
\hline Diseases of Nervous System \& Sense Organs & $\mathbf{0}$ & \\
\hline Diseases of Circulatory Systen & 18 & \\
\hline Diseases of Respiratory System & 5 & \\
\hline Diseases of Digestive System & 3 & \\
\hline Diseases of Genitourinary System & $\mathbf{0}$ & \\
\hline Complications of Pregnancy \& Childbirth & 0 & \\
\hline Diseases of Skin \& Subcutaneous Tissue & $\mathbf{0}$ & \\
\hline Diseases of Musculoskeletal System \& Connective Tissue & $\mathbf{0}$ & \\
\hline Congenital Anomalies & $\mathbf{0}$ & \\
\hline Symptoms \& III-Defined Conditions & 1 & \\
\hline Accidents, Poisoning \& Violence (External Causes) & 7 & \\
\hline
\end{tabular}

\begin{tabular}{|l|r|r|}
\hline Deaths, With ICD Code & 40 & \\
Deaths, Ne ICn Code & 0 & 40 \\
Total Deaths, All Causes & 40 & \\
\hline
\end{tabular}

$t$ No females were included in this study. 


\section{Anahy te rile hame}

\section{AMTLYSIS}

1 CER-assigned ID number 2 sex code

3 race code

4 vital status code

5 cause of death code

6 birth date

7 date first exposed to phosgene

8 date of first hire at TEC

9 last termination date from TEC

10 death date of the individual

11 sequence number of row 


\section{PANTEX}

PXSMRA01 Data J̄et

\section{Description}

This data set consists of one file generated for a cohort mortality study, published in Health Physics in 1985, of white male workers at the Pantex Plant in Texas.

This cohort mortality study of white male Pantex Plant workers was conducted to determine if there was an association between employment at the facility and mortality from various causes. A sub-analysis examined the association between mortality and exposure to extemal radiation. The published analysis focused on 3,564 white and presumed white males who were ever employed by the prime contractor operating the plant between the start of plant operations in 1951 and December 31, 1978, the study end date. The sub-analysis focused on the 209 workers who were exposed to 1 rem or more through 1978 . Total and cause-specific mortality was compared with expected mortality based on U.S. death rates. Significantly fewer deaths than expected from all causes of death. all cancers, digestive cancers, lung cancer, arteriosclerotic heart disease, and digestive diseases were observed. No causes of death occurred significantly more frequently than expected. Analyses of worker mortality by duration of employment, time since first employment, and cumulative radiation exposure greater than 1 rem produced similar results. No evidence was found that mortality from any cause of death was increased as a result of employment at the Pantex Plant

The single analytic file (ANFILE) contains demographic and exposure data for 5,438 male and female workers employed either by the prime contractor or by one of several

subcontractors from the beginning of plant operations through 1981. Exposure data in the file include exposure monitoring status and cumulative extemal radiation doses (in millirems) through 1980

Vital status was ascertained for $97 \%$ of the 3,564 white male Pantex workers included in the analysis. Death certificates were obtained for $96 \%$ (257) of the 269 known employee deaths.

The Pantex Plant is a large facility that has been engaged in the assembly and disassembly of nuclear weapons since 1951 .

Sources of occupational exposures include external radiation.

both gamma and neutron, from nuclear weapons components.

Workers may also be exposed to $x$-rays while using industrial

radiographic equipment. All exposure readings in the file are

film badge measurements and were available on " for workers employed after 1963. 


\section{PANTEX}

PXSMRA01 Data Set

\section{Citations}

Acquavella, J. F., L. D. Wiggs, R. J. Waxweiler, D. G. Macdonnell, G. L. Tietjen, and G. S. Wilkinson. 1985. "Mortality among workers at the Pantex Weapons Facility." Health Physics 48:735-746

$\begin{array}{lll}\text { No. of Files: } 1 & \\ \text { File Name } & \begin{array}{l}\text { No. of } \\ \text { Variables }\end{array} & \text { Type of Data } \\ \text { ANFILE } & 16 & \begin{array}{l}\text { demographic; } \\ \text { exposure }\end{array}\end{array}$

Summany Death Tables

\begin{tabular}{|c|c|c|}
\hline \multirow{2}{*}{ Cause of Death } & \multicolumn{2}{|c|}{ No. of Deaths } \\
\hline & Male & Female \\
\hline Infectious \& Parasitic Diseases & 2 & 0 \\
\hline All Malignant Neoplasms & 62 & 4 \\
\hline - Lip, Oral Cavity \& Pharynx & 1 & $\mathbf{0}$ \\
\hline - Digestive Organs \& Peritoneum & 15 & 1 \\
\hline - Respiratory System & 18 & $\mathbf{2}$ \\
\hline - Bone \& Connective Tissue & $\mathbf{0}$ & $\mathbf{0}$ \\
\hline - Skin & $\mathbf{0}$ & 0 \\
\hline - Breast & $\mathbf{0}$ & $\mathbf{0}$ \\
\hline - Genitourinary System & 6 & 1 \\
\hline - Brain/CNS & 4 & $\mathbf{0}$ \\
\hline - Other \& Unspecified Sites, Except Brain/CNS & 9 & $\mathbf{0}$ \\
\hline - Lymphatic/Hematopoietic & 9 & $\mathbf{0}$ \\
\hline All Benign Neoplasms & $\mathbf{0}$ & $\mathbf{0}$ \\
\hline All Neoplasms, Unspecified & 1 & $\mathbf{0}$ \\
\hline Endocrine, Nutritional, Metabolic Diseases \& Immunity Disorders & 6 & o \\
\hline Diseases of Blood \& Blood-forming Organs & 0 & $\mathbf{0}$ \\
\hline Mental Disorders & $\mathbf{0}$ & $\mathbf{0}$ \\
\hline Diseases of Nervous System \& Sense Organs & 3 & 1 \\
\hline Diseases of Circulatory System & 163 & 8 \\
\hline Diseases of Respiratory System & 14 & 1 \\
\hline Diseases of Digestive System & 11 & 1 \\
\hline Diseases of Genitourinary System & 3 & 0 \\
\hline Complications of Pregnancy \& Childbirth & 0 & o \\
\hline Diseases of Skin \& Subcutaneous Tissue & $\mathbf{0}$ & $\mathbf{0}$ \\
\hline Diseases of Musculoskeletal System \& Connective Tissue & 0 & $\mathbf{0}$ \\
\hline Congenital Anomalies & 1 & $\mathbf{0}$ \\
\hline Symptoms \& III-Defined Conditions & 4 & 2 \\
\hline Accidents, Poisoning \& Violence (External Causes) & 60 & $\mathbf{3}$ \\
\hline Deaths, With ICD Code & 330 & 20 \\
\hline Deaths, No ICD Code & 1 & 0 \\
\hline Total Deaths, All Causes & 331 & 20 \\
\hline
\end{tabular}




\section{Analiflc Flle Neme}

\section{AMFILE}

1 external radiation monitoring flag

2 cumulative extemal radiation (mrem)

3 birth state

4 education

5 race

6 sex

7 current vital status

8 SSA status

9 ICDA death code (8th rev.)

10 person-years, always 0.00

11 death date

12 birth date

13 termination date

14 hire date

15 CER-assigned ID number

16 death state 


\section{ROCKY FLATS}

\section{RFPLUA01 Data Set}

\section{Description}

This analytic data set consists of one file generated for a cohort mortality study, published in the American Joumal of Epidemiology, of white males employed at the Rocky Flats Plant (RFP).

A cohort mortality study of RFP workers was conducted to test for an association between mortality and exposure to plutonium. The analysis described in the publication focused on 5,413 white male workers employed for 2 or more years between 1951 and 1979 Fewer deaths than expected were found for all causes of death. a!l cancers, and lung cancer. No bone cancer was observed. An excess of brain tumors was found. Elevated rate ratios for all causes of death and all lymphopoietic neoplasms were found when workers with plutonium body burdens greater than or equal to 2 nanocuries ( $\mathrm{nCi}$ ) were compared to those with body burdens less than $2 \mathrm{nCi}$. No elevated rate ratios were noted for bone and liver cancers.

The single analytic file (ANFILE) in this data set contains dernographic and exposure data for 7,616 white males initially employed by RFP between 1951 (construction phase) and the end of 1979 Females, nonwhite males, and workers with missing sex or race were not included in the analytic file. Data pertaining to each worker's exposure to external ionizing radiation include: monitoring status and the date it was determined, date of first monitoring. and dates of achieving 1 rem, 5 rems. and 10 rems cumulative external whole-body doses through 1978 . Dates of exposure to plutonium-239 cover years 1952 (partial year) through 1977 and include monitoring status, date of first urine bioassay sample, dates of first achieving body burdens of $2 \mathrm{nCi}$ and $5 \mathrm{nCi}$ and the fraction of maximum permissible bocty burdens of plutonium acquired as of December 1977.

Vital status was ascertained for $(8.9 \%$ of the 5,413 white males employed for 2 or more years through December 31, 1979, the study end date. There were 409 deaths ic'entified in this group

RFP has been a weapons production facility since 1952. Sources of occupational exposure include external radiation, both gamma and neutron, and potential for intermal deposition of plutonium-239. Film dosimeters and thermoluminescent dosimeters were used to monitor for external radiation. Formal bioassay programs to monitor for internal exposures were begun in 1952. Results of both types of monitoring programs reflect technological improvements and changes in concepts and models during these years. 


\section{ROCKY FLATS}

RFPLUA01 Data Set

\section{Citations}

Wilkinson, G. S., G. L. Tietjen, I. D. Wiggs, W. A. Galke, J. F. Acquavella, M. Reyes, G. Voeltz, and R. J. Waxweiler, 1987. "Mortality among plutonium and other radiation workers at a plutonium weapons facility." American Joumal of Epidemiology 125:231-250.

No. of Files: 1

\begin{tabular}{|c|c|c|}
\hline File Name & $\begin{array}{l}\text { No. of } \\
\text { Variables }\end{array}$ & Type of Data \\
\hline ANFILE & 22 & $\begin{array}{l}\text { demographic; } \\
\text { work history; } \\
\text { vitai status: } \\
\text { summary whole- } \\
\text { body external } \\
\text { ionizing radiation } \\
\text { dose; plutonium } \\
\text { body burden } \\
\text { results }\end{array}$ \\
\hline
\end{tabular}

\section{Summary Death Tables}

\begin{tabular}{|c|c|c|}
\hline \multirow{2}{*}{ Cause of Death } & \multicolumn{2}{|c|}{ No. of Deaths } \\
\hline & Male & Femalet \\
\hline Infectious \& Parasitic Diseases & 4 & \\
\hline All Malignant Neoplasms & 180 & \\
\hline - Lip, Oral Cavity \& Pharynx & 3 & \\
\hline - Digestive Organs \& Peritoneum & 47 & \\
\hline - Respiratory System & 60 & \\
\hline - Bone \& Connective Tissue & 2 & \\
\hline - Skin & 4 & \\
\hline - Breast & $\mathbf{0}$ & \\
\hline - Genitourinary System & 24 & \\
\hline - Brain/CNS & 12 & \\
\hline - Other \& Unspecified Sites, Except Brain/CNS & 12 & \\
\hline - Lymphatid/Hematopoietic & 16 & \\
\hline All Benign Meoplasms & 3 & \\
\hline All Neoplasms, Unspecified & 6 & \\
\hline Endocrine, Nutritional, Metabolic Diseases \& Immunity Disorders & 10 & \\
\hline Diseases of Blood \& Blood-forming Organs & 1 & \\
\hline Mental Disorders & 6 & \\
\hline Diseases of Nervous System \& Sense Organs & 8 & \\
\hline Diseases of Circulatory System & 358 & \\
\hline Diseases of Respiratory System & 49 & \\
\hline Diseases of Digestive Systam & 25 & \\
\hline Diseases of Genitourinary System & 6 & \\
\hline Complications of Pregnancy \& Childbirth & - & \\
\hline Diseases of Skin \& Subcutaneous Tissue & $\mathbf{0}$ & \\
\hline Diseases of Musculoskeletal System \& Connective Tissue & 1 & \\
\hline Congenital Anomalies & 2 & \\
\hline Symptoms \& in-Defined Conditions & 13 & \\
\hline Accidents, Poisoning \& Violence (External Causes) & 96 & \\
\hline
\end{tabular}

\begin{tabular}{|l|r|r|}
\hline Deaths, With KCD Code & 768 & \\
Deaths, No ICD Code & 6 & 774 \\
Total Deaths, All Causes & \\
\hline
\end{tabular}

$t$ No females were included in this study. 


\section{AMfLE}

1 CF.R-assigned ID number

2 birth date

3 hire date

4 termination date

5 death date

6 iCD death code. 8 th rev

7 current vital status

8 sex

9 race

10 education level

11 date first achieved $2 \mathrm{nCi} \mathrm{Pu}$

12 fraction of maximum permis

sible body burden

13 Pu monitoring flag

: 14 first date at which external exposure reached 1 rem

15 first date at which external exposure reached 5 rems

16 first date at which external exposure reached 10 rems

17 cumulative external exposure as of $12 / 78$

18 external monitoring flag

19 date first achieved $5 \mathrm{nCi} \mathrm{Pu}$

20 lirst sample date for $\mathrm{Pu}$

21 estimated first external sample dat

22 state of death 


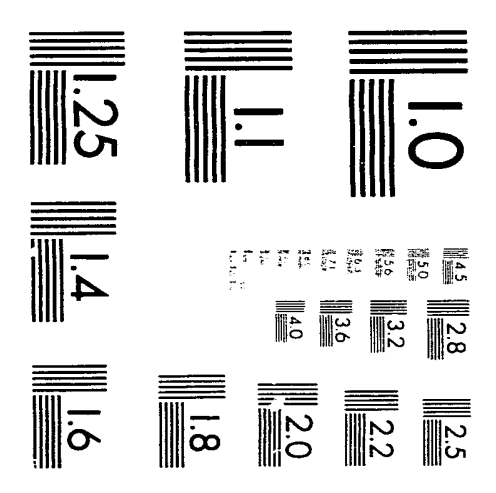



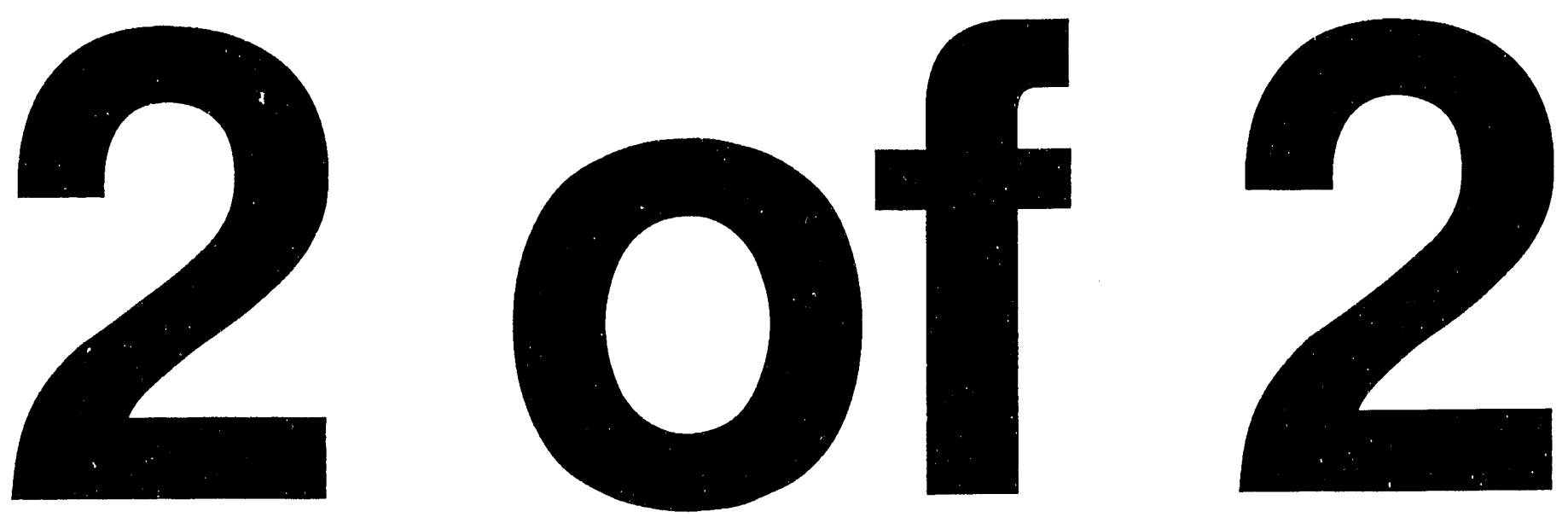


\section{SAVANNAH RIVER}

SRC88A01 Data Set

\section{Description}

This analytic data set consists of one file generated for a retrospective cohort mortality study, published in the American Joumal of Industrial Medicine in 1988, of white males employed at the Savannah River Site (SRS).

The published paper describes the overall and cause-specific mortality for a cohort of 9,860 white males who were hired between 1952 (when the facility began operation) and

December 31, 1974, and who were employed at SR.S for at least 90 days during this time. Exposures to radiation or chemicals were not considered. Separate analyses were presented for hourly employees $(6,687)$ and salaried employees $(2,745)$ by time period of first hire and by length of employment. These workers experienced mortality comparable to that of U.S. males and, in fact, exhibited fewer deaths than expected in many

categories of diseases. Specifically, fewer deaths were noted in the categories of all causes, all cancers, cancer of the digestive organs, lung cancer, brain cancer (hourly workers only), diabetes, all diseases of the circulatory system, all respiratory diseases, all digestive system diseases, all diseases of the genitourinary system (hourly workers only), and all external causes of death. A statistically significant, and as yet unexplained, increase in leukemia mortality appeared in a subset of the hourly workers who were first hired before 1955 and were employed between 5 and 15 years.

The one analytic file (SRANA4) in this data set contains one record per person in the cohort, including demographic, work history, and vital status data on all members of the cohort.

Hourly employees were judged to be those employees who worked for 90 or more consecutive days at an hourly

classification and less than 90 consecutive days at a salaried classification. Salaried employees were judged to be those employees who worked 90 or more consecutive days in a salaried classification and less than 90 days in an hourly classification. A third category consisted of those who worked 90 or more days consecutively in both classifications. Vital status was ascertained for $94.2 \%$ ( $N=$ 9,288 ) of the cohort through December 31,1980 , the study end date. There were 1,091 deaths identified, and death certificates were obtained for $96.9 \%$ of these deaths.

No personal monitoring data were used in this analysis 


\section{SAVANKAH RIVER}

\author{
SRC88A01 Data Set
}

\section{Citations}

Cragle, D., R. McLain, J. Qualters, J. L. S. Hickey, G. Wilkinson, W. G. Tankersley, and C. C. Lushbaugh. 1988. "Mortality among workers at a nuclear fuels production facility."

American Journal of Industrial Medicine 14:379401 .

\begin{tabular}{|c|c|c|}
\hline \multicolumn{3}{|c|}{ No. of Files: 1} \\
\hline File Name & $\begin{array}{l}\text { No. of } \\
\text { Variables }\end{array}$ & Type of Data \\
\hline SRANA4 & 16 & $\begin{array}{l}\text { demographic; } \\
\text { work history; } \\
\text { vital status }\end{array}$ \\
\hline
\end{tabular}

\section{Summary Death Tables}

\begin{tabular}{|c|c|c|}
\hline \multirow{2}{*}{ Cause of Death } & \multicolumn{2}{|c|}{ No. of Deaths } \\
\hline & Male & Female \\
\hline Infectious \& Parasitic Diseases & 7 & \\
\hline All Malignant Neoplasms & 215 & \\
\hline - Lip, Oral Cavity \& Pharynx & 7 & \\
\hline - Digestive Organs \& Peritoneum & 49 & \\
\hline - Respiratory Systern & 84 & \\
\hline - Bone \& Connective Tissue & 2 & \\
\hline - Skin & 5 & \\
\hline - Breast & $\mathbf{0}$ & \\
\hline - Genitourinary System & 17 & \\
\hline - Brain/CNS & 7 & \\
\hline - Other \& Unspecified Sites, Except Brain/CNS & 12. & \\
\hline - Lymphatic/Hematopoietic & 32 & \\
\hline All Benign Neoplasms & 4 & \\
\hline All Neoplasms, Unspecified & 1 & \\
\hline Endocrine, Nutritional, Metabolic Diseases \& Immunity Disorders & 13 & \\
\hline Diseases of Blood \& Blood-Forming Organs & 1 & \\
\hline Mental Disorders & 4 & \\
\hline Diseases of Nervous System \& Sense Organs & 9 & \\
\hline Diseases of Circulatory System & 518 & \\
\hline Diseases of Respiratory System & 27 & \\
\hline Diseases of Digestive System & 42 & \\
\hline Diseases of Genitourinary System & 5 & \\
\hline Complications of Pregnancy \& Childbirth & 0 & \\
\hline Diseases of Skin \& Subcutaneous Tissue & 1 & \\
\hline Diseases of Musculoskeletal System \& Connective Tissue & 1 & \\
\hline Congenital Anomalies & 1 & \\
\hline Symptoms \& III-Defined Conditions & 16 & \\
\hline Accidents, Poisoning \& Violence (External Causes) & 191 & \\
\hline Deaths, with ICD Code & 1056 & \\
\hline Deaths, No ICD Code & 34 & \\
\hline Total Deaths, All Causes & 1090 & \\
\hline
\end{tabular}

$t$ No females were included in this study. 


\section{Anaty tic flle rame}

\section{SRAMAG}

1 birth date

2 hire date into construction category

3 number of days in

4 termination date from construction category

5 last date known alive

6 hire date inio hourly category

7 number of days in hourly

8 termination date from hourly category

9 hire date into salaried

$$
\text { category }
$$

10 number of days in salaried

$$
\text { category }
$$

11 termination date from salaried category

12 CER-assigned ID number

13 status of person

14 underlying cause of death

15 cancer cause of death

16 sequence number of row 


\section{CEDR Working Data Sets}

Descriptions of working data sets currently available are presented in this section. Figure 6-1 presents a summary table that alphabetically lists the short name for each data set and provides a more descriptive name for each data set and a brief description.

The following pages present a description of each working data set that identifies each facility from which the data were collected and describes the data available. Subsequent pages list the variables found in each working file of the data set.

As explained in Section 2, working data sets are dynamic in nature and may be replaced periodically with more recent files. They also contain some of the least refined data collected by the researcher, and the level of validation varies from file to file and study to study Therefore, users should realize that precautions should be taken when working with these data. 
Figure 6-1. CEDR Working Data Sets Currently Available

\begin{tabular}{|c|c|c|c|}
\hline Data Set & General Name & Brief Description* & Page \\
\hline HFW89W01 & Hanford Site epidemiologic data & $\begin{array}{l}\text { Three working files for } 45,499 \text { Hanford workers initially emplayed } \\
\text { between } 1944 \text { and } 1978 \text { containing job histories, external dosimetry } \\
\text { data } \text { and internal deposition data }\end{array}$ & 121 \\
\hline LAFACW01 & $\begin{array}{l}\text { Los Alamos National Laboratory (LANL) } \\
\text { epidemiologic data }\end{array}$ & $\begin{array}{l}\text { Four working files for } 23,240 \text { LANL workers from } 1943 \text { to } 1978 \\
\text { containing demographic data, radiation data, plutonium bioassay } \\
\text { data, and estimated plutonium body burdens }\end{array}$ & 123 \\
\hline MDFACW01 & Mound Plant epidemiologic data & $\begin{array}{l}\text { Four working files for } 6,882 \text { Mound Plant workers from } 1941 \text { to } 1979 \\
\text { containing demographic data, occupational histories, external } \\
\text { dosimetry information, and urine bioassay results }\end{array}$ & 127 \\
\hline TORISEWDS & $\begin{array}{l}\text { Epidemiologic data for various DOE sites } \\
\text { as provided by Oak Ridge Institute for } \\
\text { Science \& Education (ORISE) }\end{array}$ & $\begin{array}{l}\text { Twenty-eight working files for approximately } 420,000 \text { individuals who } \\
\text { worked at one or more of } 59 \text { DOE sites from } 1943 \text { to } 1988 \text {. Data files, } \\
\text { segregated by data category, include demographics, work histories, } \\
\text { personnel monitoring, and vital status. }\end{array}$ & 129 \\
\hline RFFACW01 & Rocky flats Plant epidemiologic data & $\begin{array}{l}\text { Three working files for workers at the Rocky flats Plant containing } \\
\text { demographic data, urine results, and external ionizing radiation data }\end{array}$ & 139 \\
\hline ZAFACW01 & Zia Company (at LANL) epidemiologic data & $\begin{array}{l}\text { Three working files for } 15,309 \text { Zia workers at LANL from } 1946 \text { to } 1986 \\
\text { containing demographic data, external ionizing radiation data, and } \\
\text { plutonium bioassay data }\end{array}$ & 141 \\
\hline
\end{tabular}

* The numbers in the brief description represent the number of workers in the file, which is not necessarily the number of workers included in the published studies. $t$ A few of the files in this working data set may not be available through CEDRtext until October 1993 


\section{HANFORD}

HFW89W01 Data Set

\section{Description}

The HFW89W01 data set consists of three working files prepared for mortality studies of workers at the Hanford Facility.

This working data set consists of three working files that were generated by the Epidemiology and Biometry Department (EBD) of Pacific Northwest Laboratory (PNL) for mortality studies of workers initially employed at the Hanford Facility between 1944 and 1978. Data were obtained in various formats and media from the facilities where the workers were employed and from several other agencies, including the Hanford Environmental Health Foundation (HEHF) and the Social Security Administration. The files in HFW89W01 originated as part of EBD's data base of information supporting their mortality studir. several of which were completed in 1992, of operations workers at Hanford.

The three files in the HFW89W01 working data set are roughly segregated by the following types of data: demographic, external radiation dosimetry, and internal monitoring results. Data pertaining to an individual that appear in one or more files may be linked together by use of the individual pseudo-identifier number that was assigned to each worker. To help ensure data integrity, similar data from various suurces and files, such as those in the HFC78A01, were compared for inconsistencies. Discrepancies were resolved with assistance from the appropriate department or organization.

The first working file (JOB89) consists primarily of demographic data that were provided to EBD by HEHF in 1988 . JOB89 includes employment and job histories, social class data, and vital status data for the years 1944 through 1987 for operations workers at

Hanford. Social class was assigned by EBD using Bureau of Census job codes that were modified to correct inconsistencies between recorded job descriptions and assigned codes. These modifications corrected the most frequent inconsistencies. The modifications also corrected descriptions and codes that were important for use by EBD in assigning social class and for defining special categories of nuclear workers. Sequential entries for periods of continuous employment in which the social class code did not change were combined. Sequential entries were also combined if the time interval between the termination code and the next code was less than 1 month. JOB89 contains a total of 94,176 records for the 44,408 workers that have job histories.

The second working file (DOS89) contains extemal dosimetry data for the years 1944 through 1989. Occupational radiation exposure data, including occupational exposures received offsite for operations workers and construction workers, were provided by the PNL Health Physics Department (HPD) in 1990. The HPD is responsible for radiological protection and monitoring services for the entire Hanford Site. The EBD excluded exposure data for individuals solely employed as construction workers; however. doses received by operations workers while performing construction work were retained. Annual whole-body doses for each worker were compiled from dose estimates generated during onsite monitoring for radiation by PNL. DOS89 has a total of 429,795 records for the 45,499 workers that were monitored

The third working file (INT89) contains internal monitoring results for the years 1944 through 1989. Data on workers with confirmed internal depositions of various radionuclides

including plutonium, were provided by PNL's HPD in 1991. This file contains one record for each of the 560 workers with interna depositions 


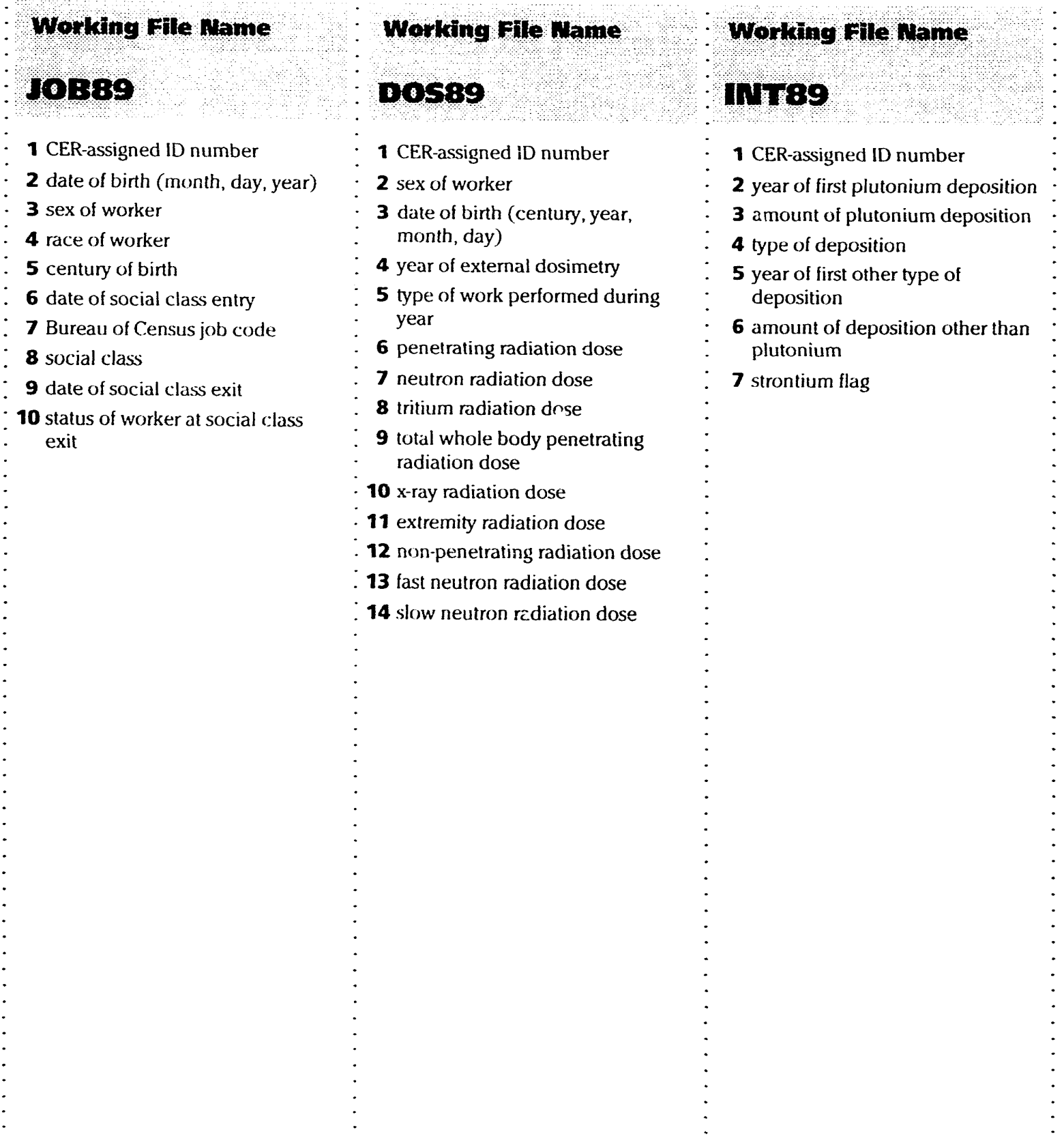




\section{LANL}

LAFACW01 Data Set

\section{Description}

The LAFACW01 data set consists of four working files prepared for epidemiologic studies of workers at Los Alamos National Laboratory (LANL)

The LAFACW01 data set consists of four related working files that were generated by the Epidemiology Section at LANL for mortality studies of workers employed at LANL. Data were obtained in various formats and media from different LANL departments and other agencies. Personnel data were abstracted from microfiche copies of each worker's personnel records. Supplemental data were obtained from LANL's security badge book, personnel security questionnaires, LANL medical records, and personnel records from other employers under study by LANL. Death information was abstracted from death certificates obtained from various states. Computerized external ionizing radiation data plutonium bioassay results, and estimated plutonium body burdens were obtained from LANL health physics.

The four files in the LAFACW01 data set are segregated by type of data: demographic, extemal exposure, plutonium bioassay results, and plutonium depositions. Data pertaining to an individual that appear in one or more files may be linked by the individual pseudo-identifier number assigned to each worker.

The first working file (LAPFILE) contains demographic information including birth and death dates, race, sex, work histories, coded cause of death, and state of death. The file includes 23,240 workers hired between 1943 and 1978, inclusive. A few later hires are also included. The file includes 6,803 females, 16,317 males and 120 workers with unknown sex. Race was determined for $68 \%$ of the workers. A roster of LANL workers was submitted to the Social Security Administration (SSA) for vital status ascertainment. Information on vital status through December 31, 1983, was obtained in 1987. There are 3,368 deaths identified in this working file. Cause of death information (ICDA-8) is not available for 122 deaths.

The second file (LAEFILE) contains external radiation exposure data consisting of annual whole-body doses, in centirem, where the whole-body dose was defined to be the sum of gamma. neutron, and tritium doses. During the early years of the monitoring programs, 1943 to 1945 , pocket chambers were used to measure exposure to radiation, and no official records of these early readings exist with the current LANL health physics group. Film dosimeters (badges) were used to measure exposures from 1944 through 1979, when thermoluminescent dosimeters (TLDs) replaced them. This file contains 97,309 records of exposure data from 1944 through 1985 for 11,917 monitored workers. These data include all measurements for individuals while working at LANL. Workers who were employed both at LANL and by a contractor may have measurements for both periods of employment.

Therefore, all measurements in this file may not fall within a worker's period of employment at LANL.

The third working file (LABFILE) contains plutonium bioassay data for 1944 through October 1985. There are 73,908 records for 4,358 individuals. Measurements in 1944 are for nose swipes or urine samples. In March 1945, a formal bioassay program was established. Before 1968, all urine bioassay results were for plutonium-239 because that was the isotope used in that time frame. After then, the results are labelled as plutonium-238 or plutonium-239. Until 1952, results were units of cpm/24 hours from 1952 through 1977, they were dpm/24 hours; and from 1977 to 1985 , they were $\mathrm{pCi} / 24$ hours. Generally, they are annual measurements, but some individuals have multiple readings for one plutonium isotope within a year and some have separate readings for both isotopes within a year. All measurements are 


\section{LAFIL}

\section{LAFACW01 Data Set}

- included in the file for each monitored worker. Some workers - may have measurements that do not fall within the LANL period of employment.

The fourth working file (LACFILE) contains estimated plutonium whole-body burdens as of January 1, 1987. There are 6,902 records for 4,329 individuals. Results are given separately for the two isotopes of plutonium (238 and 239) in units of nanocuries ( $\mathrm{nCi}$ ) and nCi-years. The computer code PUQFUA was utilized at LANL to estimate plutonium body burdens using bioassay data. 


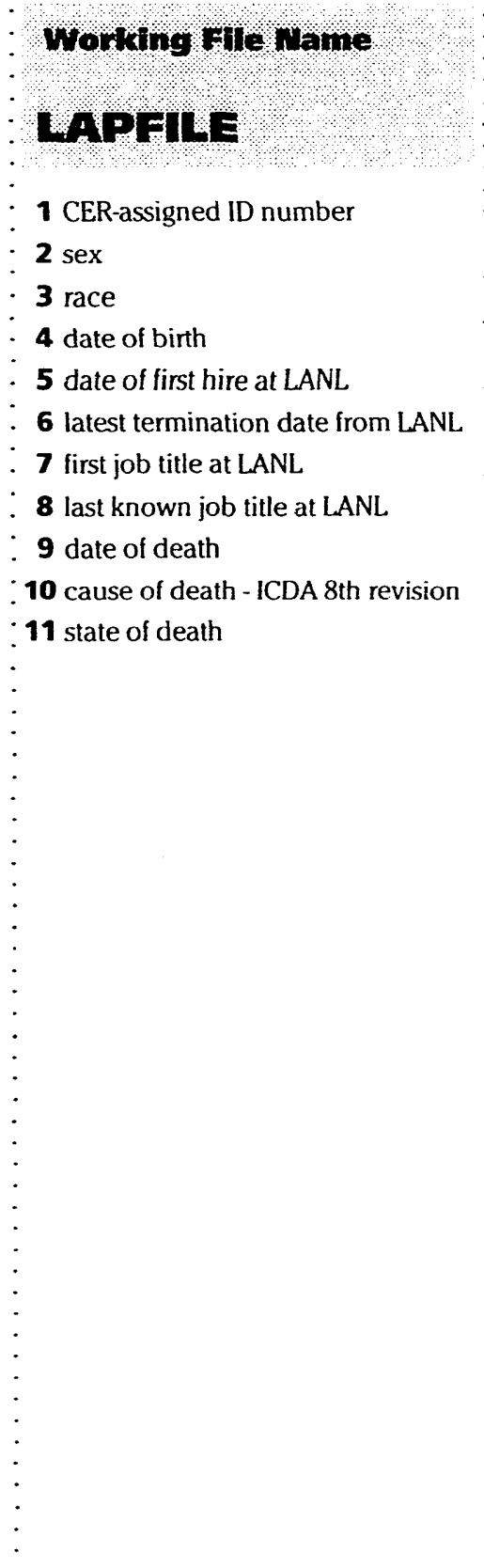

Working file wame

\section{WAEFIUE}

1 CER-assigned ID number

2 year worker monitored for external radiation

3 annual whole-body dose in centirem

\section{Working Ftle Hame}

\section{MABFILE}

1 CER-assigned ID number

2 date counts were taken on bioassay sample

3 measured value of bioassay reading

4 type of assay 


\title{
MOUND
}

\author{
MDFACW01 Data Set
}

\section{Description}

The MDFACW01 data set consists of four working files prepared for epidemiologic studies of workers at the Mound Plant in Ohio

The MDFACW01 data set consists of four working files that were generated by the Epidemiology Section at the Los Alamos National Laboratory (LANL) for mortality studies of workers employed at Mound. Data were obtained in various formats and media from Mound departments and other agencies. Demographic data were collected from two primary sources of records provided by the personnel department at Mound. Supplemental data were obtained from the Social Security Administration's (SSA's) 941A forms, Mound medical and health physics records, and from records previously collected. Death information was abstracted from death certificates obtained from various states. Radiation exposure and polonium bioassay data, in hard copy, were provided by the heath physics department at Mound.

The four files in the MDFACW01 data set are segregated by type of data: demographic, work history, external exposure and polonium bioassay results. Data pertaining to an individual that appear in one or more files may be linked by the individual pseudo-identifier number assigned to each worker.

The first working file (PERSON) contains demographic information, including race, sex, and birth date; limited work history

information; and death information, such as cause of death, date of death, and state of death, for 6,882 male and female workers hired between 1941 and 1979, inclusive. The file includes 1,692 females, 5,183 males and 7 with unknown sex. Race was determined for $88 \%$ of the workers. A roster of Mound workers was submitted to the SSA for vital status ascertainment. Information on vital status through December 31, 1983, was obtained in 1987. There are 1,716 deaths identified in this working file. Cause of death information (ICDA-8) is not available for 9 deaths.

The second working file (MNDOCCUP) contains occupational histories of each employee. There are $20,97 \mathrm{~T}$ records containing job titles and employment dates for 6,771 individuals. The earliest job date is January 1, 1941, and the latest is January 15,1981 . The file includes dates started on the job, the verbatim job title used by Mound, and an alphanumeric job code used by Mound that was associate with each job title.

The third working file (MNDEXTER) contains the external exposure data. There are 31,844 records for 4,081 individuals. The years covered by this file are 1947 through 1979. The variables include annual neutron, tritium, and whole-body dose (in millirems) incurred while working at the Mound Plant and the neutron, tritium, and whole-body doses received prior to employment at Mound.

The fourth working file (MNDPOLON) contains results of polonium urine bioassays between March 30, 1944, and June 5 , 1984. There are 201,652 records for 2,788 individuals. The data include the date of the sample, polonium activity in the sample, volume of urine in the sample. and any comments about the particular sample or its results. 


\section{Working File Mame}

\section{PERSON}

1 CER-assigned ID number

2 sex

3 race

4 date of birth

5 date of first hire at Mound

6 date of last termination from Mound

7 date of death

8 cause of death - ICDA 8th revision

9 the slate of death

\section{Working File Name}

\section{MNDEXTER}

1 CER-assigned ID number

2 date started on this job

3 job title

4 job code

\section{Working Flle Wame $:$ Working File Hame}

\section{MNDOCCUP}

1 CER-assigned ID number

2 neutron dose prior to dace of hire

3 tritium dose prior to date of hire

4 wholebody dose prior to date of hire

5 year of exposure

6 yearly neutron exposure

7 tritium exposure for the year

8 whole-body exposure for the year

\section{MIDPOLOI}

1 CER-assigned ID number

2 date of sample

3 polonium activity in counts per minute

4 volume of the sample for analyses 5 comments regarding the sample 


\section{OR SITE}

ORISEWDS Data Set

\section{Description}

The ORISEWDS data set is comprised of 28 working files that

were developed by the Center for Epidemiologic Research

(CER), Medical Sciences Division, Oak Ridge Institute for Science

and Education (ORISE). CER obtained these data in various

formats and media from the facilities where the workers were

employed and from several other agencies, such as the Social

Security Administration. To ensure the integrity of the data in the transcription from hard copy to electronic media, a double-entry

method was used whereby one person entered the data and a

second person entered the same data for verification purposes.

The files in the ORISEWDS working data set originated as part of CER's data model. Most of the files contain a large volume of data, which usually pertain to more than one site or facility, and are maintained in a relational data base management system. This design provides efficient data storage and facilitates the frequent addition of new or corrected data. The dynamic nature of the data model means that the working files comprising the ORISEWDS data set are a snapshot of the files at CER and that subsequent updates that will be placed in CEDR may be different from the current working files in the ORISEWDS data set.

The files in the ORISEWDS are roughly segregated by type of data rather than by facility. Each worker has been assigned a unique pseudo-identification number, which can be used to relate data that may appear in a number of files. This allows users to compile all data for a given individual or cohort.

There are ten files in the ORISEWDS data set that primarily contain demographic and work history data. They are MR, EMP, PAYCD, JOB, DEPTCD, MVITAL, DEATH, ERR, MERGED and FIXED. The MR (master roster) file contains one record per person. All other files may have multiple records, or no records, for an individual, depending on the type and availability of the data. The remaining working files in the ORISEWDS data set contain data relating to personal radiation monitoring information that was obtained from various facilities at which the individual worked. Due to the volume and nature of these data, they are segregated by facility and by type of monitoring, such as extemal monitoring, whole-body counting, and urinalysis results. The individual pseudoidentifier number in these files allow these data to be linked to pertinent data that may appear in other files in the ORISEWDS data set. Therefore, the proper combination of files will provide a complete picture of data for an individual or for a particular cohort of interest. More detailed information about each of the working files in the ORISEWDS data set is provided in the file-level metadata. 


\begin{tabular}{|c|c|c|c|}
\hline $\begin{array}{l}\text { Womking fille Hame } \\
\text { BEAHI }\end{array}$ & $\begin{array}{l}\text { Working File tame } \\
\text { BEPTCB }\end{array}$ & $\begin{array}{l}\text { Working File Name } \\
\text { EMP }\end{array}$ & Moring File wame \\
\hline $\begin{array}{l}1 \text { underlying cancer cause of death } \\
\text { coded to ICD8 rules } \\
2 \text { underlying cancer cause of death } \\
\text { coded to ICD9 rules } \\
3 \text { date of death } \\
4 \text { cause of death coded to ICD8 } \\
\text { rules } \\
5 \text { cause of death coded to ICD9 } \\
\text { rules } \\
6 \text { status of ICD coding } \\
7 \text { CER-assigned ID number } \\
8 \text { state of death } \\
9 \text { status of verification }\end{array}$ & $\begin{array}{l}\mathbf{1} \text { CER-assigned ID number } \\
\mathbf{2} \text { date department code become } \\
\text { effective } \\
\mathbf{3} \text { date archive flag } \\
\mathbf{4} \text { date estimation flag } \\
\mathbf{5} \text { department code archive flag } \\
\mathbf{6} \text { code value for department } \\
\mathbf{7} \text { facility code } \\
\mathbf{8} \text { plant code archive flag } \\
\mathbf{9} \text { plant code }\end{array}$ & $\begin{array}{l}1 \text { CER-assigned ID number } \\
\mathbf{2} \text { facility code } \\
\mathbf{3} \text { date of hire at facility } \\
\mathbf{4} \text { hire date archive flag } \\
5 \text { date of termination at facility } \\
6 \text { termination date archive flag } \\
7 \text { first hire/last ierm. flag } \\
\mathbf{8} \text { flag indicating if person is active } \\
9 \text { date associated with active } \\
\text { employees } \\
10 \text { hire/term. estimation flag }\end{array}$ & $\begin{array}{l}1 \text { CER-assigned ID number } \\
2 \text { facility code } \\
\mathbf{3} \text { name of program detecting error } \\
4 \text { date error was detected } \\
5 \text { error code } \\
6 \text { comment field } \# 1 \\
7 \text { comment field } \# 2 \\
\mathbf{8} \text { comment field } \# 3\end{array}$ \\
\hline
\end{tabular}




\section{Working Flle Hame \\ $1 F(\geq 3$ \\ 1 CER-assigned ID number \\ 2 facility code \\ 3 name of program detecting error \\ 4 date error was detected \\ 5 error code \\ 6 date error was fixed \\ 7 comment field \#1 \\ 8 comment field $\# 2$ \\ 9 comment field $\# 3$ \\ 10 source of how error was fixed}

\section{Workfing File Mame}

\section{JOB}

1 CER-assigned ID number

2 date job code/title became effective

3 date estimation flag

4 date archive flag

5 code associated with job title

6 job code archive flag

7 job title archive flag

8 facility code

9 job title per the facility
Working File name

\section{MERGED}

1 request number of merge

2 date merge took effect

3 ID merged "into"

4 ID merged "from"

5 status of merge

6 person making request
Working File Mame

\section{MR}

1 CER-assigned ID number

2 sex code of individual

3 sex archive flag

4 race code

5 race archive flag

6 birth date of individual

7 birth date estimation flag

8 birth date archive flag

9 number of facilities worked at

10 facility 1

11 facility 2

12 facility 3

13 facility 4

14 facility 5

15 facility 6

16 facility 7

17 facility 8

18 facility 9

19 facility 10 


\section{Working File Name}

\section{PAYCB}

1 CER-assigned ID number

2 facility code

3 date pay code became effective

4 date archive flag

5 date estimation flag

6 pay code archive flag

7 pay code for this individual

\section{Working File Wame}

\section{WNWAL}

1 CER-assigned ID number

2 agency (source) supplying vital status

3 year submission was made

4 sequential submission number for this year

5 vital status

6 status date

7 comment flag

8 state of vital status

\section{Working Fll Fane}

\section{IIPQFB}

1 CER-a.ssigned ID number

2 badge number of individual

3 burth date of individual

4 sex code of individual

5 result date of $F B / T L D$ reading

6 link code indicating how record was linked

7 file identification

8 termination code (if applicable)

9 cost center employee assigned to

10 beta exposure

11 gamma exposure

12 beta year-to-date exposure

13 gamma year-to-date exposure

14 beta code

15 gamma code

16 employee's beta dose for period

17 employee's gamma dose for employment period

18 excess beta code

19 excess gamma code

20 damaged badge code

21 total exceeded flag

22 data entry code

23 radiation constant

24 start and end period

\section{Working File iame}

\section{FilPanRII}

1 CER-assigned ID number

2 badge number of individual

3 CER file identifier

4 date sample was taken

5 a flag associated with some date

6 month sample was taken

7 day sample was taken

8 year sample was taken

9 hour when sample was taken

10 result of urinalysis sample

11 a flag associated with urinalysis result

12 result of urinalysis sample

13 (this field is unknown)

14 starting and ending year

15 Fernald cost center

16 type of sample taken

17 plant number

18 plant area

19 a code to indicate employee's work level

20 a code to indicate employee's job code

21 the shift the sample was taken

22 record sequence number

23 sex code of the person

24 sample grouping code

25 urinalysis constraint

26 material exposure code

27 sample requisition number

28 code for material analyzed for

29 number assigned to sample 
30 employee job title

31 employee's department/division

32 location of where employee

worked

33 reason for sample

34 other job comments

35 comments

36 (unknown)

37 link code indicating how record was linked

38 link code indicating how record was linked

- 39 CER file identifier

\section{Workine rth hame}

\section{FMPGWEC}

1 CER file identifier

2 CER-assigned ID number

3 badge number of individual

4 thorium worker

5 termination date

6 last day worked by employee

7 medical flag

8 in vivo counting date

9 description of plant area (building) where employee worked

10 employee's job title

11 days off without exposure

12 counting time in relation to shift

13 resuit of $U-235$ in vivo count

14 result of total uranium in vivo count

15 result of thorium in vivo count

16 result of lead-212 in vivo count

17 result of actinium in vivo count

18 result of additional material in the in vivo count

19 result of a second additional material in the in vivo count

20 remarks field

21 remarks field

22 flag indicating general text on form

23 row number

24 code indicating how record was linked

25 CER-assigned ID number

\section{Woring Hla Hame}

\section{LWDEE FB}

$1 \mathrm{CF}$ ?-assigned ID number

2 bi ginning date for this

mi nitoring record

3 badge nu nher

4 job description

5 beta reading

6 gamma reading

7 total external dose

8 comments regarding exposure

9 flag indicating employer

10 pass number of linking software

11 a code indicating how record was linking

\section{Woritar Fle name}

\section{K25WBC}

1 CER-assigned ID number

2 code indicating how record was linked

3 unique identifier assigned to run

4 date of the run

5 run made for a control

6 department code at time of run

7 year of bith of individual

8 sex of individual

9 weight of subject

10 chest thickness of subject

11 amount of surface contamination

12 length of run in minutes

13 type of analysis performed

14 type of material exposed to

15 front-to-back ratio

16 amount of thorium in lungs

17 amount of U-235 in lungs

18 cesium 137 count at time of run

19 potassium count at time of run

20 amount of U-238 in lungs

21 actinium count at time of the run 22 lead 212 count at time of the run

23 technetium count at time of run

24 month results reported

25 current department code of subject 


\section{Working Flle wame}

\section{TREURIM}

1 CER-assigned ID number

2 code indicating how record was linked

3 number assigned to bioassay sample

4 code indicating division of individual

5 department code of individual

6 code indicating subgroup of department

7 salaried/hourly indicator

8 type or reason for analysis

9 number of times recalled

10 shift employee worked

11 frequency of monitoring

12 date sample was taken

13 radioisotope/chemical sampling for

14 results of the urinalysis

15 building/area where employee worked

16 sample taken for $\mathrm{IH}$ or $\mathrm{HP}$ purposes

17 time sample was taken

\section{Working File wane}

\section{E}

1 CER-assigned ID number

$\mathbf{2}$ code indicating how record was linked

3 year of monitoring

4 quarter of monitoring

5 result for beta exposure

6 resuit for gamma exposure

7 result for skin dose

8 result for penetrating dose

9 plant code

10 group code

11 code showing if film was damaged

12 rack number used in processing

13 tray number used in processing

14 film density behind plastic shield

15 film density behind aluminum shield

16 film density behind cadmium shield

17 film density behind open window

18 neutron dose

19 individual s department code

20 4-digit year of monitoring

$\mathbf{2 1}$ sequence number if multiple quarter results

22 quarter film was input

23 flag showing if film was damaged

24 date of birth of individual

25 TLD damage flag

26 date TLD was damaged

27 comments on damaged, lost, estimated TLD
28 TLD number

29 date TLD was read

30 penetrating dose per TLD reading

31 skin dose per TLD reading

32 date TLD was assigned

33 schedule for exchanging TLD

34 date of comment

35 comments on TLD readings

36 plant code

37 department of employment

\section{Woring Fle Wane}

\section{$240=54$}

1 CER-assigned ID number

2 code indi ating how record was linked

3 date of birth

4 service date of employee

5 department code employee assigned to

6 sex of employee

7 employee status

8 sample date

9 film badge year

10 film badge quarter

11 film badge week

12 ORNL employee designation

13 monitoring information

14 additional monitoring

information

15 skin dose in mrem

16 penetrating dose in mrem

17 sort key for employee's records

18 damaged/lost film badge codes 


\section{Worting File Wame}

\section{TOURII}

1 CER-assigned ID number

2 code indicating how record was linked

3 sample date

4 isotope monitored

5 result of sample in DPM

6 result count for 24 hour voiding

7 department code employee assigned to

8 flag linking employee's department

\section{Working rlle name}

\section{X1017BC}

1 CER-assigned ID number

$\mathbf{2}$ code indicating how record was linked

3 division employee worked in

4 health physics area (building)

5 count date

6 reason for whole body count

7 body area of whole body count

8 ORNL assigned serial number of run

9 result in terms of MPOB

10 comments about the whole body count

11 department code employee assigned to

12 flag linking employee to department
Worlding File Name

\section{TPI:}

1 CER-assigned ID number

2 code indicating how record was linked

3 unique identification number for run

4 date run was made

5 run made for a control

6 department code at time of run

7 year of birth of person

8 sex on person

9 weight of subject in pounds

10 chest thickness of person

11 surface contamination

12 length of run in minutes

13 analysis and target materials code

14 material type and additional information

15 front-to-back contamination ratio

16 amount of U-235 in lungs

17 amount of thorium in lungs

18 cesium 137 count

19 potassium count

20 amount of $\mathrm{U}-238$ in lungs

21 reported month

22 type analysis pre-1971

23 pre-1971 count of U-235

24 activity of actinium detected

25 activity of lead detected

26 activity of technetium detected

\section{Working File Wame}

\section{SRSFILE1}

1 CER-assigned ID number

$\mathbf{2}$ code indicating how record was linked

3 payroll status (salary, nonexempt, etc)

4 craft classification

5 employee number

6 birth date of employee

7 service date of employee

8 plant service year

9 health physics area where exposed

10 specific identifier of where exposed

11 department of employee's supervisor

12 employee status at time of reading

13 transuranic registry number

14 accumulated plant tritium exposure

15 accumulated plant neutron exposure

16 accumulated plant skin exposure

17 accumulated plant gamma exposure 


\section{Working File Name}

\section{SRSFILE2}

1 CER-assigned ID number

2 code indicating how record was linked

3 body burden received

4 nuclide of exposure

5 body organ receiving dose

6 month of intake

7 year of intake

\section{Working File Name}

\section{SRSFILE}

1 CER-assigned ID number

2 code indicating how record was linked

3 annual tritium exposure

4 annual neutron exposure

5 annual skin (open window) exposure

6 annual shielded exposure

7 year of exposure

\section{Working File Dame}

\section{SRSFILE4}

1 CER-assigned ID number

2 code indicating how record was linked

3 health physics area

4 health physics department

5 year of exposure

6 annual open window exposure

7 annual shielded exposure

8 annual tritium exposure

9 annual neutron exposure

10 accumulated open window exposure

11 accumulated shielded exposure

12 accumulated tritium exposure

13 accumulated neutron exposure

14 special codes and notes

\section{Worling He Hame}

\section{YPEXX5080}

1 CER-assigned ID number

2 code indicating how record was linked

3 year of monitoring

4 quarter of monitoring

5 beta exposure

6 gamma exposure

7 skin dose in mrem

8 penetrating dose in mrem

9 code indicating plant

10 facility group code

11 film description code

12 rack number when processed

13 tray number when processed

14 film density behind plastic shield

15 film density behind aluminum shield

16 film density behind cadmium shield

17 film density behind open window

18 neutron dose

19 department number for this individual

20 4-digit year of monitoring

21 quarter of monitoring

22 multiple sequence number

23 quarter film was input

24 damaged film flag 


\section{Workfan Fle nhane}

\section{TPuilu}

1 CER-assigned ID number

2 code indicating how record was linked

3 date of voiding

4 sequence number if multiple samples

5 sample scheduling code

6 urinalysis sampling technique

7 department code at time of sample

8 number of regular plate counts taken

9 urine volume in sample

10 time since last void

11 flag indicating if sample usable 12 plate 1 count

13 plate 1 second count

14 plate 2 count

15 plate 2 second count

16 plate 3 count

17 plate 3 second count

18 fluorometric sampling code

19 type of participation

20 routine sample flag

21 special departmental sample

22 averaged results flag

23 data change flag

24 flag showing person removed from program

25 result in disintegrations per minute

26 background count for plating
27 flag showing if calculations were made

28 result received in past 91 days $(\mathrm{Y} / \mathrm{N})$
Workfug Fle name

\section{YTEXT8184}

1 CER-assigned ID number

2 code indicating how record was linked

3 year TLD was assigned to

individual

4 quarter TLD was assigned

5 beta position (1) from TLD reader

6 gamma position (2) from TLD reader

7 skin dose in mrem

8 penetrating dose in mrem

9 plant code

10 group code

11 flag indicating if TLD was camaged

12 date if damaged

13 damaged, lost, or estimated commen

14 TLD number

15 date TLD was read

16 lab report on penetrating dose

17 date TLD was assigned

18 department code for person at this time

19 result code if damaged, lost, estimated

20 date of birth

21 code indicating when TLD is exchanged 


\section{ROCKY FLATS}

RFFACW01 Data Set

\author{
Description \\ The RFFACW01 data set consists of three working files prepared for \\ epidemiologic studies of workers at the Rocky Flats Plant (RFP) \\ The RFFACW01 data set consists of three working files that were \\ generated by the Epidemiology Section at the Los Alamos National \\ Laboratory (LANL) for mortality studies of workers employed at \\ RFP. Data were obtained in various formats and media from Rocky \\ Flats departments and other agencies. Demographic data were \\ collected from two primary sources of records provided by the \\ personnel department at RFP. Supplemental data were obtained \\ from RFP medical and health physics records. Death information \\ was abstracted from death certificates obtained from various states. \\ Externa! radiation exposure and plutonium bioassay data were \\ provided by the health physics department at RFP. The external \\ radiation data were computerized by the Epidemiology Section at \\ LANL. \\ The three files in the RFFACW01 data set are segregated by type of \\ data: demographic, extemal exposure, and plutonium-239 bioassay \\ results. Data pertaining to an individual that appear in one or more \\ files may be linked by the individual pseudo-identifier number \\ assigned to each worker. \\ The first working file (PERSON) contains demographic \\ information, including race, sex, birth date, limited work history
}

information, and death information, such as cause of death, date of death, and state of death for 9,537 males and females hired : between 1951 and 1979, inclusive. The file includes 1,563 females, 7,973 males, and 1 with unknown sex. Race was determined for $99 \%$ of the workers. A roster of Rocky Flats workers was submitted to the Social Security Administration for - vital status ascertainment. Information on vital status through - December 31, 1983, was obtained in 1987. There are 1,107 - deaths identified in this working file. Cause of death information (ICDA8) is not available for 12 deaths.

: The second working file (BIOASSAY) contains results of urine : bioassay measurements for gross alpha, uranium, enriched uranium, depleted uranium, plutonium-239, and americium-241 - that were made between August 11, 1952, and January 15, 1982. : The file contains 209,015 records for 7,761 workers. The data include the date of the sample, type of analysis, activity of each isotope, estimated body burdens for plutonium-239, and estimated body burdens for americium-241

The third working file (RFEXTRAD) contains external exposure data. There are 83,159 records for 9,388 workers for the years 1951 through 1978. The variables inciude year of monitoring and annual whole-body doses (in millirems) incurred while working at RFP. 


\section{Worting flle Name}

\section{PERSON}

1 CER-assigned ID number

2 sex

3 race

4 date of birth

5 date of first hire

6 date of last termination prior to 1980

7 date of death

8 cause of death - ICDA 8th revision

9 state of death

\section{Working ffle rame}

\section{BIOASSAY}

1 date assigned to sample by Rocky Flats

2 CER-assigned ID number

3 type of sample assay activity

4 activity level (nCi)

5 fractional MPBB

\section{Working Flle Name}

\section{RFEXTRAD}

1 CER-assigned ID number

2 year of exposure

3 annual whole-body penetrating dose 


\section{Description}

The ZAFACW0I data set consists of three working files prepared for epidemiologic studies of workers at the Zia Company (Zia).

The ZAFACW01 data set consists of three working files that were generated by the Epidemiology Section at the Los Alamos National Laboratory (LANL) for mortality studies of workers employed at $\mathrm{Zia}$. Data were obtained in various formats and media from Zia, LANL departments, and other agencies. Demographic data were collected from three primary record sources provided by the Zia Company. Supplemental data were obtained from LANL's security badge book, personnel security questionnaires, LANL medical records, and LANL personnel records. Death information was abstracted from death certificates obtained from various states. Computerized data on exposure to external radiation and results of plutonium bioassays were obtained from the health physics department at LANL. Radiation protection and monitoring services are provided for Zia Company by LANL.

The three files in the ZAFACW01 data set are segegrated by type of data: demographic, extemal exposure, and plutonium bioassay results. Data pertaining to an individual that appear in one or more files may be linked by the individual pseudo-identifier number assigned to each worker.

The first working file (ZIAPFILE) contains demographic information, including birth and death dates, race, sex, work histories, coded cause of death, and state of death. The file includes 15,309 workers hired between 1946 and 1978, inclusive The file includes data for 1,469 females, 11,215 males, and 2,625 workers with unknown sex. Race is determined for $74 \%$ of the workers. A roster of Zia workers was submitted to the Social Security Administration for vital status ascertainment. Information on vital status through December 31, 1984, was obtained in 1987.
There are 4,317 deaths identified in this working file.

The second working file (ZIAEFILE) contains extemal radiation exposure data consisting of annual whole-body doses (in centirem) where the whole-body dose was defined to be the sum of gamma, neutron, and tritium doses. Film dosimeters (badges) were used to measure exposures from 1944 through 1979, when thermoluminescent dosimeters (TLDs) replaced them. This file contains 44,452 records of exposure data from 1944 through 1985 for 5.911 monitored workers. These data include all measurements for individuals while working at Zia. Workers who were employed at Zia and also by LANL or another contractor may have measurements for both periods of employment. Therefore, all measurements in this file may not fall within a worker's period of employment at Zia.

The third working file (ZIABFILE) contains plutonium bioassay data for 1944 through October 1985. There are 35,434 records for 3,104 individuals. Measurements in 1944 are for nose swipes or urine samples. In March 1945. a formal bioassay program was established. Before 1968, all urine bioassay results were for plutonium-239 because that was the isotope used during that time. Beginning in 1968, the results are labelled as plutonium-238 or plutonium-239. Until 1952, resuits were in units of cpm/24 hours; from 1952 th:-)ugh 1977 , they were in dpm/24 hours; and from 1977 to 1985 , they were in $\mathrm{pCi} / 24$ hours. Generally, they are annual measurements, but some individuals have multiple readings for one plutonium isotope within a year and some have separate readings for both isotopes within a year. All measurements are included in the file for each monitored worker. Some workers may have measurements that do not fall within the Zia period of employment 


\section{Working File Name}

\section{ZIAPFILE}

1 CER-assigned ID number

2 sex

3 race

4 date of birth

5 date of first hire at the Zia

Company

6 latest termination date from $\mathrm{Zia}$

Company

7 first job title

8 last known job title

9 date of death

10 cause of death - ICDA 8th revision

11 state of death

\section{Morking File Mame}

ZIAEFLE

1 CER-assigned ID number

2 year monitored for external radiation

3 annual wholebody dose in centirem

\section{Working File Wane}

\section{4:1:44:}

1 CER-assigned ID number

2 date counts taken on bioassay sample

3 measured value of Pu bioassay reading

4 type of assi:y 


\section{APPENDIX A}




\section{Glossary}

NOTE: For definitions of epidemiological terms, readers are referred to A Dictionary of Epidemiology'edited by John $\mathrm{M}$. Last for the International Epridemiological Association (1983).

\section{Analytic Data \\ Set}

Analytic File A static file containing data upon which a researcher

Bulletin Board A mechanism that allows users to post and review

CEDR The acronym for the Comprehensive Epidemiologic Data

CEDR OnLine A customized electronic bulletin board that facilitates

CEDRtex

CER

The collection of static files that contain the data upon which a researcher directly bases a study's reported findings. directly bases a study's reported findings. information much like traditional bulletin boards. CEDR OnLine is a customized electronic bulletin board designed specifically for CEDR users. Resource. The CEDR Program is managed by the U.S Department of Energy, Office of Health (EH-42I). information exchange among CEDR users.

A text-based CEDR software tool that allows authorized CEDR users to view essential aspects of CEDR data sets on-line.

The acronym for the Center for Epidemiologic Research at the Oak Ridge Institute for Research and Education.

The abbreviation for curie. The curie is a unit of measure used to describe the amount of radioactivity in material. One curie is that amount of radioactive material in which 37 billion $\left(3.7 \times 10^{10}\right)$ atoms are transformed per second. Fractions of a curie may be shown as nanocuries $(\mathrm{nCi})$ or picocuries (pCi).

The acronym for Confidence Interval
ICD Codes

The acronym for central nervous system.

Any designated group of persons who are followed or traced over a period of time. For example, a cohort may be defined as all white males working at a specific facility during a specific period of time.

\section{Counts per minute}

A collection of logically related files. CEDR contains two types of data sets: analytic and working.

The acronym for the U.S. Department of Energy.

\section{Disintegrations per minute.}

A specific DOE plant. It may be one of several DOE plants or facilities, such as X-10, at a particular DOE site.

A collection of similarly structured records that contain a set of variables.

The acronym for health physics.

The acronym for International Agency for Research on Cancer.

The International Classification of Diseases diagnostic codes are standardized codes used to classify morbidity and mortality information for statistical purposes. The 8 th revision of the ICD codes (ICD-8, ICDA-8) are currently used in various CEDR files.

Informix

A commercially available relational data base management system that is used to manage the CEDR data.

Internet A worldwide netw rk for computer communications.

Interactive standard query language that is used to query an Informix data base.

MPBB 


\begin{tabular}{|c|c|}
\hline mSv & $\begin{array}{l}\text { Millisievert. A millisievert equals } 1 / 1,000 \mathrm{rem} \text {. Please refer } \\
\text { to definition of rem. }\end{array}$ \\
\hline NIOSH & $\begin{array}{l}\text { The acronym for the National Institute for Occupational } \\
\text { Safety and Heatth. }\end{array}$ \\
\hline Po & The accepted symbol for polonium. \\
\hline ppm & Parts per million. \\
\hline Primary User & $\begin{array}{l}\text { An authorized CEDR user who is assigned a CEDR account } \\
\text { number and may be the direct recipient of CEDR data. }\end{array}$ \\
\hline $\begin{array}{l}\text { pseudo- } \\
\text { identifier }\end{array}$ & $\begin{array}{l}\text { A unique, impersonai identifier sometimes } \\
\text { referred to as the CER-assigned ID number. }\end{array}$ \\
\hline Pu & The accepted symbol for the element plutonium. \\
\hline rem & $\begin{array}{l}\text { A measure of radiation dose related to biological effect. } \\
\text { Fractions of a rem may be shown as millirem or centirem. } \\
\text { Also, } 1 \text { rem equals } 1 \text { centisievert }(\mathrm{cSv}) \text {, and } 100 \text { rem equals } \\
\text { I sievert (Sv). }\end{array}$ \\
\hline rlogin & $\begin{array}{l}\text { A remote log-in command allowing access to } \\
\text { remote computers on the Intemet. }\end{array}$ \\
\hline SAS & $\begin{array}{l}\text { A commercially available statistical analysis software } \\
\text { package. }\end{array}$ \\
\hline Secondary User & $\begin{array}{l}\text { An authorized CEDR user with whom a primary user may } \\
\text { share CEDR data. }\end{array}$ \\
\hline Site & $\begin{array}{l}\text { A geographical area on which one or more major facilities } \\
\text { or plants are located. For example, the Oak Ridge Site } \\
\text { includes the X-10, Y-12, and } \mathrm{K}-25 \text { facilities. A site is } \\
\text { sometimes referred to as a reservation. }\end{array}$ \\
\hline SMR & The acronym for Standardized Mortality Ratio. \\
\hline SSA & The acronym for Social Security Administration. \\
\hline $\begin{array}{l}\text { Structured } \\
\text { Documentation }\end{array}$ & Information that describes CEDR data. \\
\hline $\ln \epsilon$ & ation $p$ \\
\hline
\end{tabular}

Variable

Working Data Set

orking File

term
Thermoluminescent dosimeter used to assess exposure to radiation.

The accepted symbol for uranium.

A computer operating system. The CEDRtext application and the CEDR data reside on a UNIX-based computer.

A specific field or data element in a file.

The collection of dynamic files that contains the data from which a researcher selects variables to analyze and forms an initial analytic data set. The data in working data sets may be gathered from a variety of sources and contain the least refined form of data in CEDR.

A dynamic file that contains the data from which a researcher selects variables to analyze and forms an initial analytic data set. The data in working files may be gathered from a variety of sources and contain the least refined form of data in CEDR.

A terminal emulation for the $\mathrm{X}$-Window system. 


\section{APPENDIX B}




\section{User Authorization}

Instructions for Completion of

Confidentiality Statements Required for Access to the Comprehensive Epidemiologic Data Resource (CEDR)

\section{General Instructions}

The attached confidentiality statements must be completed and returned to the Department of Energy (DOE) at the following address before the data being made available through the CEDR Program can be released.

\section{Barbara G. Brooks \\ CEDR Program Manager \\ Office of Health, EH-421 \\ U.S. Department of Energy \\ Washington, DC, 20585}

The first confidentiality statement assures DOE that the data will be used in a manner which ensures the protection of individual privacy and in compliance with DOE regulations. The additional three forms are required by the States of Alabama, Pennsylvania, and Rhode Island. Upon receipt of the completed statements, the Office of Health at DOE will retain the DOE statements and will forward the others to the appropriate state officials. The review of these statements should take place in a very short time. Written approval is needed from the State of Pennsylvania; a signed release from

Pennsylvania will be sent to you and to DOE. Within two weeks after the date of your approval by Pennsylvania, DOE will review the completed confidentiality statements and will notify you when your application is approved. Personnel at Lawrence Berkeley Laboratory (LBL) will contact you to establish your account

\section{Specific Instructions for Each Statement}

DOE Confidentiality Statements (Attachments 1 and 2) There are two types of statements: The first is for a "Primary User" who is defined as the person to whom a CEDR account number is given and who is the actual recipient of the data from the CEDR personnel at LBL. It is selfexplanatory and should be completed by those who wish to establish their own CEDR account.

The second statement is for "Secondary Users" who are defined to be those with whom a primary user may share CEDR data. Secondary users do not interact directly with LBL and the CEDR information system and do not need their own CEDR account. The statement is selfexplanatory and should be completed by those having access to CEDR data though the primary user's account.

\section{Pennsylvania's Individual Case Record Release Form (At-} tachment 3)

Each prospective CEDR user must complete this selfexplanatory form and retum it to DOE. Personnel in DOE's Office of Health will submit it to the Pennsylvania Department of Health for written approval.

\section{Alabama's Confidentiality Statement for CEDR Users (At-} tachment 4)

Each prospective CEDR user must complete this selfexplanatory form and retum it to DOE. Personnel in DOE's Office of Health will submit it to the Alabama Department of Public Health before allowing the user access to the CEDR data.

\section{Rhode Island's Research Assurance Form (Attachment 5)}

Each prospective CEDR user must complete this form and retum it to DOE. Personnel in DOE's Office of Health will submit it to the Rhode Island Department of Health before allowing the user access to the CEDR data.

Most of the questions and terms are selfexplanatory. However, Item 5 (b) means that computer tapes or other electronic media containing data originating from Rhode Island's vital records should be completely erased or returned to DOE. In Item 7, please note that the data should be returned to DOE. 


\section{U.S. DEPARTMENT OF ENERGY COMPREHENSIVE EPIDEMIOLOGIC DATA RESOURCE (CEDR) Confidentiality Statement for Primary Users}

In order to access the epidemiologic data in CEDR, 1 , the primary user, agree to the following conditions which are necessary to ensure the protection of individual privacy and to comply with certain regulations and agreements.

1. I understand that the Departnient of Energy (DOE) releases CEDR data for statistical purposes only. Therefore, I will not link data from CEDR with any other sources of information that leads to the identification of an individual having records in CEDR. I accept responsibility for any misuse of the data provided to me and agree to hold DOE harmless for such misuse.

2. I will not disclose CEDR data to any parties other than those working directly with or for me on the specific project for which I am using CEDR data. I will designate these individuals as Secondary Users and will ensure their submittal of Confidentiality Statements. I will not by any means disclose CEDR data to anyone else.

3. I will not allow the use of my CEDR account number by anyone else.

4. I agree that if a publication results from the analysis of CEDR data, the primary author will provide a copy of the analysis files to CEDR when the study is prepared for presentation or is accepted for publication. I understand that all analysis files will be made available to other CEDR users.

5. 1 agree to acknowledge the use of CEDR data in any resulting publications or presentations and agree to include a disclaimer statement that the protocol and results of my study were not reviewed by DOE and that conclusions do not necessarily reflect those of the U.S. Government or DOE.

User Signature (written and printed)

Date

Organization, Address, Phone No

Description of Statistical Use of the Data

There will be Secondary Users of my CEDR Data. [ ] No [ ] Y Yes

Names of Secondary Users whose Confidentiality Statements Are Attached

DOE Reviewing Official 


\section{U.S. DEPARTMENT OF ENERGY COMPREHENSIVE EPIDEMIOLOGIC DATA RESOURCE Confidentiality Statement for Secondary Users}

In order to access the epidemiologic data in CEDR, I agree to the following conditions which are necessary to ensure the protection of individual privacy and to comply with certain regulations and agreements.

1. I understand that the Department of Energy (DOE) releases CEDR data for statistical purposes only. Therefore, I will not link data from CEDR with any other sources of information that leads to the identification of an individual having records in CEDR. 1 accept responsibility for any misuse of the data provided to me and agree to hold the Department of Energy harmless for such misuse.

2. I will not disclose CEDR data to any other parties, either by allowing them to see the data, giving them copies of the data, or by any other means.

3. I agree that if a publication results from the analysis of CEDR data, the primary author will provide a copy of the analysis files to CEDR when the study is prepared for presentation or is accepted for publication. I understand that all analysis files will be made available to other CEDR users.

4. I agree to acknowledge the use of CEDR data in any resulting publications or presentations and agree to include a disclaimer statement that the protocol and results of my study were not reviewed by DOE and that conclusions do not necessarily reflect those of the U.S. Government or DOE.

User Signature (written and printed) -

Organization, Address, Phone No.

Description of Statistical Use of the Data

DOE Reviewing Official

Date 


\section{CONFIDENTIALITY STATEMENT FOR USERS OF ALABAMA DEATH CERTIFICATE DATA FROM CEDR}

I, the undersigned, hereby agree to the following terms and conditions related to the use of information obtained from Alabama death certificates contained in the Department of Energy Comprehensive Epidemiologic Data Resource (CEDR) data base:

1. All identifiable data obtained from Alabama death certifica:es contained in the CE.DR data base will be used only for scientific research and statistical purposes. No data will be published or released in any form if a particular individual or establishment supplying the information or described in it is identifiable. Furthermore, the identifiable information will not be used as a basis for legal, administrative, or other actions which may directly affect those particular individuals or establishments as a result of their specific identification in this project.

2. No data from Alabama death certificates contained in CEDR will be linked to computer files or other sources of information that might lead to identification of individuals or establishments.

3. No data from Alabama death certificates contained in CEDR will be used to compile lists of individuals or establishments for commercial purposes.

4. Information obtained from Alabama death certificates from the CEDR data base will not be disclosed to any parties other than those working directly on the specific project for which CEDR data is being used and for which a CEDR Confidentiality Statement for Primary Users has been signed. In no way will Alabama death certificate data be disclosed to anyone else.

\section{THIS CONFIDENTIALITY STATEMENT MUST BE SIGNED BY THE PRIMARY USER.}

Signature

Date

Typed Name

Title

Organization

Address

Name of Study

DOE Approval

Date 


\section{PENNSYLVANIA DEPARTMENT OF HEALTH APPLICATION FOR ACCESS TO PROTECTED DATA Individual Case Record Release Form}

1. Original Study Title/Applicant Information:

Study Title:

Applicant:

Application Number and Approval Date:

II. Information to be Released:

Organization Name (that is requesting the data):

Study Title:

Data to be Released:

Please attach a Summary Study Protocol.

III. Applicant Assurances (to be completed by the organization that will receive the data):

The undersigned hereby agrees that use of the individual case record data obtained from Pennsylvania death records will not be undertaken for any purposes other than the above stated study to the extent approved separately in writing by the Department.

Name:

Title:

Address:

Telephone Number:

Signature:

Date: 


\section{RESEARCH ASSURANCES FORM}

\section{Division of Vital Records, R.I. Department of Health}

1. The purpose of this research study is (please summarize in space below or attach additional sheets if necessary):

2. I acknowledge that access to information contained in vital records fumished by the Division of Vital Records is granted solely upon the condition that I agree to utilize sald information in the manner and upon the terms set forth in this Research Assurances Form. Specifically, I agree to comply with the following conditions:

a) That the information will be used solely for the purpose stated above;

b) That no communication shall be made with individuals named or listed on vital records, or with family members, or with informants ( individual or institutional), unless approval in writing has been obtained from the Director of Health or his designee:

c) That no information from vital records shall be published or disseminated in a form that might permit identification of individuals named or listed in vital records;

d) That no statement shall be made indicating or suggesting that interpretations drawn from vital statistics are those of the Department of Health or of the state of Rhode Island; and

e) That the confidentiality of all information obtained from vital records will le maintained as required by Chapter 5-37.3.4 of the General Laws of Rhode Island and by all federal and state laws and regulations related to confidentiality of such information, and by requirements specified by the Institutional Review Board of the Department for the protection of human subjects.

3. I understand that the Rhode Island Department of Health reserves the right to final determination of access to confidential information it provides for research purposes, and may terminate access at any time.

4. I understand that I cannot use any information provided under this agreement for any commercial purpose, as defined in Section 38.2-6 of the General Laws of Rhode Island. 
5. I agree that all information provided under this agreement, when disposed of, will be handled as follows:

a) Paper records will be shredded or burned; and

b) Computer tapes will be completely erased or retumed to the Division of Vital Records. Computer diskettes will be retumed to the Division of Vital Records.

6. I accept responsibility for any misuse of the information provided and agree to hold Rhode Island Department of Health harmless for such misuse.

7. Should I fail to comply with the terms and conditions of this Research Assurance Form, access to information on vital records will be terminated immediately, and all data will be retumed to the Division of Vital Records. I understand that unauthorized disclosure of information from confidential records may be punishable, upon conviction, by a fine and/or imprisonment or both, and/or civil penalties as prescribed by law.

(Signature)

(Tille)

(Organization)

(Date)

Approved by:

(Signature of State Registrar)

VS109 (8/90) 


\section{\begin{tabular}{l}
\hline APPENDIX C \\
\hline
\end{tabular}}

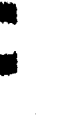

(

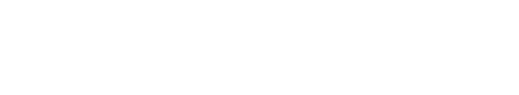

(n)
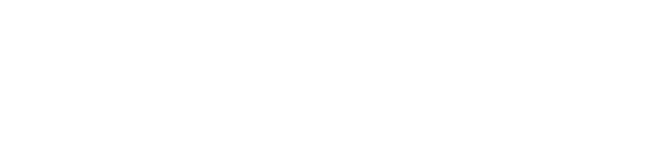

.

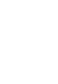

App

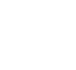




\section{U.S. DEPARTMENT OF ENERGY COMPREHENSIVE EPIDEMIOLOGIC DATA RESOURCE (CEDR)}

Data Request Form

To request CEDR data, complete this form and mail or fax to:

CEDR Project

Lawrence Berkeley Laboratory

1 Cyclotron Road, MS 50B-3238

Berkeley, CA 94720

Phone: $510-486-4136$

FAX: $510-486-6363$

YOU MUST BE AN AUTHORIZED CEDR

PRIMARY USER TO REQUEST CEDR

ANALYTIC OR WORKING DATA SETS.

HOWEVER, STRUCTURED DOCUMENTATION FOR CEDR DATA SETS IS AVALABLE TO ANYONE UPON REQUEST.

Primary User Name

Organization:

Address:

Phone:

Data Sets Requested:

1.

2.

3

6.

(Please attach an additional page if you wish to receive additional data sets.)

Please indicate the type on which you wish to receive the data:

1] 9-track tape (IBM unlabelled, ASCII)

9-rack tape (IBM unlabelled, EBCDIC)

[] $51 / 4^{\prime \prime}$ diskette (DOS format)

[] $31 / 2^{\prime \prime}$ diskette (DOS format)

1 ) Other. please specify:

I agree to use CEDR data as specified in the DOE CEDR Confidentiality Statement 
APPENDIX D 


\section{Site and Facility Deseriptions}

- This appendix provides a reference of all facilities/plants and sites for which data exist in CEDR. The analytic datio sets that include data from the facility or site are also provided as a cross-reference.

\section{Fernald Facility}

The Fernald facility, located at Fernald, Ohio, is approximately 20 miles northwest of Cincinnati. National Lead Company of Ohio (NLO), a subsidiary of National Lead Industries, was the original operating contractor. In 1992, Fernald Environmental Restoration Management Company (FERMCO), a subsidiary of Fluor-Daniel, took over the management of the facility. Early processes included receiving, sampling, and assaying foreign and domestic uranium ores; chemical processins; reduction of uranium tetrafluoride to metal; and fabrication of the metal by rolling and machining into fuel shapes. The processes changed somewhat in later years, and all plants at the facility were used for production of slightly enriched (less than $1 \%$ of $U-\_35$ ) metal. The facility was in operation from 1951 to 1989 as a fe d materials plant; it is currently undergoing environmental restoration.

\section{Analytic Data Set: FRW83A01}

\section{Hanford Site}

The Hanford facility encompasses 560 square miles within the Columbia River Basin in southeastem Washington State. This semidesert area is located north of the cities of Richland, Kennewick, and Pasco (combined population 100,000). Activities at Hanford, which formerly focused on plutonium production, have shifted to envirommental restoration, in managing the wastes generated by past reactor and processing operations, and to research and development for advanced reactors, energy technologies, basic sciences, and waste disposal technologies. The site has been in use since 1943; however, several of its facilities are no longer operational.

Analytic Data Sets: HFC78A01, HF189A01, HFS93A03

\section{Linde Plant}

The Linde Plant, located in Buffalo, New York, was in operation from 1943 to1949. The primary operation at the plant was uranium processing, whereby Congo pitchblende and domestic uranium ores were converted to uranum tetrafluoride. The Linde Plant also developed and produced barrier material for the Oak Ridge Gaseous Diffusion Plant (now the K-25 Site). The Manhattan Engineer District constructed four buildings on land owned by Union Carbide Corporation. Upon termination of the contract with the Atomic Energy Commission, ownership of the facility was transferred to Union Carbide.

\section{Analytic Data Set: LND87A01}

\section{Los Alamos National Laboratory Facility}

The Los Alamos National Laboratory (LANL) facility occupies about 43 square miles (27,800 acres) in Los Alamos County, New Mexico, approximately 60 miles north of Albuquerque and 25 air miles northwest of Santa Fe. The laboratory is situated on the Pajarito Plateau, which is made up of fingerlike mesas ranging in elevation from 6,200 to $7,800 \mathrm{ft}$. LANL was 
established in January $194: 3$ as Project $Y$ of the War Department's World War II Manhattan Engineer District. The mission of Project $Y$ was the design and assembly of the first nuclear fission bornb. After World War II, LANL has continued to design fission and, subsequently, fusion-based nuclear weapons. I ANL has played a major role in the research and development of nuclear reactors, and it has had a long-standing interest in nuclear fusion power generation. In the 1960s and 1970) I ANI. greatly expanded its research and development activities through large areas of

physics, chemistry, and material science.

\section{Analytic Data Sets: LAFEMA01, LASU1A02}

\section{Mound Plant}

The Mound Plant is located on a 306 -acre site in southern Montgomery County in southwestern Ohio, within the solithern boundary of the Miamisbury city limits and approximately (0.6) miles due east of the

Great Miami River.

The facility is located about 10 miles south southwest of Dayton and 31 miles north northeast of Cincin-

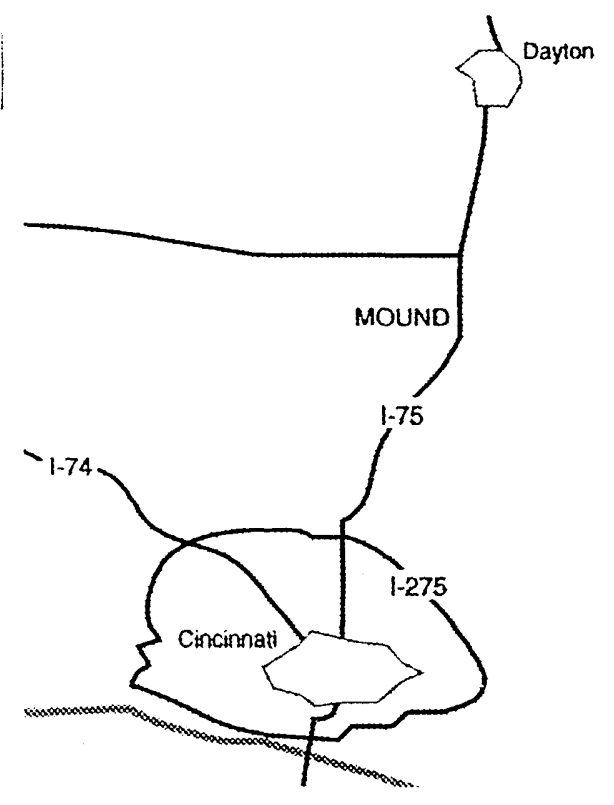
nati. This facility was

operated first by the Monsanto Chemical Corporation and later by EG\&(i. From 1943 to 1948, the work was done under the title of Dayton Project. During this period, work was carried out at several locations within the city of Dayton. In 1948, operations were consolidated at the current central Mound Plant. In 1991, EG\&C replaced Monsanto Chemical Corporation as the operating contractor. Historically, major operations conducted there included the separation, chemistry, and metallurgy of polonium210 and the processing of plutonium-238 for heat sources. Later, small research projects involved other isotopes, including radium and thorium.

\section{Analytic Data Sets: MDSMRA01, MDEXTA02,}

\section{MDPOLAO3}

\section{Oak Ridge Site}

This DOE site includes $\mathrm{X}-10$ [Oak Ridge National Laboratory (ORNL)], Y-12 Plant, and K-25 [Oak Ridge

Gaseous Diffusion Plant

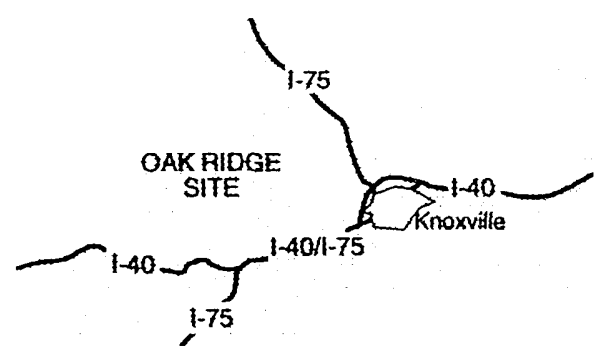
(ORGDP)]. Martin

Marietta Energy Systems, Inc. is the contractor currently operating all three facilities.

Analytic Data Sets: ORMulaO1, ORMULA02,

ORMUla03, ORK25A01, ORX10A01, ORX10A02, ORX10A03, ORY12A01, ORY12A02, ORY12A03, ORY12A04

\section{Oak Ridge K-25 Facility}

The Oak Ridge K-25 facility, previously called the Oak Ridge Gaseous Diffusion Plant (ORGDP), occupies a 1,500-acre area adjacent to the Clinch River, approximately 13 miles west of downtown Oak Ridge, Tennessee. The K-25 facility originally produced enriched uranium hexafluoride for defense purposes. Due to a declining demand for enriched uranium, the enrichment process at the K-25 facility was placed on standby in 1985 and subsequently shutdown in 1987 . The $\mathrm{K}-25$ facility now serves as a center for applied technology and is the location of many contractor central staff functions, including the operation of waste treatment and storage facilities.

Analytic Data Sets: ORK25A01, ORMULA01, ORMULA02, ormulaoz 


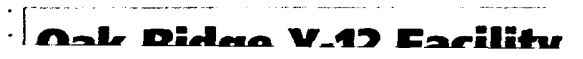

\section{Oak Ridge Y-12 Facifity}

The Oak Ridge Y-12 facility occupies an 811 -acre site in the Bear Creek Valley, approximately 2 miles from Oak Ridge. Tennessee. The Y-12 Plant, built in 1943 as part of the Manhattan Project, was established to separate uranium isotopes by the electromagnetic process. The original operating contractor was Tennessee Eastman Corporation (TEC). In May 1947, Union Carbide Corpora tion Nuclear Division became the operating contractor. At the time of this change, the work force at the plant had a significant turnover, and the processes changed from uranium enrichment to manufacturing and developmental engineering of enriched uranium metal products. For these reasons, a split in the plant population was identifed for epidemiological purposes. The workers employed at the plant when TEC was the operating contractor are known as the TEC population, while workers employed from May 1947 onward are known as the Y-12 population.

\section{Analytic Data Sets: ORY12A01, ORY12A02, ORY12A03,} ORY12A04, ORMUla01, ORMula02, ORMula03

\section{Oak Ridge $\mathbf{X}-10$ Facility}

The Oak Ridge X-10 facility, also known as the Oak Ridge National Laboratory (ORNL), occupies several sites and covers approximately 2,900 acres in Melton Valley and Bethel Valley, 10 miles southwest of downtown Oak Ridge, Tennessee. ORNL's mission is to conduct applied research and engineering development in support of DOE programs in fusion, fission, conservation, fossil, and other energy technologies and to perform basic scientific research in selected areas of the physical and life sciences. The site has been in use since 1943.

\section{Analytic Data Sets: ORX10A01, ORX10A02, ORX10A03,} ORmulao1, ORMula02, ORmulao3
| Pantex Plant

\section{Pantex Plant}

The 9,100-acre Pantex Plant is located in the Panhardle of Texas in Carson County about 17 miles northeast of downtown Amarillo and 10 miles west of downtown Panhandle. The site was first used in

1942 by the Army Ordnance Corps for loading conventional ammunition shells and bombs during World War II. In 1950, the U.S. Atomic Energy Commission started rehabilitating portions of the original plant and building new facilities for fabricating chemical high explosives used in nuclear weapons and for final assembly of nuclear weapons. These new functions began in 1951. The Pantex Plant has been the nation's primary weapons assembly/disassembly plant. It received conventional (nonnuclear) high-explosive materials and prefabricated nuclear weapons components from external suppliers. Historically, there have been three major operations: (1) production of new nuclear weapons; (2) maintenance, modification, and quality assurance testing of nuclear weapons already in the military stockpile; and (3) retirement by disassembly of nuclear weapons no longer required in the military stockpile.

The high explosives shipped to the Pantex Plant were fabricated into the required shapes for use in nuclear weapons. All other nuclear weapons components were supplied by other manufacturers. These components were then assembled to produce nuclear weapons for delivery to the U.S. Department of Defense.

The Pantex Plant has also conducted research and development work on conventional high explosives to support weapons design and development programs for the U.S. Department of Energy. Analytic Data Set: PXSMra01 


\section{Rocky Flats Plant}

The Rocky Flats Plant almost covers 11 square miles. It is located at Golden, Colorado, in northern Jefferson County, about 16 air miles northwest of Denver. Historically, major operations conducted there included fabrication and assembly (of plutonium, beryllium, uranium, and other metals), plutonium recovery, americium separation, and research and development. Support operations included quality control, safety, maintenance, and utilities. Construction of the plant began in 1951, and limited production operations commenced in 1952. By 1954, the plant was fully operational. In 1989, all production of nuclear weapons components ceased. A period of cleanup and new production preparation began. The end of the Cold War has left the future of the plant in doubt. Environmental restoration activities are underway. The plant was operated by tinree contractors beginning with Dow Chemical Company (1951), followed by Rockwell International (1975), and finally by EG\&G (1990).

Analytic Data Set: RFPlua01

\section{Savannah River Site}

The Savannah River Plant covers a 315-square-mile site near Aiken, South Carolina. At the inception of the plant in 1952 , the primary process was the production of nuclear fuels and other materials. The physical

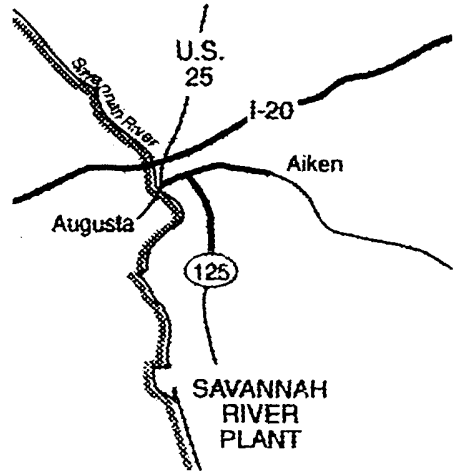

plant includes five large production reactors, two chemical separation plants, plants for reprocessing irradiated nuclear fuel, a fuel fabrication plant, a heavy water manufacturing plant, and a variety of research and development laboratories. E.l. duPont de Nemours and Company was the original operating contractor until 1989, when Westinghouse assumed management of the operations.

\section{Analytic Data Set: SRC88A01}

\section{Zia Company}

The Zia Company was a support services contractor to the Los Alamos National Laboratory (LANL) from April 1, 1946, to June 30, 1986. At that time, Pan American World Services replaced the Zia Company as the primary support services contractor to LANL. Later, Pan American World Services was sold to Johnson Controls World Services Incorporated, the current contractor. The Zia Company's offices were located in Los Alamos, New Mexico, and its employees worked throughout the LANL facilities. In April 1946, the Zia Company replaced the U.S. Army Corp of Engineers Base Post as the provider of construction, maintenance, and quasi-governmental functions. As the 1940s ended, and the 1950s began, civilian government appeared in Los Alamos County and the quasi-governmental activities were turned over to the local government. Support services provided by the Zia Company toward the end of its contract included construction and maintenance at the technical sites of LANL.

\section{Analytic Data Set: LAFEMA01, LASU1A02}



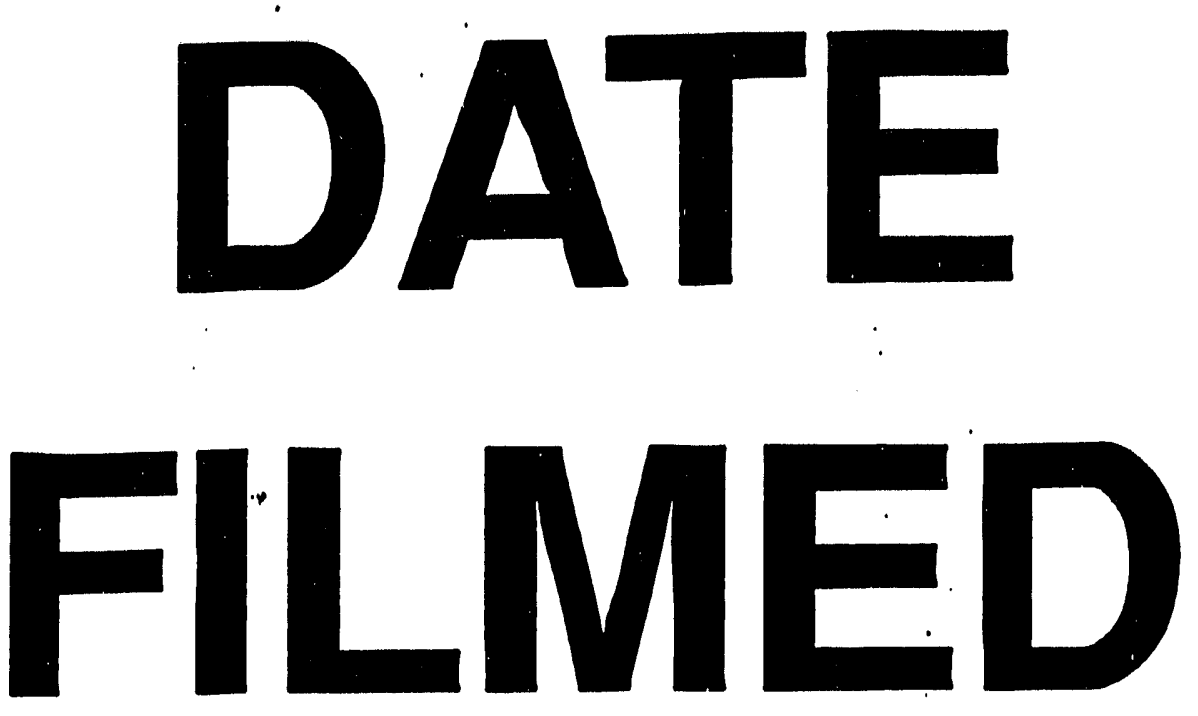

$12 / 29 / 93$
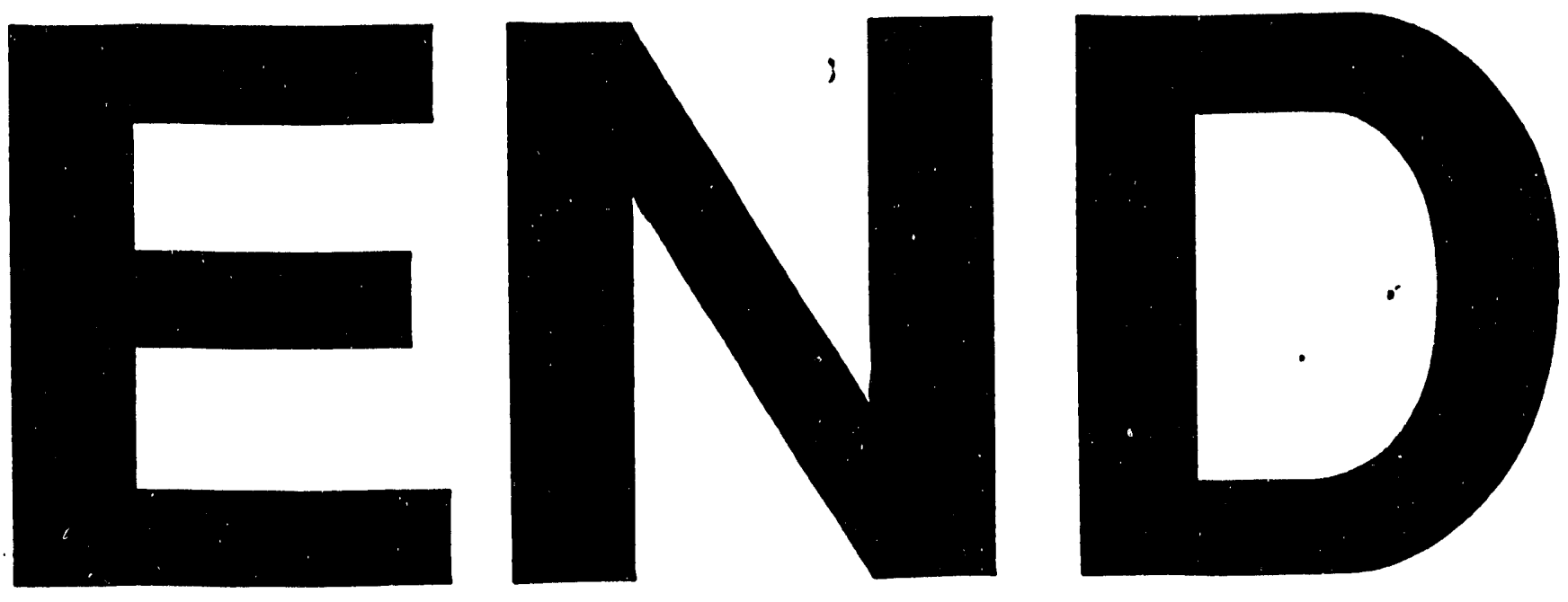
